\title{
ॠUSGS
}

science for a changing world

In Cooperation with the New Jersey Department of Environmental Protection

\section{Users' Manual for the Hydroecological Integrity Assessment Process Software (including the New Jersey Assessment Tools)}

By James A. Henriksen, John Heasley, Jonathan G. Kennen, and Steven Nieswand

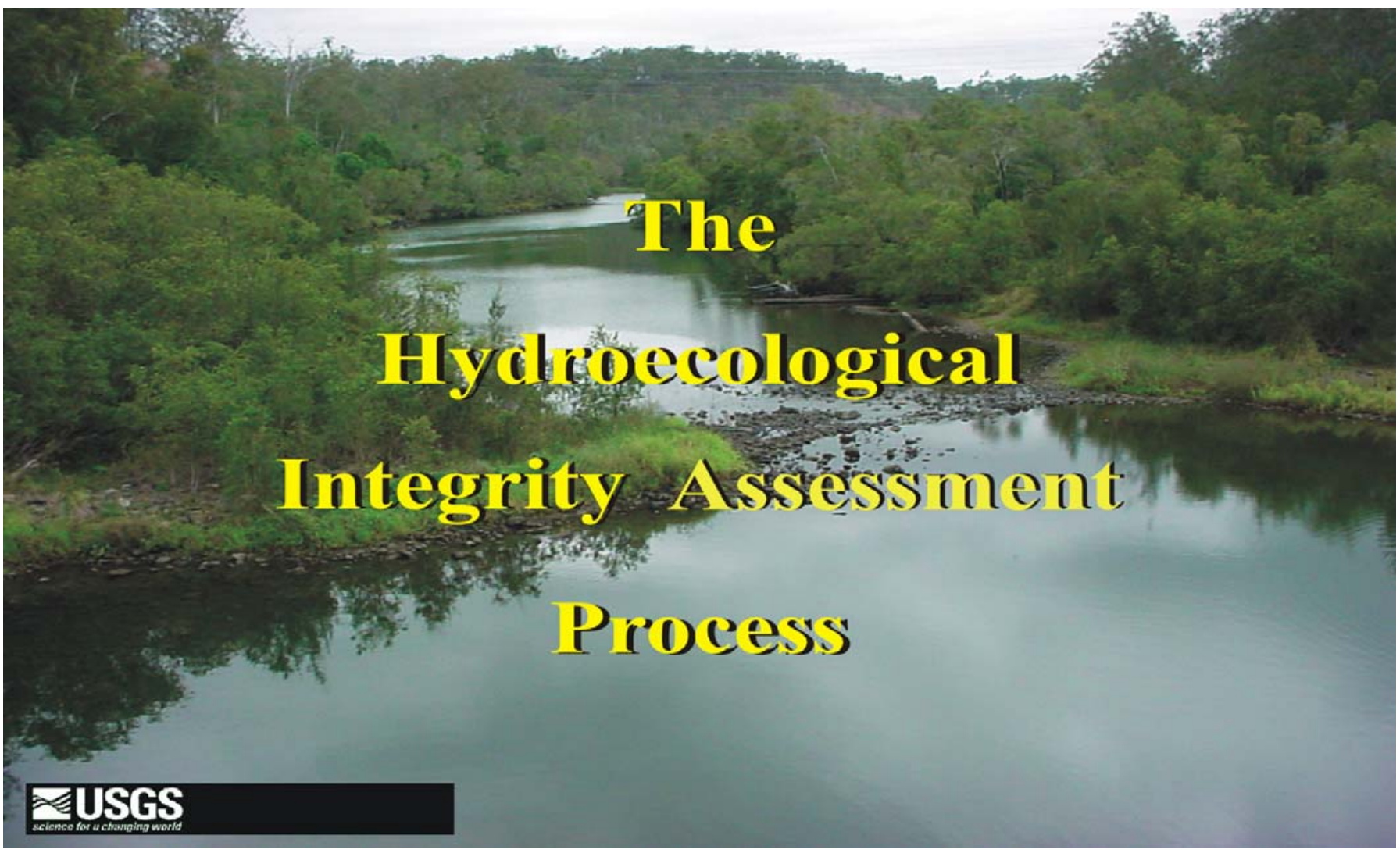

Open File Report 2006-1093

U.S. Department of the Interior

U.S. Geological Survey 


\section{Department of the Interior \\ Gale A. Norton, Secretary}

U.S. Geological Survey

P. Patrick Leahy, Acting Director

U.S. Geological Survey, Reston, Virginia 2006

For product and ordering information:

World Wide Web: http://www.usgs.gov/pubprod

Telephone: 1-888-ASK-USGS

For more information on the USGS - the Federal source for science about the Earth, its natural and living resources, natural hazards, and the environment:

World Wide Web: http://www.usgs.gov

Telephone: 1-888-ASK-USGS

Suggested citation:

Henriksen, J. A., Heasley, J., Kennen, J.G., and Niewsand, S. 2006, Users' manual for the hydroecological integrity assessment process software (including the New Jersey Assessment Tools): U.S. Geological Survey, Biological Resources Discipline, Open File Report 2006-1093, 71 p.

Any use of trade, product, or firm names is for descriptive purposes only and does not imply endorsement by the U.S. Government.

Although this report is in the public domain, permission must be secured from the individual owners to reproduce any copyrighted material contained within this report. 


\section{Preface}

Special recognition and thanks goes to John Heasley who developed the Hydroecological Integrity Assessment Process software. John's creative ideas produced a suite of tools with great utility that has yet to be fully realized. 


\section{Contents}

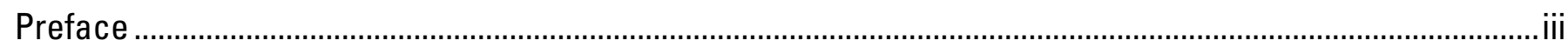

Abstract

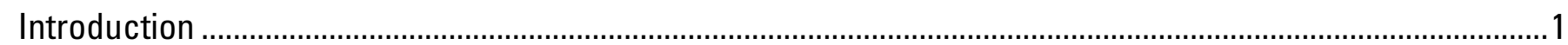

New Jersey Hydroecological Integrity Assessment Software ......................................................................

National Hydroecological Integrity Assessment Software ……….................................................................

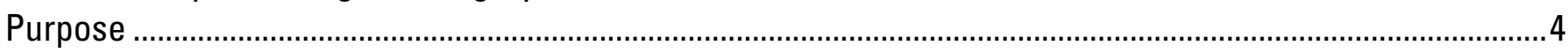

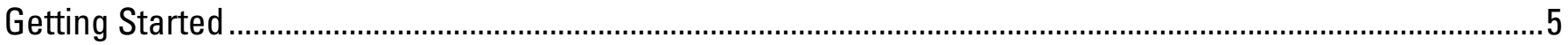

Memory and Hardware Requirements ....................................................................................................

Installing the Hydroecological Integrity Assessment Software on Your Computer..........................................

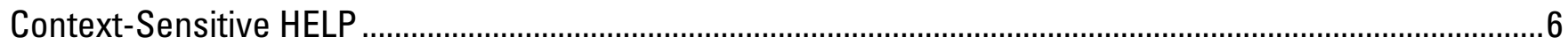

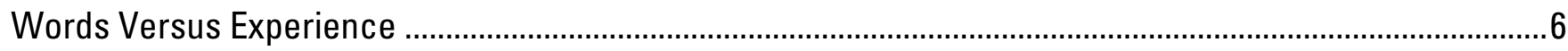

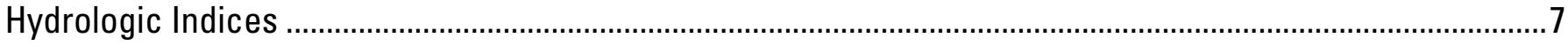

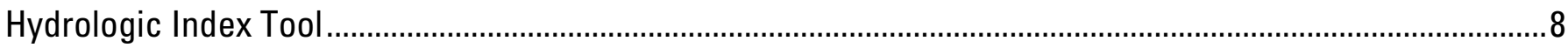

Conducting a Stream-Reach Analysis .................................................................................................12

Classifying an Unclassified Stream by Using New Jersey Stream Classification Tool.................................12

Using the New Jersey Hydrologic Assessment Tool..................................................................................

File Menu

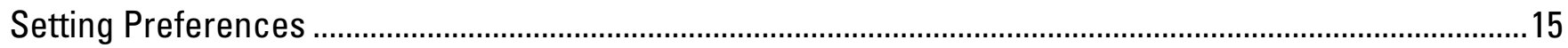

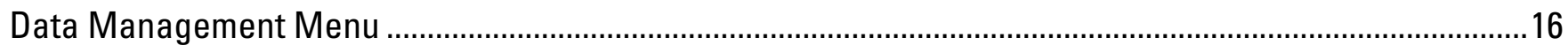

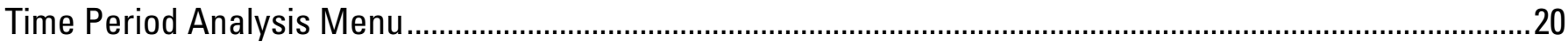

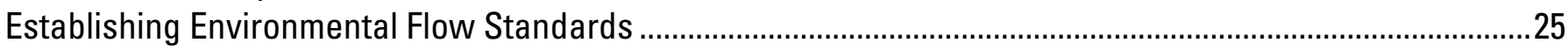

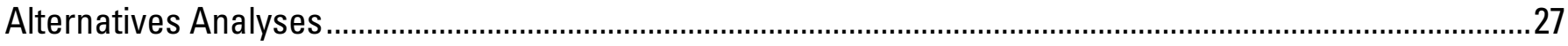

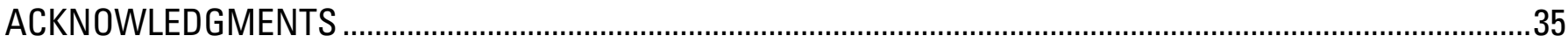

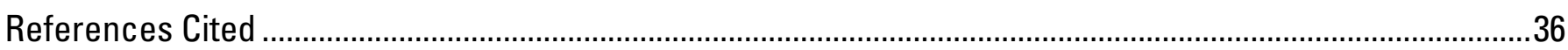

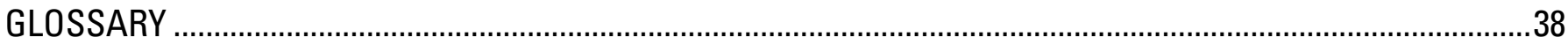

Appendix 1. Distinctive characteristics of the four stream types in New Jersey..........................................39

Appendix 2. Gaging stations used to classify New Jersey streams, stream type, and pertinent information

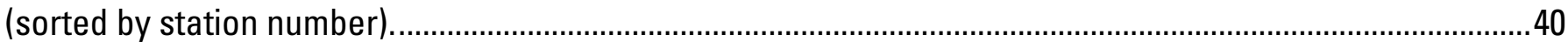

Appendix 3. Table III. (with permission from Olden and Poff, 2003) Hydrologic indices with the largest absolute loading for each of the two to four statistical significant principal components for each stream type in each of the nine components of the flow regime..

Appendix 4. Hydrologic indices with the largest absolute loading on each of the four and five significant principal components for each group in each of the nine components of the flow regime for four New Jersey stream types.

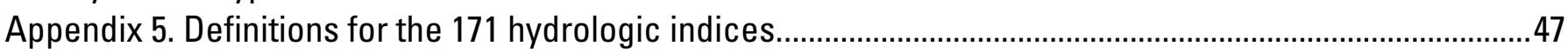

Appendix 6. Verification Results for the 171 Hydrologic Indices .....................................................................62 


\section{Figures}

1. Steps taken to develop and apply a regional Hydroecological Integrity Assessment Process (HIP). 'XX' refers to any geographic area.

2. Application of the National Hydroecological Integrity Assessment Process................................................

3. Difference between how the New Jersey Hydrologic Assessment Tool (NJHAT) and the National

Hydrologic Assessment Tool (NATHAT) use temporal and spatial data..

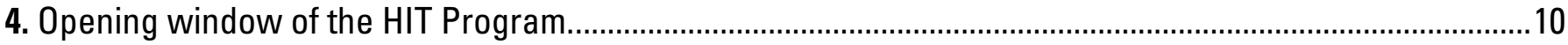

5. Import data window for the HIT Program. ........................................................................................ 10

6. Run Hydrologic Index Tool window for the HIT program........................................................................11

7. The opening window for New Jersey Stream Classification Tool. ..............................................................13

8. The New Jersey stream classification window. ………....................................................................13

9. General approach to using the New Jersey Hydrologic Assessment Tool analysis options. .......................15

10. Window for setting primary and surrogate hydrologic indices preferences for stream group A. .............16

11. Data management - Graph data set data window. ………................................................................... 18

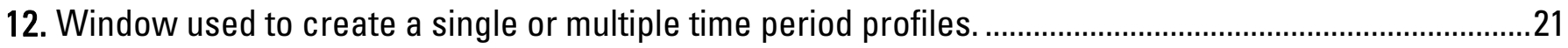

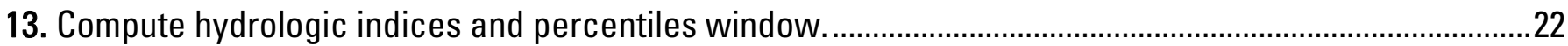

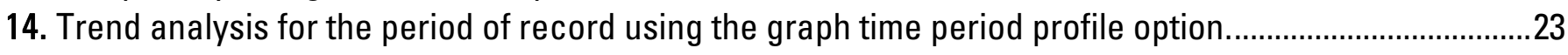

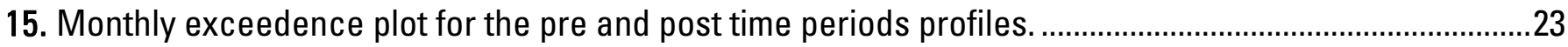

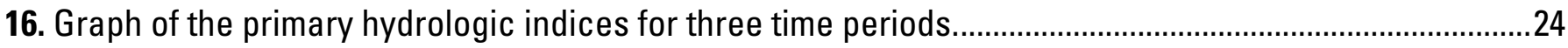

17. Example of the median of the minimum flows (ML1-12) for three time periods. ........................................25

18. Example period of record, baseline, modified pre-project and modified post-project time periods for cumulative impact analyses.

19. Graph alternative data set option for comparing a baseline to the modified post-project exceedence graph.

20. Alternative analyses index graph (high-range) comparing 10 baseline-modified pre-project hydrologic indices to two baseline modified post-project alternatives.

21. Alternative analyses index graph (high-range) rescaled comparing eight baseline- modified pre-project indices to two baseline-modified post-project alternatives.

22. Alternative analyses index graph (high-range) rescaled to comparing the baseline- modified pre-project indices to two baseline-modified post-project alternatives.

23. Alternative analyses index graph with 12 manually selected indices to comparing the baseline modified

pre-project indices to two baseline modified post-project alternatives...

A6-1. Verification results - percent difference between HIT index values and commercial available software values.

\section{Tables}

1. Drop-down menu selections available in New Jersey Hydrologic Assessment Tool.

2. Partial example of a hydrologic index report from alternatives analysis. 
3. Partial example of comparison report for alternatives analysis.

A6-1. Verification results for 171 indices calculated in Hydrologic Indices Tool.

A6-2. Verification results for the computer code used in National Hydrologic Assessment Tool to calculate 64 indices -19 gaging stations. 


\section{CONVERSION FACTORS}

\begin{tabular}{|c|c|c|}
\hline Multiply & By & To obtain \\
\hline \multicolumn{3}{|c|}{ Flow rate } \\
\hline acre-foot per day (acre-ft/d) & 0.01427 & cubic meter per second $\left(\mathrm{m}^{3} / \mathrm{s}\right)$ \\
\hline acre-foot per year (acre-ft/yr) & 1,233 & cubic meter per year $\left(\mathrm{m}^{3} / \mathrm{yr}\right)$ \\
\hline acre-foot per year (acre-ft/yr) & 0.001233 & $\begin{array}{l}\text { cubic hectometer per year } \\
\left(\mathrm{hm}^{3} / \mathrm{yr}\right)\end{array}$ \\
\hline foot per second $(\mathrm{ft} / \mathrm{s})$ & 0.3048 & meter per second $(\mathrm{m} / \mathrm{s})$ \\
\hline foot per minute (ft/min) & 0.3048 & meter per minute $(\mathrm{m} / \mathrm{min})$ \\
\hline foot per hour (ft/hr) & 0.3048 & meter per hour $(\mathrm{m} / \mathrm{hr})$ \\
\hline foot per day (ft/d) & 0.3048 & meter per day $(\mathrm{m} / \mathrm{d})$ \\
\hline foot per year ( $\mathrm{ft} / \mathrm{yr}$ ) & 0.3048 & meter per year $(\mathrm{m} / \mathrm{yr})$ \\
\hline cubic foot per second $\left(\mathrm{ft}^{3} / \mathrm{s}\right)$ & 0.02832 & cubic meter per second $\left(\mathrm{m}^{3} / \mathrm{s}\right)$ \\
\hline $\begin{array}{l}\text { cubic foot per second per square } \\
\text { mile }\left[\left(\mathrm{ft}^{3} / \mathrm{s}\right) / \mathrm{mi}^{2}\right]\end{array}$ & 0.01093 & $\begin{array}{l}\text { cubic meter per second per } \\
\text { square kilometer }\left[\left(\mathrm{m}^{3} / \mathrm{s}\right) / \mathrm{km}^{2}\right]\end{array}$ \\
\hline cubic foot per day $\left(\mathrm{ft}^{3} / \mathrm{d}\right)$ & 0.02832 & cubic meter per day $\left(\mathrm{m}^{3} / \mathrm{d}\right)$ \\
\hline gallon per minute (gal/min) & 0.06309 & liter per second $(\mathrm{L} / \mathrm{s})$ \\
\hline gallon per day (gal/d) & 0.003785 & cubic meter per day $\left(\mathrm{m}^{3} / \mathrm{d}\right)$ \\
\hline $\begin{array}{l}\text { gallon per day per square mile } \\
{\left[(\mathrm{gal} / \mathrm{d}) / \mathrm{mi}^{2}\right]}\end{array}$ & 0.001461 & $\begin{array}{l}\text { cubic meter per day per square } \\
\text { kilometer }\left[\left(\mathrm{m}^{3} / \mathrm{d}\right) / \mathrm{km}^{2}\right]\end{array}$ \\
\hline $\begin{array}{l}\text { million gallons per day per } \\
\text { square mile }\left[(\mathrm{Mgal} / \mathrm{d}) / \mathrm{mi}^{2}\right]\end{array}$ & 1,461 & $\begin{array}{l}\text { cubic meter per day per square } \\
\text { kilometer }\left[\left(\mathrm{m}^{3} / \mathrm{d}\right) / \mathrm{km}^{2}\right]\end{array}$ \\
\hline
\end{tabular}




\section{Abstract}

This manual is a user's guide to four computer software tools that have been developed for the Hydroecological Integrity Assessment Process. The Hydroecological Integrity Assessment Process recognizes that streamflow is strongly related to many critical physiochemical components of rivers, such as dissolved oxygen, channel geomorphology, and water temperature, and can be considered a "master variable" that limits the disturbance, abundance, and diversity of many aquatic plant and animal species.

Applying the Hydroecological Integrity Assessment Process involves four steps: (1) a hydrologic classification of relatively unmodified streams in a geographic area using long-term gage records and 171 ecologically relevant indices; (2) the identification of statistically significant, nonredundant, hydroecologically relevant indices associated with the five major flow components for each stream class; and (3) the development of a stream-classification tool and a hydrologic assessment tool. Four computer software tools have been developed.

- The Hydrologic Index Tool calculates 171 biologically relevant hydrologic indices using daily and peak flow records. The indices are then used for a regional (State) stream classification analysis. The program is designed to import U.S. Geological Survey mean daily and peak flow discharges from the National Water Information System databases.

- The National Hydrologic Assessment Tool is based on a hydrologic classification of streams which used 420 gaging stations across the contiguous United States. The National Hydrologic Assessment Tool has six stream classes identified. The program is used to establish a hydrologic baseline (reference time period), to establish environmental flow standards, and to evaluate past and proposed hydrologic modification. This is accomplished by using flow statistics, trend analysis, and 10 primary stream class specific indices that address the five major components of flow.

- A New Jersey stream classification tool classifies any stream within the State into one of the four stream types found in the State. The four classes of streams identified in New Jersey are characterized by the relative degree of skewness of daily flows (low $=$ stable flow, high $=$ flashy flow) and frequency of low-flow events (low = high base flow; high = low base flow). Thus, streams belonging to stream class A are semiflashy with moderately low baseflow, class B streams are stable with high base flow, class $\mathrm{C}$ streams are moderately stable with a moderately high base flow, and class D streams are flashy with a low base flow.

- The New Jersey Hydrologic Assessment Tool is used to establish a hydrologic baseline (reference time period), establish environmental flow standards, and evaluate past and proposed hydrologic modifications of streams in New Jersey. This is accomplished by using flow statistics, trend analysis, and 10 primary stream class specific indices that address the five major components of flow. 


\title{
Users' Manual for the Hydroecological Integrity Assessment Process Software
}

\author{
By James A. Henriksen, ${ }^{1}$ John Heasley, ${ }^{2}$ Jonathan G. Kennen, ${ }^{3}$ and Steven Nieswand ${ }^{3}$
}

\section{Introduction}

The Hydroecological Integrity Assessment Process (HIP -see Glossary) is based on a large body of research linking hydrological variability and aquatic ecosystem integrity. This research strongly supports a natural flow paradigm, which states, "the full range of natural intra- and interannual variation of hydrological regimes, and associated characteristics of magnitude, frequency, duration, timing, and rate of change, are critical in sustaining the full diversity and integrity of aquatic ecosystems" (Poff and others, 1997; Powers and others, 1995; Resh and others, 1988). Streamflow is strongly related to many critical physiochemical components of rivers, such as dissolved oxygen, channel geomorphology, and water temperature, and can be considered a "master variable" that limits the disturbance, abundance, and diversity of many aquatic plant and animal species (Resh and others, 1988; Poff and others, 1997). The need for applicable management tools that encapsulate this connection and assist in the establishment of flow standards protective of aquatic ecosystem integrity was one of the major forces behind the development of HIP.

The HIP is intended for use by any Federal or State agency, institution, private firm, or nongovernmental entity that has a responsibility or interest in the management and (or) regulation of streams with an objective to address ecological integrity at the reach or watershed scale. In addition, HIP can assist researchers by identifying critical, stream class specific, HIs that adequately characterizes the five major components of the flow regime (magnitude, frequency, duration, timing, and rate of change) by using 10 nonredundant indices (see Olden and Poff, 2003).

The Hydroecological Integrity Assessment Process (HIP) involves four major steps:

1. Perform a hydrologic classification of streams in a geographic area using long-term gage records for relatively unmodified streams and 171 ecologically relevant indices. Employ an Un-Weighted Pair Group Method Analysis (McCune and Medford, 1999; McCune and others, 2002) and Principal Components Analyses (SAS Institute Inc., 1989).

2. Identify statistically significant, nonredundant, hydroecologically relevant indices (surrogate indices are also identified) associated with the five major flow components (a total of 10 subcomponents) of the flow regime for each stream class. This suite of HIs adequately characterizes the flow regime for each stream class (Olden and Poff, 2003).

\footnotetext{
${ }^{1}$ U.S. Geological Survey, 2150 Centre Avenue, Fort Collins, CO 80526.

${ }^{2}$ IAP World Services, 2150 Centre Avenue, Fort Collins, CO 80526.

${ }^{3}$ U.S. Geological Survey, 810 Bear Tavern Road, Suite 206, West Trenton, NJ 08628.
} 
3. Develop an area-specific Stream Classification (computer software) Tool (SCT) for placing streams not used in the classification analysis into one of the identified stream classes. The SCT software uses Multiple Discriminant Function Analyses (SYSTAT, 2004) to match a stream with a specific stream class based on the significant hydrological parameters originally identified during the classification analysis.

4. Develop an area-specific Hydrologic Assessment Tool (HAT). This software is used to (a) establish a hydrologic baseline (that is, a reference time period), (b) establish environmental flow standards, and (c) evaluate past and proposed hydrologic modifications for a stream reach. The HAT software uses 10 primary, stream class specific indices out of an available 171 .

\section{New Jersey Hydroecological Integrity Assessment Software}

The initial development of HIP occurred under a joint project between the U.S. Geological Survey (New Jersey Water Science Center, West Trenton, N.J.; Fort Collins Science Center, Fort Collins, Colo.; and the New Jersey Department of Environmental Protection (NJDEP). Three computer software tools have been developed for the New Jersey HIP:

- Hydrologic Index Tool - Version 1.0 (HIT) - The HIT is used to calculate the 171 HIs for the stream classification analysis. The program is designed to import USGS daily mean and peak flow discharges from the National Water Information System (NWIS) databases (http://waterdata.usgs.gov/nwis/sw). Simulated data can also be used, but the format has to be consistent with the USGS format. HIT can be used for any gage site and is not specific to New Jersey.

- New Jersey Stream classification Tool - Version 1.0 (NJSCT) - The NJSCT classifies a stream as belonging to one of four stream classes. It does this by comparing specific HI values for an unclassified stream with indices defining each of the stream classes. The four classes of streams identified in New Jersey are characterized by the relative degree of skewness of daily flows (low $=$ stable flow, high $=$ flashy flow) and frequency of low-flow events (low $=$ high base flow, high $=$ low base flow). Thus, streams belonging to stream class A are semiflashy with moderately low base flow, class B streams are stable with high base flow, class $\mathrm{C}$ streams are moderately stable with moderately high base flow, and class D streams are flashy with low base flow. Appendix 1 illustrates these distinctive characteristics of the four classes of streams in New Jersey.

- New Jersey Hydrologic Assessment Tool - Version 3.0 (NJHAT) - The NJHAT is used to establish a hydrologic baseline (reference time period), environmental flow standards, and evaluate past and proposed hydrologic modifications of streams in New Jersey. It accomplishes this by using flow statistics, trend analysis, and 10 primary stream class specific indices chosen from the available $171 \mathrm{HI}$.

Figure 1 illustrates the steps necessary to develop and apply the Hydroecological Integrity Assessment Process and associated software tools at the State or regional level. The stream gages, drainage area, and period of record (POR) used in the New Jersey stream classification analysis are listed in Appendix 2. 


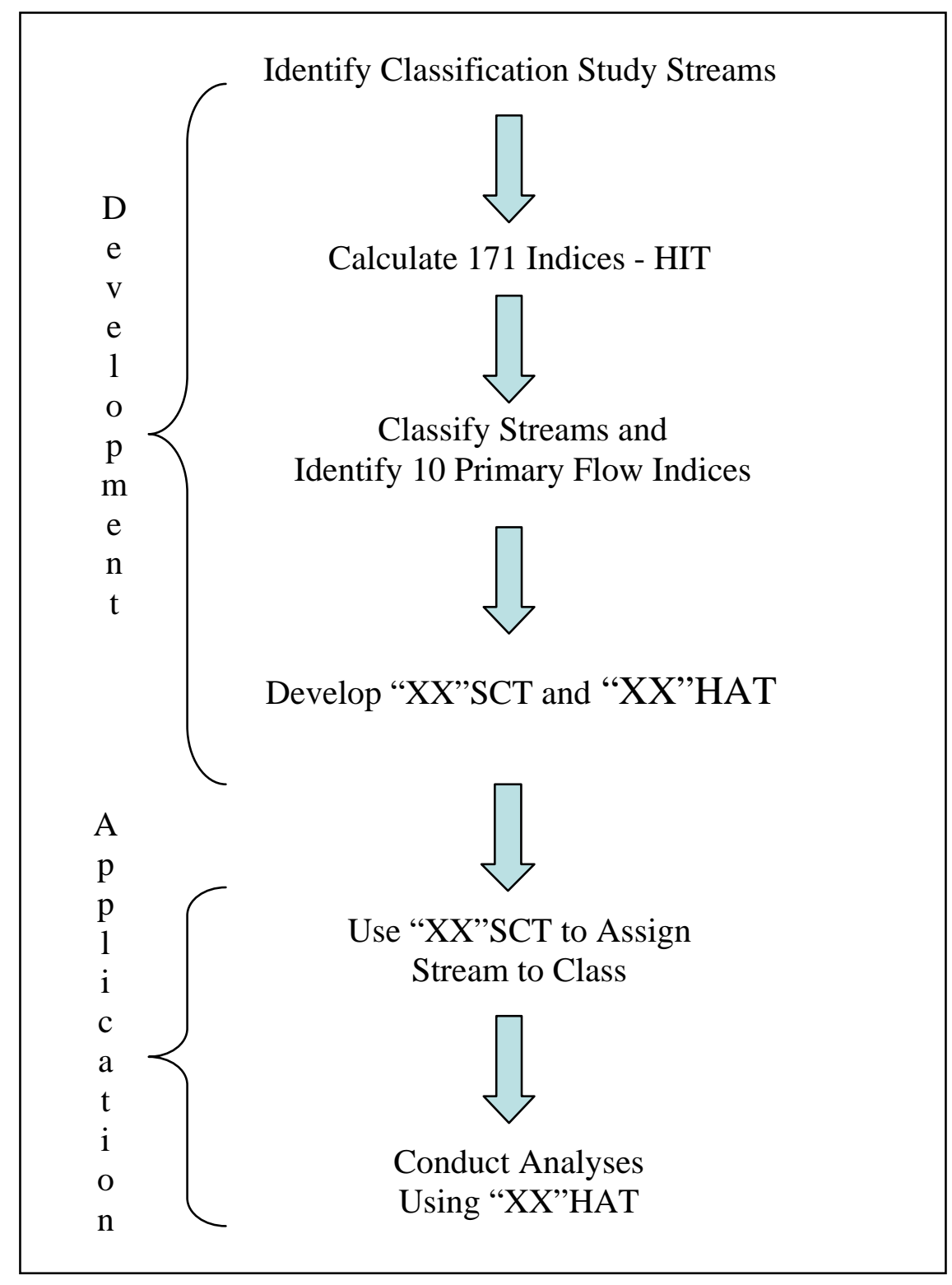

Figure 1. Steps taken to develop and apply a regional Hydroecological Integrity Assessment Process (HIP). 'XX' refers to any geographic area.

\section{National Hydroecological Integrity Assessment Software}

A national HAT - Version 3.0 (NATHAT) has also been developed. This tool is based on a hydrologic classification conducted by Poff (1996) using 420 sites across the contiguous United States. NATHAT contains six stream classes and has the same capabilities as NJHAT. The program can be used to establish a hydrologic baseline (reference time period), environmental flow standards, and to evaluate past and proposed hydrologic modification for six streams classes. However, USGS have not developed, nor do they intend to develop a national SCT to classify unclassified streams.

When Poff (1996) classified streams nationally, six stream classes were identified using records from 420 sites. Only a few of the 420 gage sites may be located in a specific region or State. When 
streams were classified for the New Jersey HIP, using records from 94 sites in the State, four stream classes were identified (see above). Only two of these stream classes fit into Poff's classification. Because a regional classification results in greater discrimination among stream classes, and correspondingly, a refined identification of critical HI values, we recommend a regional analysis. Until such time that streams within each State, or alternatively streams within a region are classified, users can use NATHAT. However, NATHAT requires the user to make an informed decision as to which stream class is being analyzed based on the six stream classes identified by Poff (1996). We recommend the user study Poff (1996) and Olden and Poff (2003) to aid in making this decision. Figure 2 shows the applications steps taken to use the National HIP.

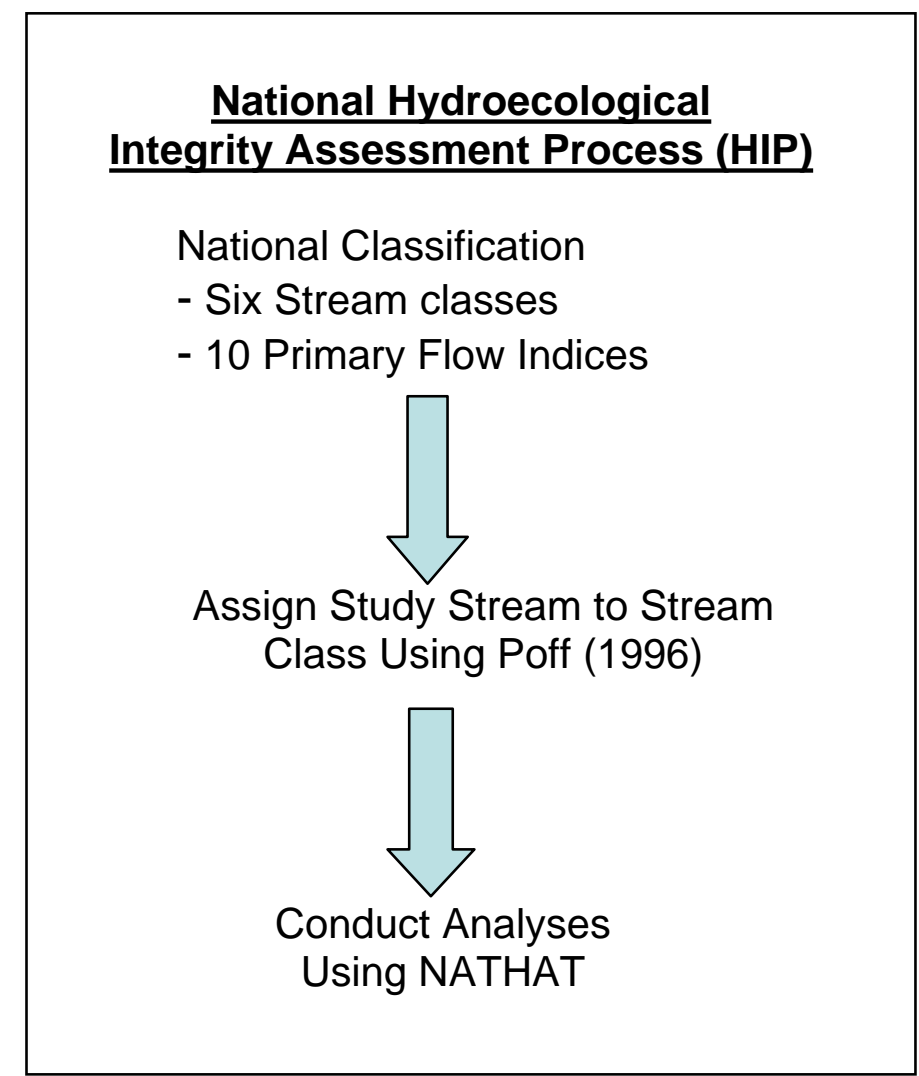

Figure 2. Application of the National Hydroecological Integrity Assessment Process.

\section{Purpose}

The purpose of this USGS Open-File Report is to disseminate information about the development and application of the HIP. The HIP is intended for use by any Federal or State agency, institution, private firm, or nongovernmental entity that has a responsibility or interest in the management and (or) regulation of streams with an objective to address ecological integrity at the reach or watershed scale. In addition, HIP can assist researchers by identifying critical, stream class specific, HIs that adequately characterize the five major components of the flow regime (magnitude, frequency, duration, timing, and rate of change) using 10 nonredundant indices (see Olden and Poff, 2003). A USGS Scientific Investigations Report titled is in preparation that will further describe the development of the HIP process, research it is based on, and additional information regarding the application of the software. 
The primary purpose of this document is to provide an introduction to using the HIP computer software tools to conduct streamflow analyses. This report covers the use of HIT, NJSCT, NJHAT, and NATHAT. However, since NATHAT is basically identical to NJHAT, except that it contains different stream classes, NJHAT is used to explain the capabilities of both HATs. The application of these tools is in its infancy, and their use for a broader array of applications is not fully discussed in this document. Consequently, we encourage you to be analytical and innovative in your approach to using these programs. The authors believe that your will find these tools useful beyond the uses described in this report.

\section{Getting Started}

Prior to using the HIP software, we suggest that all potential users start by reading the following:

A. Instream flows for riverine resources. Annear, T., Chisholm, I., Beecher, H., Locke, A., and 12 other authors. 2004. Revised edition, Instream flow Council, Cheyenne, WY, 268 p.

B. Basic principles and ecological consequences of altered flow regimes for aquatic biodiversity. Bunn, S.E., and Arthington, A.H. 2002. Environmental Management, v. 30, no. 4, p. $492-507$.

C. Basic principles and ecological consequences of changing water regimes: riparian plant communities. Nilsson C., and Svedmark M. 2002. Environmental Management, v. 30, no. 4, p. 468-480.

D. The natural flow regime. Poff, N.L., Allan, J.D., Bain, M.B., Karr, J.R. , Prestegaard, K.L., Richter, B.D., Sparks, R.E., and Stromberg, J.C. 1997. Bioscience, v. 47, no.11, p. 769-784.

E. Redundancy and the choice of hydrologic indices for characterizing streamflow regimes. Olden, J.D., and Poff, N.L. 2003. River Research and Applications, v. 19, p. 101-121.

Once these references have been read, please proceed to Internet Web page http://www.fort. usgs. gov/products/software/software.asp and download the software of interest (see Installation section below). That is, download HIT only, NATHAT only, or NJSCT and NJHAT as a package. Note that downloadable files online are installation programs. Double click on the downloaded programs and follow the instructions to install the software.

\section{Memory and Hardware Requirements}

The HIP software requires a personal computer running the Windows 95/98/2000/XP operating system. A typical installation (for example, HIT, NJHAT, and NJSCT) requires about $10 \mathrm{MB}$ of hard disk space. Although the software will run on less, it is recommended that at least $64 \mathrm{MB}$ of RAM be installed on the computer. Individual projects can require $200 \mathrm{~KB}$ to over $2 \mathrm{MB}$ of hard disk space, depending on the extent and complexity of the analysis. The computer must have a graphics card capable of at least $800 \times 600$ pixel resolution. A resolution of 1,024 x 768 pixels is recommended. 


\section{Installing the Hydroecological Integrity Assessment Software on Your Computer}

Installation of HIP software is much like that for other Windows programs. You may have been supplied with a CD, or you may have a single file downloaded from the Internet. You may proceed with installation by double-clicking on the installation executable file (for example, hitinst.exe, hatinst.exe, or njhatinst.exe). The installation "wizard" will ask you several questions about where to install the software on your hard drive - that is up to you, but accepting the defaults is recommended. Regional software such as NJHAT will have the Stream classification Tool (NJSCT) bundled with it. This software will be installed in the same folder as the NJHAT software. If you are reinstalling the software for some reason, you must first uninstall the previously installed version.

\section{Context-Sensitive HELP}

While all four pieces of software have a HELP option, they also have a context-sensitive HELP feature. Context-sensitive HELP assists users by providing help based on a specific dialog box or menu option in a program. This enables users to get specific information about whatever part of the program they are using at any given moment. We recommend that, after installing NJHAT or NATHAT, every user begin by selecting the Toolbar's Context Help button ?. When you select the ? icon, the mouse pointer will change to an arrow and question mark. Proceed by clicking on the menu item or toolbar button that you wish help on. The Help topic will be shown for this item you when you click on it. You can also access Help subjects by pressing the F1 key. If you place your mouse cursor on a menu item and press F1, help information about that item will be displayed. Pressing F1 when a dialog is displayed will present help information about that dialog.

For example, clicking on the New Project option of the File menu after clicking the $[?]$ button results in the following help text:

"Use this command to create a new project in HAT. Click on the New Project menu option or its toolbar button. Enter a project name and description. HAT will create a project folder to hold all of the project data."

We recommend that this feature be used when you first start learning the software by progressively working down each drop-down menu from left to right for each menu item, applying the context-

sensitive help button ?. You may also use the HELP Topics item of the Help menu. Here you will find three standard options for obtaining help information - Contents, Index, and Find.

\section{Words Versus Experience}

The HIP software tools are organized like most contemporary Windows applications and thus should be familiar to experienced users. This document does not attempt to explain every menu item or all of the nuances of each program. Menu items are self-explanatory. Thus, the selected topics explained below are the ones most important to conducting analyses and producing insightful information to aid in decision making. 


\title{
Hydrologic Indices
}

Olden and Poff (2003) provide an excellent, succinct history of the use of HIs in river ecology, streamflow characterization, and stream classification. Their article, "Redundancy and the choice of hydrologic indices for characterizing streamflow regimes," explains the source of the 171 indices used in their research and in NATHAT and NJHAT. Equally important, they discuss the search for HIs that account for characteristics of streamflow variability that are "biologically relevant" and important in regard to ecological processes. Olden and Poff make an important contribution to the field of river research by identifying statistically significant, nonredundant, hydroecologically relevant indices (surrogate indices are also identified) associated for the five major flow components (a total of nine subcomponents) of the flow regime for each stream class (Table 3 in Olden and Poff, 2003; Appendix 3 in this document). Furthermore, users of NJHAT should note that a comparable table (Appendix 4) has been created for the four stream types in New Jersey; however, NATHAT and NJHAT use 10 primary indices instead of nine by replacing the average timing of a flow condition (TA\#) with the timing of the low (TL\#) and high (TH\#) flow since these events are more biologically relevant.

The definition for each index is provided in HELP - index/definitions. An explanation of the information provided in addition to the definitions for 171 HIs is necessary to fully understand each index. The following, in part, applies to all three programs - HIT, NATHAT, and NJHAT. The alphanumeric code preceding each definition refers to the category of the flow regime $(\mathrm{M}$, magnitude; F, frequency; D, duration; T, timing; and R, rate of change) and type of flow event (A, average; L, low; H, high) the hydrologic index (HI) describes, and indices are numbered successively within each category. For example, MA1 is the first index describing magnitude of the average flow condition:

\author{
MA\# - Magnitude, average flow event \\ ML\# - Magnitude, low flow event \\ MH\# - Magnitude, high flow event \\ FL\# - Frequency, low flow event \\ FH\# - Frequency, high flow event \\ DL\# - Duration, low flow event \\ DH\# - Duration, high flow event \\ TA\# - Timing, average flow event \\ TL\# - Timing, low flow event \\ TH\# - Timing, high flow event \\ RA\# - Rate of change, average event
}

Exceedence and percentile are used in the calculation for a number of indices. Note the difference a 90 percent exceedence means that 90 percent of the values are equal to or greater than the 90 percent exceedence value, while a 90 th percentile means that 10 percent of the values are equal to or greater than the 90th percentile value (or 90 percent of the values are less than the value) . Following each definition in all three programs, in parentheses, are the units of the index. 
The definitions in NJHAT contain a third piece of information provided in parentheses following the definition - the type of data, temporal or spatial, from which the upper and lower percentile limits (user defined, for example, $75 / 25$ or 60/40) are derived. Temporal data are from a multiyear daily mean discharge or peak flow record from a single stream gage. For example, index MA1 mean for the entire flow record - uses 365 mean daily discharge values for each year in the flow record to calculate the mean for the entire flow record. Consequently, there are 365 values for each year to calculate upper and lower percentile limits. However, formulas for 60 indices in NATHAT do not produce a range of values from which percentile limits can be calculated. MA5 (skewness),

for example - mean for the entire flow record divided by the median for the entire record - results in a single value, and thus, upper and lower percentile limits cannot be calculated. NJHAT uses spatial data, values for each stream gage for all the streams within a New Jersey stream type, to compute limits. For example, upper and lower percentile limits are calculated from the 31 stream gages identified from the classification analysis as stream type A (stream type B, 13; C, 20; D, 26). Consequently, a percentile range can be calculated, from either temporal or spatial data. Note, however, that using spatial data will result in a wider percentile range than when using temporal data to calculate the range. Consequently, you may want to consider using a narrower percentile range (for example, 60/40 rather than 75/25) when the range for an index is identified as being spatially derived. Finally, figure 3 shows the difference between NJHAT and NATHAT regarding the use of temporal and spatial data and explains why the mean or median may fall outside a percentile range.

Many of the 171 indices from Olden and Poff (2003) calculate only a mean value and not a median value. Since flow data are frequently skewed, the mean may fall outside a percentile range. Therefore, while HIT calculates the "Olden and Poff" indices exactly as described by them (only a mean or a median), an option is available in NATHAT and NJHAT to use the median in place of the mean for 87 of the 171 indices. Finally, recognize that in NATHAT there are 60 indices for which the final calculation results in a single value from which no percentile ranges can be calculated. For example, MA4 produces a single percent value. Alternatively, you might consider examining the available surrogate indices listed for each stream type under Preferences|Hydrologic Indices|Stream Group.

\section{Hydrologic Index Tool}

HIT is a stand-alone program that calculates 171 HIs by using daily mean and peak flow discharge values. The USGS (Fort Collins Science Center and the New Jersey Water Science Center) conducted tests to verify that the computer code in the Hydroecological Integrity Assessment Process computer programs (HIT, NATHAT, and the NJHAT) correctly applies the definitions and the formulas for the calculation of the 171 HIs. The results of these tests are presented in Appendix 4. HIT is used in conjunction with the classification analysis for any geographic area but is not used again in conjunction with NJSCT or NJHAT. It is the starting point once the decision has been made to develop HIP by creating a geographic-area-specific Stream classification Tool and 


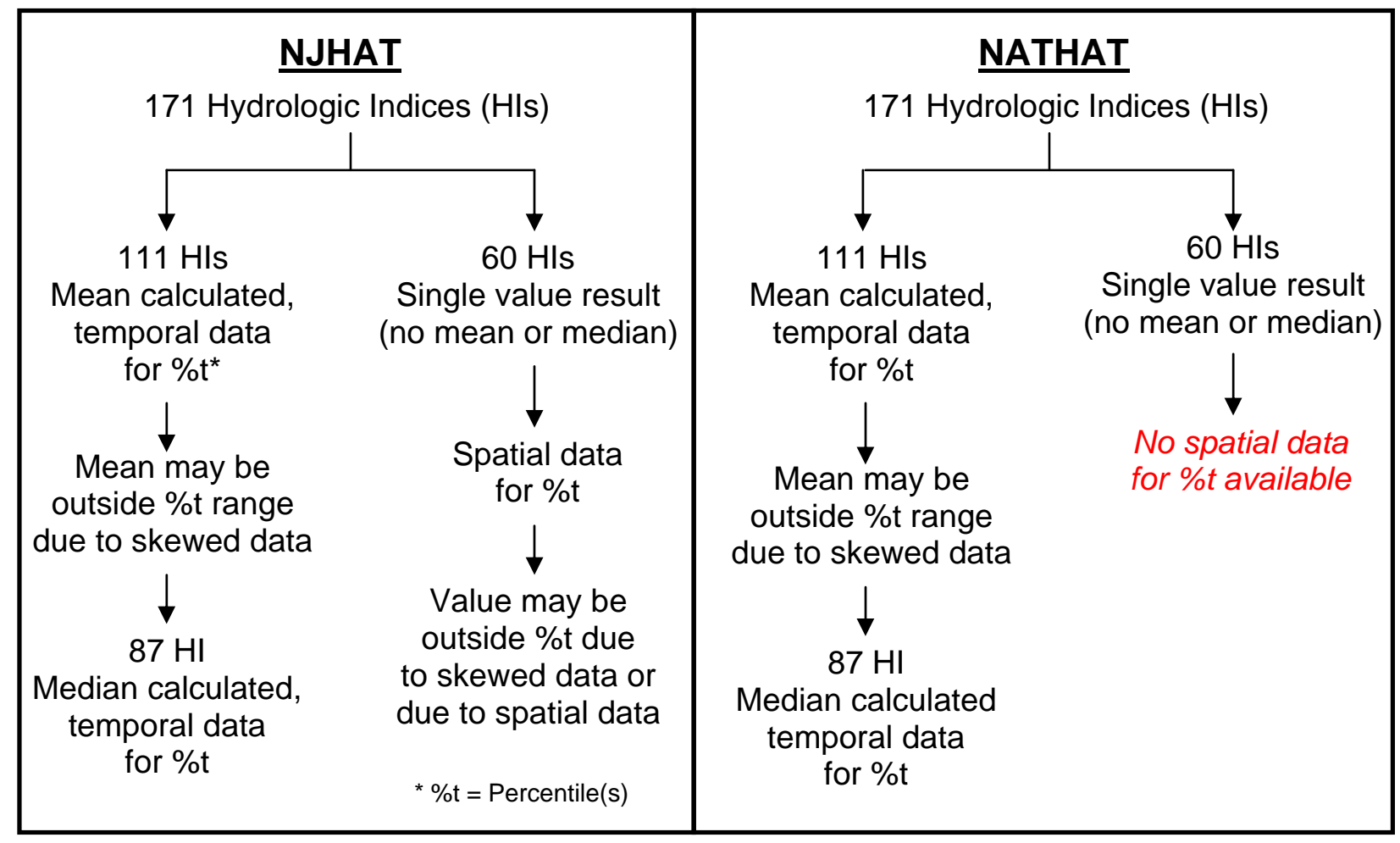

Figure 3. Difference between how the New Jersey Hydrologic Assessment Tool (NJHAT) and the National Hydrologic Assessment Tool (NATHAT) use temporal and spatial data.

Hydrologic Assessment Tool. Prior to using HIT, a researcher would select all stream gages within a geographic area of interest using the POR that provides the least altered stream flow record. These gage records should have an acceptable POR, that is a minimum of 10 years with 25 years preferred (Interagency Advisory Committee, 1981). Daily mean discharge and peak (if available) flow data would be processed using HIT; that is, the program would calculate the 171 indices for each stream. If peak flow data are not available, then eight indices are not calculated - FH11, DH22, DH23, DH24, TA3, TH3, TL3, and TL4. The daily mean discharge values could also be acquired by simulating daily flow data.

Daily mean discharges and peak annual flows are necessary to run a complete HIT analysis. These data can be downloaded from the USGS Website, NWIS Web Data for the Nation. The address is: http://waterdata.usgs.gov/nwis/. Simulated data can also be used, but the format has to be consistent with that of USGS continuous gaging records.

The current procedure for downloading NWIS data starts by logging onto the Website and selecting Surface Water. Select Streamflow for daily mean discharges and Peak for peak annual flows. Using the USGS site number is a quick way to locate these data. There are also other methods (for example, site name) for locating flow data. Click on Submit and enter the site number. For daily flows, click on Submit and then click the Tab-separated data radio button. Click on Submit and enter a filename in a folder in which you wish to save the data. For peak flow data, click the Tabseparated data radio button that is on the same page as the site number entry. Click on Submit and enter a filename in a folder that you wish to save the data. You should download the entire data file as HIT allows you to select specific periods within the entire data set. 
HIT has three windows: an opening window, figure 4; the import data window, figure 5; and the run hydrologic index tool window, figure 6. Clicking on the Import USGS Peak and Daily Flow Files button opens the import data window. There are three required and two optional entries on the import USGS data dialog (fig. 5) to create the data files necessary for a HIT analysis. These include:

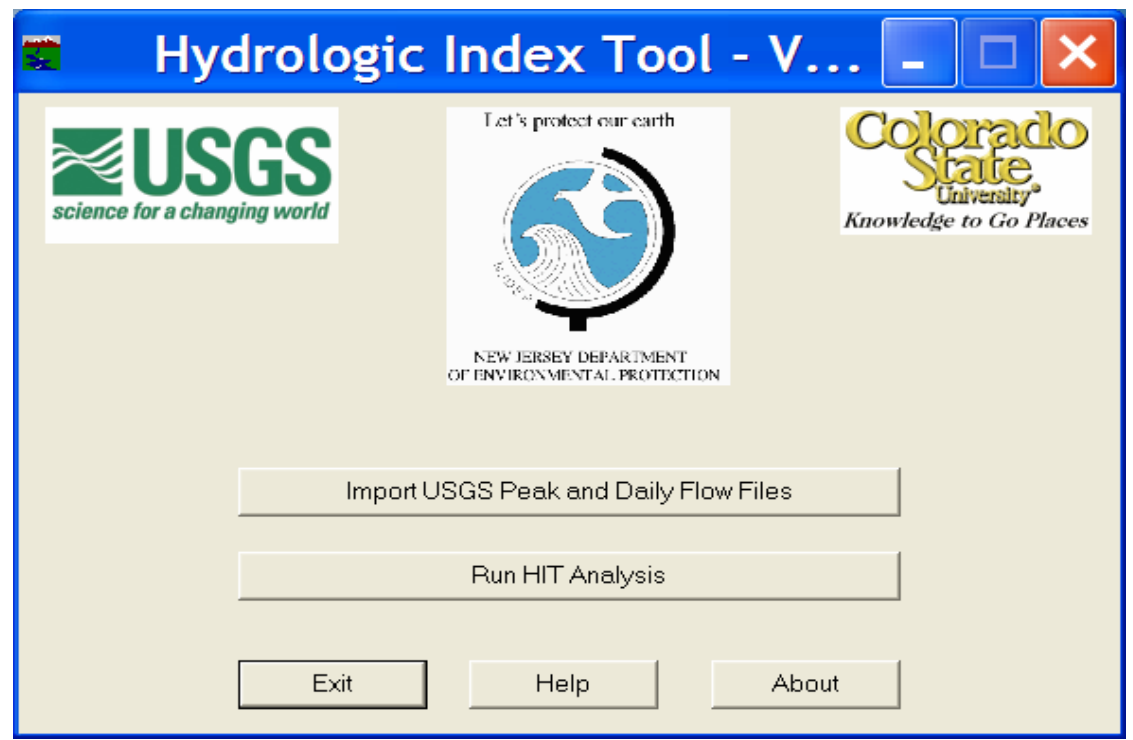

Figure 4. Opening window of the HIT Program.

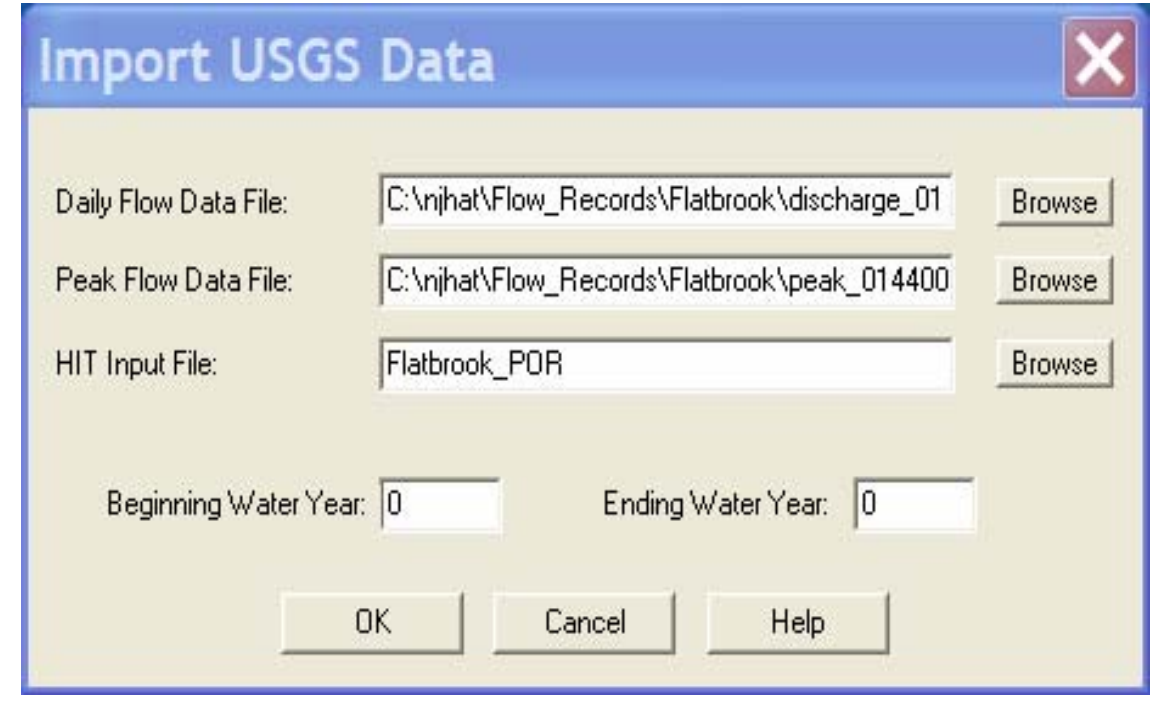

Figure 5. Import data window for the HIT Program.

1. Daily Flow Data File: Enter the path to the downloaded daily streamflow file or use the browse button to locate the file.

2. Peak Flow Data File: Enter the path to the downloaded peak annual streamflow file or use the browse button to locate the file (optional). 
3. HIT Input File: Enter the path to the file that you wish to store the imported data in or use the browse button to locate the file.

4. Beginning Water Year: Enter the beginning water year for the data to be imported (optional).

5. Ending Water Year: Enter the ending water year for the data to be imported (optional).

If you do not enter a beginning and ending water year, the entire flow file will be imported. Once the necessary files are identified select $O K$. A message window will appear stating "Import Successfully Completed."

Clicking on the Run HIT analysis button opens the Run Hydrologic Index Tool window (fig. 6).

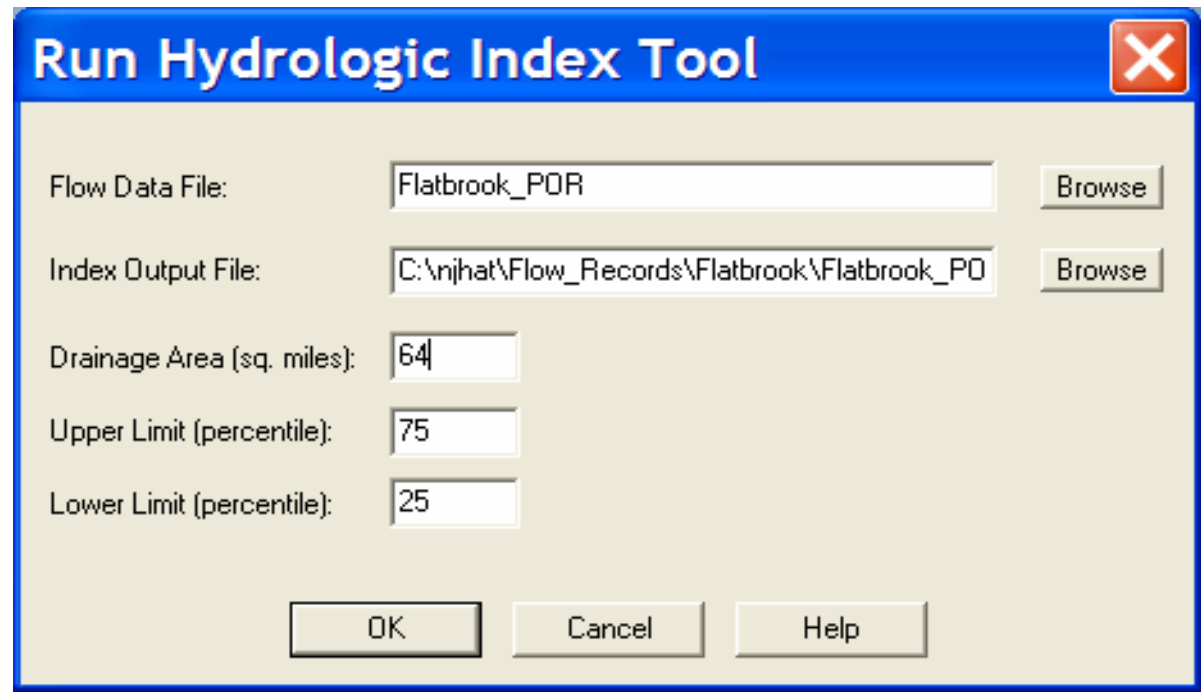

Figure 6. Run Hydrologic Index Tool window for the HIT program.

There are five items that you must enter on the run analysis dialog in order to compute the HI. These include:

1. Flow Data File: Enter the path to the HIT input file or use the browse button to locate the file. This is the file that was created when you imported the USGS flow data. If you just imported the data, the file name will automatically be filled in.

2. Index Output File: Enter the path to the file that will contain the computed HIs or use the browse button to locate an existing file. A comma-separated variable file will be created. These files can be opened by a spreadsheet program such as EXCEL. Each row of the file contains the index name, lower limit value, index value, and upper limit value.

3. Drainage Area: Enter the catchment or drainage area in square miles. This value can be found on the gage site page for the daily flows.

4. Upper Limit: Enter the upper limit for the index as a percentile (for example 75th percentile).

5. Lower Limit: Enter the lower limit for the index as a percentile (for example 25th percentile). 
You can run a HIT analysis without peak flows by leaving the peak flow filename blank. You will be asked to choose between reentering the filename or running the analysis without peak flows. If you choose the latter, FH11, DH22, DH23, DH24, TA3, TH3, TL3, and TL4 will not be computed. Refer to Appendix 5 for full definitions of the HIs.

The output data, the calculated 171 indices generated as a .csv file, are created by running a HIT analysis and are typically what is used to classify streams in a geographic region. This file can be opened using a spreadsheet program, such as Excel. Definitions for the indices are in the HELP under Index Definitions.

\section{Conducting a Stream-Reach Analysis}

There are two general objectives for conducting analyses using HIP:

A. Establishing environmental flow standards using 10 primary indices (at a minimum) for a stream reach.

B. Conducting alternatives (project) analyses.

To establish environmental flow standards (objective A) there are three major steps:

1. Determine class membership of the candidate stream.

2. Establish the hydrologic baseline (reference time period).

3. Determine the stream class specific environmental-flow standards (indices) for the baseline condition according to the five major components of the flow regime by using 10 indices: three for magnitude - low, median, high values; two for frequency - low, high values; two for duration - low, high values; two for timing - low, high values; and one for rate of change - median value.

Depending upon the availability of applicable research on stream species or communities, riparian wetlands, or channel geomorphology specific to a stream or a region, the user may decide to supplement or substitute the 10 primary indices (see "Establishing Environmental Flow Standards" section).

Two additional steps are undertaken to conduct the alternatives analysis (objective B above).

4. Calculate the alternative(s) daily and peak flow hydrologic regimes; that is, project modified flow regime(s) and indices.

5. Compare the 10 baseline (target) environmental flow indices (standards) to the 10 project altered indices.

Most likely, analysis B (above) will be an iterative process.

\section{Classifying an Unclassified Stream by Using New Jersey Stream Classification Tool}

The classification of New Jersey streams resulted in four stream classes. For simplicity, they have been designated as class A, B, C, or D. Appendix 1 shows two distinctive flow characteristics skewness of daily flows and frequency of low flow events - and the range of the drainage areas for 
the four classes. Both types of analyses described above require that each stream-reach being analyzed be correctly classified. Examine the list of streams contained in Appendix 2 to determine if the stream was used in the classification analysis and subsequently already assigned to one of the four streams classes in New Jersey. If not, the NJSCT software should be used. Recognize that a stream from its headwaters to the mouth may belong in different classes (for example, 01383500 is class C while 01384000 is class D). This software also has only two windows (see below). The opening window is shown in figure 7.

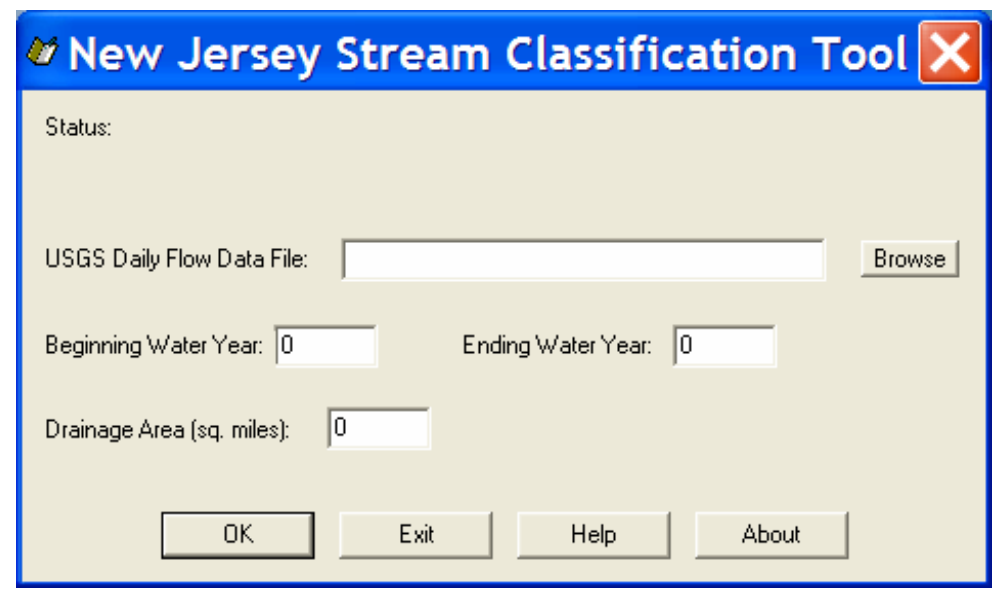

Figure 7. The opening window for New Jersey Stream Classification Tool.

NJSCT requires only the USGS daily mean discharge flow file (or simulated daily flows) and the drainage area in order to classify a New Jersey stream. Once the daily mean flow file (a peak flow file is not required) and the drainage area are provided, $\mathrm{OK}$ is selected, and the program will classify the stream as shown in figure 8 .

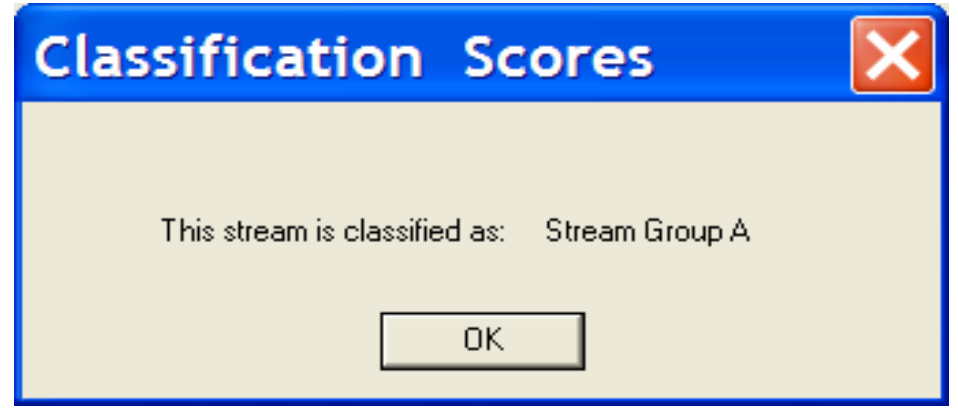

Figure 8. The New Jersey stream classification window.

\section{Using the New Jersey Hydrologic Assessment Tool}

HIP is based upon ecologically relevant indices. Which component of the flow regime each index describes and the definition of each index are critical to using and interpreting output produced in NJHAT. Therefore, we recommend that a user frequently refer to the 171 index definitions available by going to the HELP Topics - Index - (Index) Definitions, or preferably, have a hard copy always on hand. Please do this now. 
Note that the definitions are taken from Olden and Poff (2003); however, USGS revised a limited number of the formula and (or) definitions when deemed appropriate.

NJHAT (as is NATHAT) is used to:

1. Establish the hydrologic baseline (reference time period). This is determined by trend analysis or known, point in time, hydrologic modification and becomes the time period for which the primary HIs are calculated.

2. Establish environmental flow standards using 10 primary, stream class specific indices that address the five components of the baseline flow regime: magnitude, low, median, high; frequency, low, high; duration, low, high; timing, low, high; and rate of change, median.

3. Evaluate past and proposed hydrologic modifications comparing the baseline environmental flow standards to the alternative hydrologic condition.

Note that the user may elect to use relevant, stream class specific, surrogate indices (explained below in - "Setting Preferences") instead of the first-order primary indices. This can occur if, for example, an index that calculates a mean value and a median value is desired. The user may alternatively choose to use additional available indices (from the remaining 161) if regional or stream-specific ecological research has established an ecological response relationship that justifies its use as a supplemental standard. Table 1 lists all of the major drop- down menu items and submenu items available in NJHAT. Figure 9 shows the two routes the user takes to conducting analyses when using NJHAT.

Table 1. Drop-down menu selections available in New Jersey Hydrologic Assessment Tool.

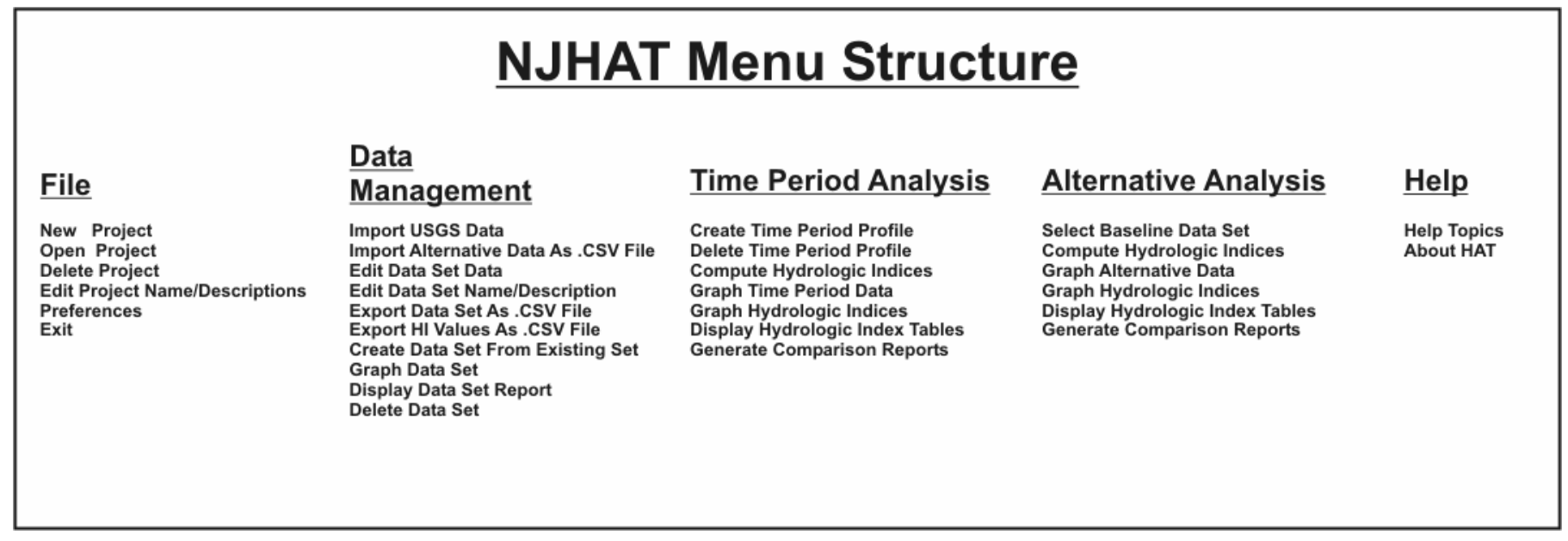

\section{File Menu}

The File menu contains options for creating new projects, opening existing projects, deleting projects, editing a project name or description, and setting preferences for graphics, stream class, and HI default parameters. Select New Project or click on the $\square$ button to create a new project. Enter a project name and description (optional). NJHAT will create a folder to store the project data. Select Open Project or click on the $\vec{\theta}$ button to open an existing project. Select the desired project from a list of existing projects. The Delete Project option is used to remove all data 
associated with a project from your hard disk. Click on this option or the 9 button and select the project to be deleted from a list of existing projects. You will be asked twice to verify that you wish to delete the project. After clicking YES to the first verification message, a DOS window will be displayed asking you to enter a $\mathrm{Y}$ or $\mathrm{N}$. If you enter $\mathrm{Y}$, the project folder and its contents will be

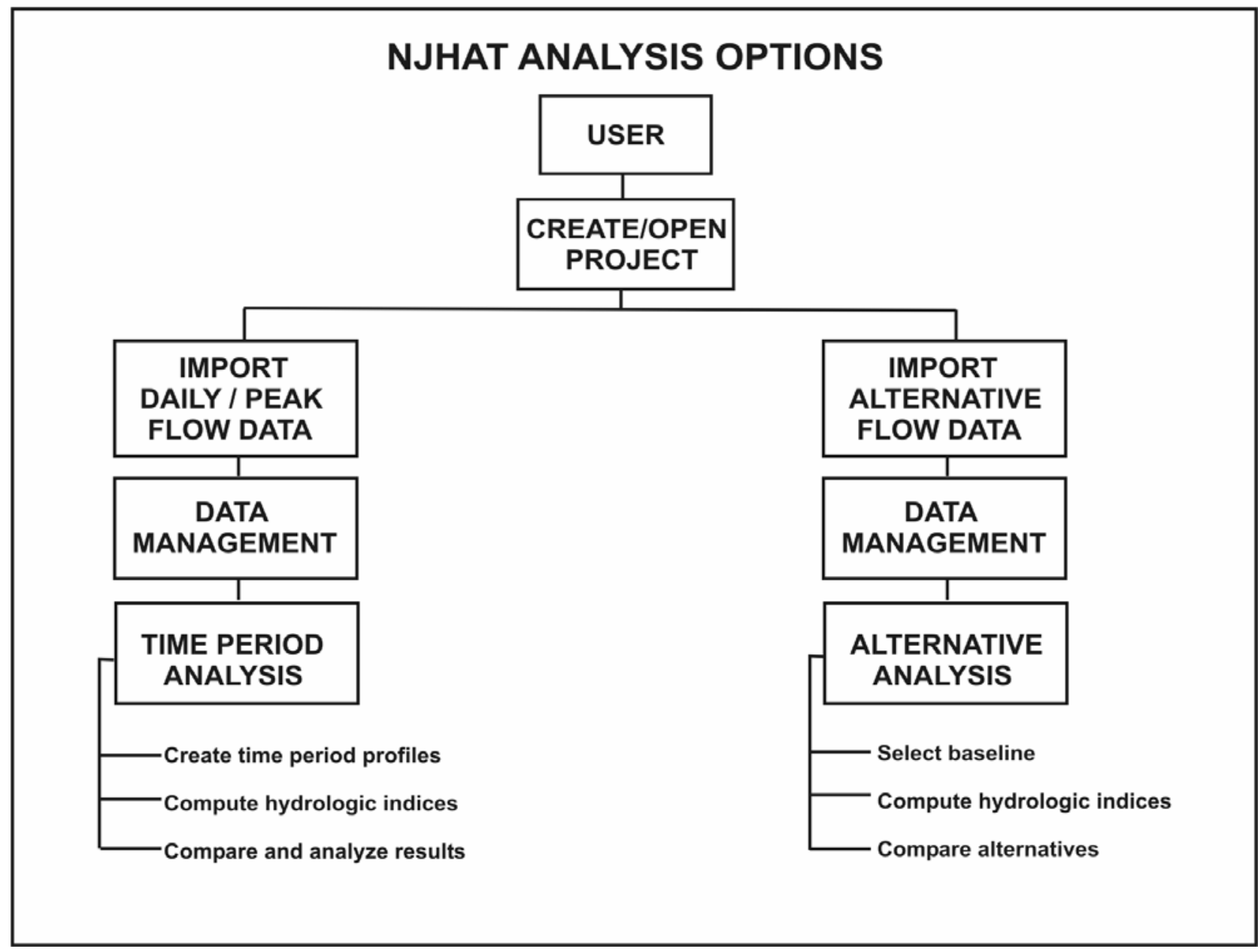

Figure 9. General approach to using the New Jersey Hydrologic Assessment Tool analysis options.

\section{Setting Preferences}

The Preferences option allows you to set defaults for graphics, stream classes, and HI. Select

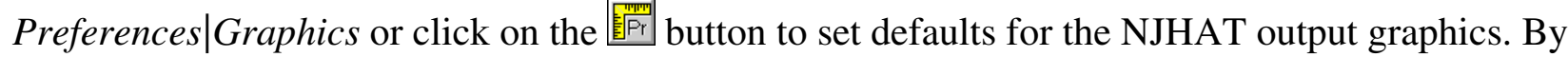
selecting Preferences|Default Stream class, you can set the default stream class. Select Preferences|Hydrologic Indices|Stream Group A to choose the 10 primary HIs to be used for analyses of streams classified as Group A streams. Similarly, select indices for Groups B, C, and D. Figure 10 shows the dialog used to set the primary indices for stream group A. The option Preferences|Modify Indices allows you to specify that median values instead of means are used for 87 of the indices that were originally calculated by Olden and Poff (2003). A list of the 87 indices for which you can choose to calculate the median instead of the mean is shown in the Modify indices window. In addition, they are identified in the HI definitions in the Help file. 


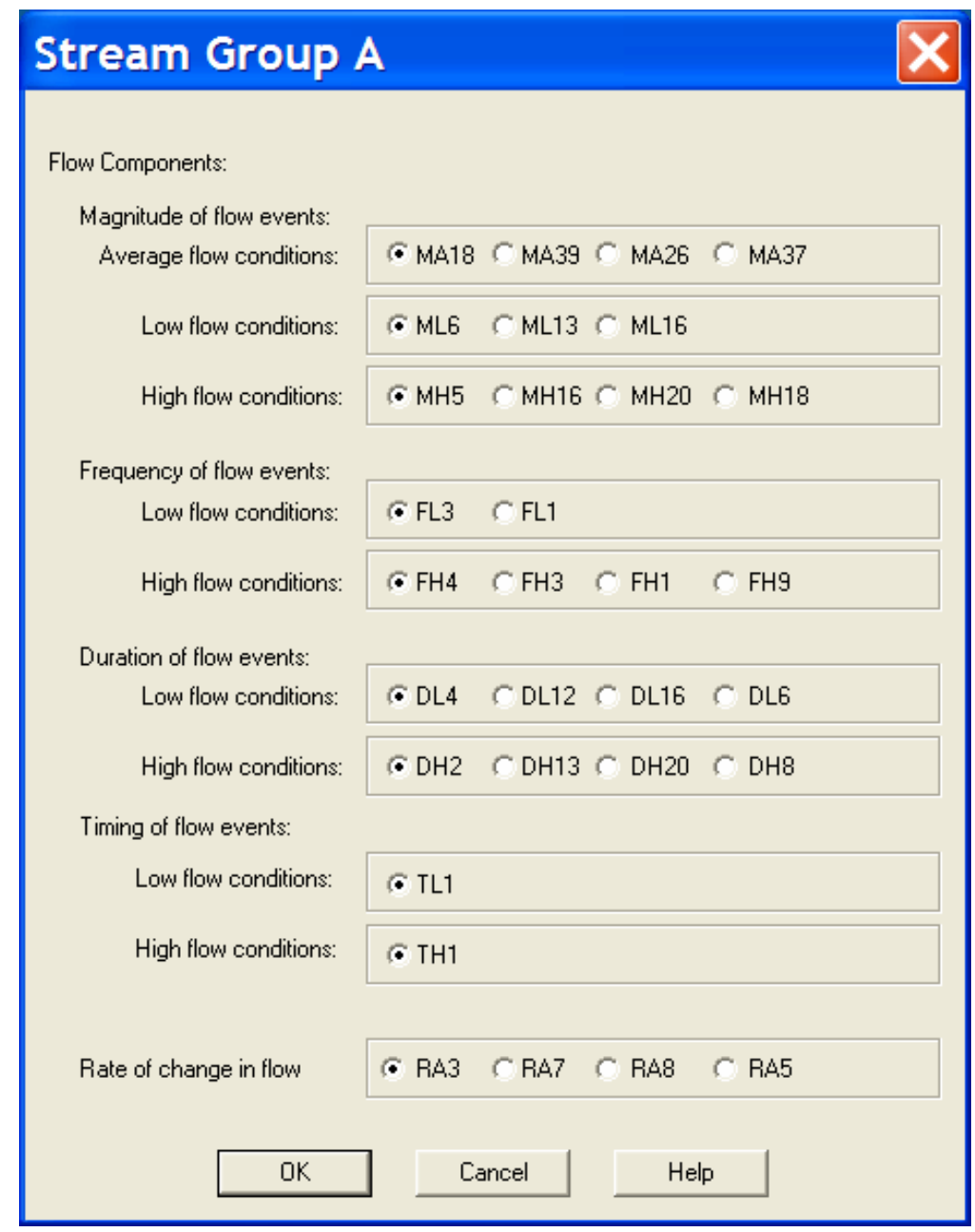

Figure 10. Window for setting primary and surrogate hydrologic indices preferences for stream group $A$.

\section{Data Management Menu}

The Data Management menu provides tools for maintaining your project data. This is where you import your daily mean discharge and peak flow data, edit data sets, and export data sets and HI values as .csv files. You can also graph data sets, display a data set report, and delete data sets. A data set is a set of flow data that has been imported from a USGS flow data file, imported from a .csv file, or created from an existing project data set. You should download the entire data file as HAT allows you to select specific periods within the entire data set. The procedure for obtaining the daily mean and peak flow files is explained in the "Hydrologic Index Tool" section.

After downloading your flow data, click on the Import USGS Data option of the Data Management menu or the Enter a description (optional) for the data set. Select the stream class that best characterizes the class of stream represented by the flow data. 
There are two required and two optional entries on the import dialog to create the data files necessary for an $\mathrm{HI}$ analysis. These include:

Daily Flow Data File: Enter the path to the downloaded daily streamflow file or use the browse button to locate the file.

Peak Flow Data File: Enter the path to the downloaded peak annual streamflow file or use the browse button to locate the file (optional).

Beginning Water Year: Enter the beginning water year for the data to be imported (optional).

Ending Water Year: Enter the ending water year for the data to be imported (optional).

If you do not enter a beginning and ending water year, the entire flow file will be imported. You can run an $\mathrm{HI}$ analysis without peak flows by leaving the peak flow filename blank. You will be asked to choose between reentering the filename or running the analysis without peak flows. If you choose the latter, FH11, DH22, DH23, DH24, TA3, TH3, TL3, and TL4 will not be computed.

Click on the Import Alternative Data As .CSV File option of the Data Management menu or click on the $\delta^{3}$ toolbar button to import alternative data as a .csv file. Enter a path and file name for the flow-data file or use the Browse button. Enter a title and description for the new data set. A new data set will be created for the imported flow data. The data must be formatted as:

Import data format: Comma-separated data

\begin{tabular}{|c|c|}
\hline Record 1 & Year1, Year2, Year3 \\
\hline Record 2 & day1 flow, day1 flow, day1 flow........................................ \\
\hline Record 3 & day 2 flow, day 2 flow, day 2 flow...................................... 2 flow \\
\hline Record 367 & day 366 flow, day 366 flow, day 366 flow ....................day 366 flow \\
\hline Record 368 & Number of peak flow values (n) \\
\hline Record 369 & peak flow 1 , peak flow 2 , peak flow $3 \ldots \ldots \ldots \ldots \ldots \ldots \ldots \ldots \ldots \ldots$...peak flow 'n' \\
\hline Record 370 & $\begin{array}{l}\text { average flow on peak flow day } 1 \text {, average flow on peak flow day } 2 \\
\ldots\end{array}$ \\
\hline
\end{tabular}

Menu items Edit Data Set Data and Edit Data Set Title/Description allow you to examine your input data for errors. Select a data set from a list of existing data sets and examine the file. Note the 999999.00 value where flow data are missing. For example, the last day in February for non-leap years is always 999999 . You can edit individual cells or delete entire rows. If you delete a row, make sure that you insert a replacement row by pressing the "insert" key and then fill in the individual cell values. If you don't replace the deleted row, the data will be shifted, resulting in 
erroneous computations. You may also cut and paste groups of cells using control+C (cut) and control+V (paste) keys.

You can also export your data sets for additional manipulation using this menu. For example, you may want to create an alternative data set that simulates a proposed project that will withdraw " $\mathrm{x}$ " cubic feet per second (cfs) of flow during a specific time period. Use the Export Data Set As .CSV File ... option for this. The Export HI Values As .CSV File menu item allows you to export calculated HI values (you have not calculated yet but will when you get to the Time Period and Alternative Analysis steps) in a .csv format for use in reports. You may want to create a data set that is slightly different from an existing data set or is a subset of an existing data set. Select the Create Data Set From Existing Set option and enter a data set name, description, and the beginning and ending water years for the new data set.

You have reached the point where you can produce a product - a graph of your input data (fig. 11). Select Graph Data Set from drop-down menu or click on the button and then select the data set

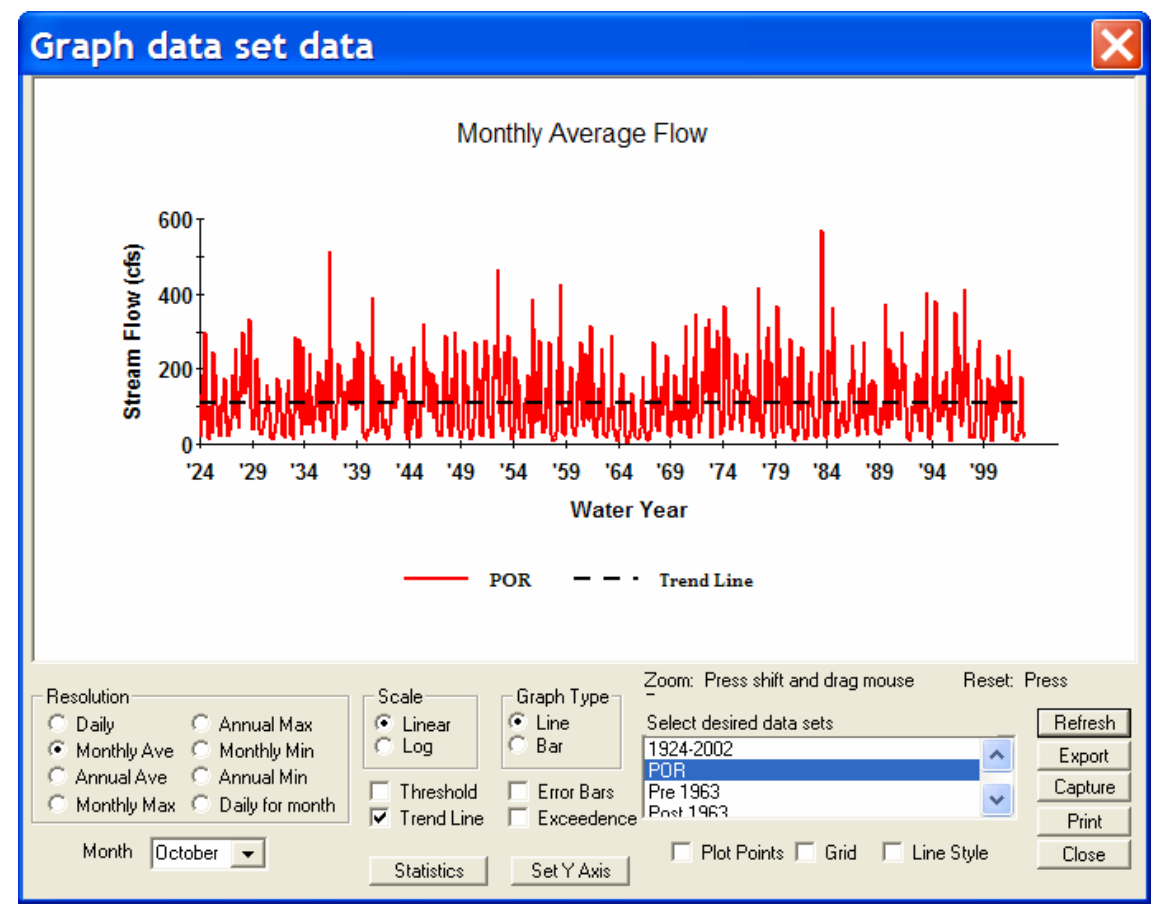

Figure 11. Data management - Graph data set data window.

that you wish to plot. You may select up to 20 data sets to be plotted at the same time. Click on the Refresh button to display the graph. This is a good time to become familiar with the capabilities in this window as this is the same window that is used for a Time Period Analysis and an Alternative Analysis. After you try the various options available, this is where you will become familiar with the historical flow characteristics of the project stream.

Various controls are provided that control what data are displayed, control the appearance of the graph, and control how the data are displayed. These controls include: 
Graph Type: Data sets can be displayed as line or bar graphs. Click on the appropriate radio button to set the graph type.

Scale: Graphs can be linear or logarithmic. Click on the appropriate radio button to set the graph scale.

Resolution: There are eight data resolutions that can be plotted. These include daily, monthly average, annual average, monthly max, annual max, monthly min, annual min, and daily for month. Click on the appropriate radio button to select the resolution.

Month: Use this combo box to select the month to be used with the daily for month plots.

Grid: $\quad$ Checking the Grid check box will result in grid lines being displayed on the graph.

Plot Points: This check box controls whether individual points are displayed on the graph.

Line Style: If you check the Line Style check box, the line style as well as the color of each successive curve will be different.

Threshold: A threshold can be displayed on the graph by checking the Threshold check box and entering a value in cubic feet per second. An example application would be to set a bankfull discharge to determine how frequently the bankfull discharge is exceeded.

Trend Line: If you want to generate a trend line (simple linear regression) for a single data set (the control is disabled when more than one data set is plotted), check the Trend Line box.

Error Bars: Error bars can be displayed when single data sets are displayed by checking the Error Bar box.

Exceedence: You can display exceedence values for data sets by checking the Exceedence box.

Statistics: Click on the Statistics button to display the number of points, minimum curve value, maximum curve value, curve median, curve mean, standard deviation, and total for the data sets that are plotted.

Set Y Axis: You can set the extents for the Y-axis scale by clicking on the Set Y-axis button. Enter the minimum and maximum y values or click on Use Defaults to restore the axis to its default values.

Data destination controls are common to all graphic screens and are located in the lower right corner of the graphic screen. These include: Refresh, Export, Capture, Print, and Close. The functions of these buttons are:

Refresh: Redisplays the graphics based on the settings of the controls. 
Export: $\quad$ Creates a comma-separated value file (.csv) containing the data to be graphed. This file can be read easily by MS Excel.

TIP: You can quickly view the values in Excel by pressing the Export button again after the original Export, highlighting the file just saved, right-clicking, and choosing Open off of the popup menu.

Capture: $\quad$ Save the graph as a Windows graphic file (.bmp) that you can import into a word processing program.

Print: $\quad$ Sends the data to be graphed to your printer after an additional dialog. Note that the printed graph will not include the control frame.

Close: $\quad$ Closes the window for this dialog.

Step through the eight resolution options noting that the Error Bars (for example, 75/25 percentile range) are available for only the Monthly and Average Annual time steps. Depending on the period of time displayed, these graphs may be too cluttered or of limited use. You can, of course, use the Zoom feature to rescale the graph and show fewer years. Being a smart user, you realize that it is not meaningful to produce exceedence graphs with a trend line. Note that all eight resolutions can be displayed as exceedence graphs including Daily for month. This option requires you to select a month. Take a moment to examine the statistics report that is available for each resolution option. You can plot points and grid lines by checking their respective check boxes. The Line Style option plots each curve as a different line style.

Select the Display Data Set Report item to produce a report on all of the data sets contained in a project. This report tracks the creation of each data set and the sequence in which they were created. In addition, the title for the data set, start date and end date for the POR, file name, stream class, and if peak flows are included in the data set are reported. Data sets can be deleted by selecting Delete Data Set.

\section{Time Period Analysis Menu}

It is at this point that you will analyze the daily and peak flow POR data to determine the hydrologic baseline that will be used for establishing environmental standards and conducting alternative analyses. This is a critical step, and once the hydrologic baseline for a specific streamreach is established it should remain the baseline time period for all future analyses. To start, you should examine Appendix 2 to determine if the stream-reach of interest is represented by a gage that was used in the classification analysis. The time periods used for these gages for the classification analysis represents the least modified hydrologic condition prior to refinement using NJHAT. The user may accept the POR in Appendix 2 as the baseline condition or conduct additional analyses. NJDEP has contracted with the USGS to reexamine all gages in Appendix 2 to determine if a refinement of the baseline POR is appropriate. At this time the user must make the decision to accept the POR used in the classification analysis as the baseline or reexamine the entire POR to redefine the baseline time period.

How you go about establishing the hydrologic baseline depends on what information is available regarding water development and land-use activities upstream from your gage site. If you know 
that a major water development occurred at a specific point in time, you can start by creating a "pre" and "post" time period. If water use has incrementally increased over a period of time or, for example, land use in the drainage area has gradually changed over time, a trend analysis will be necessary. Your objective for this analysis is to identify the time period when the flow regime was unmodified, or the least modified condition. Keep in mind, however, that the length of time that your baseline condition represents is important. An interagency advisory committee on water data convened by the USGS published a report (Interagency Advisory Committee, 1981) that states that a minimum of 10 years is necessary and recommends 25 years for an adequate POR for floodfrequency analyses. The USGS New Jersey Water Science Center has adopted 20 years as a minimum period of record (Robert Schoop, oral commun. USGS Water Science Center, July 2005). Yet another author states that 'stable' estimates of streamflow predictability result when about 40 years of data are used (Gan, 1991).

Select Create Time Period Profile or click on the 슨 button to generate time period profiles for a data set. Select the data set to be used for creating a time period profile. Figure 12 shows the window for defining time period profiles. In this example, assume that it has been established that no major water development has occurred. However, it is known that urban development

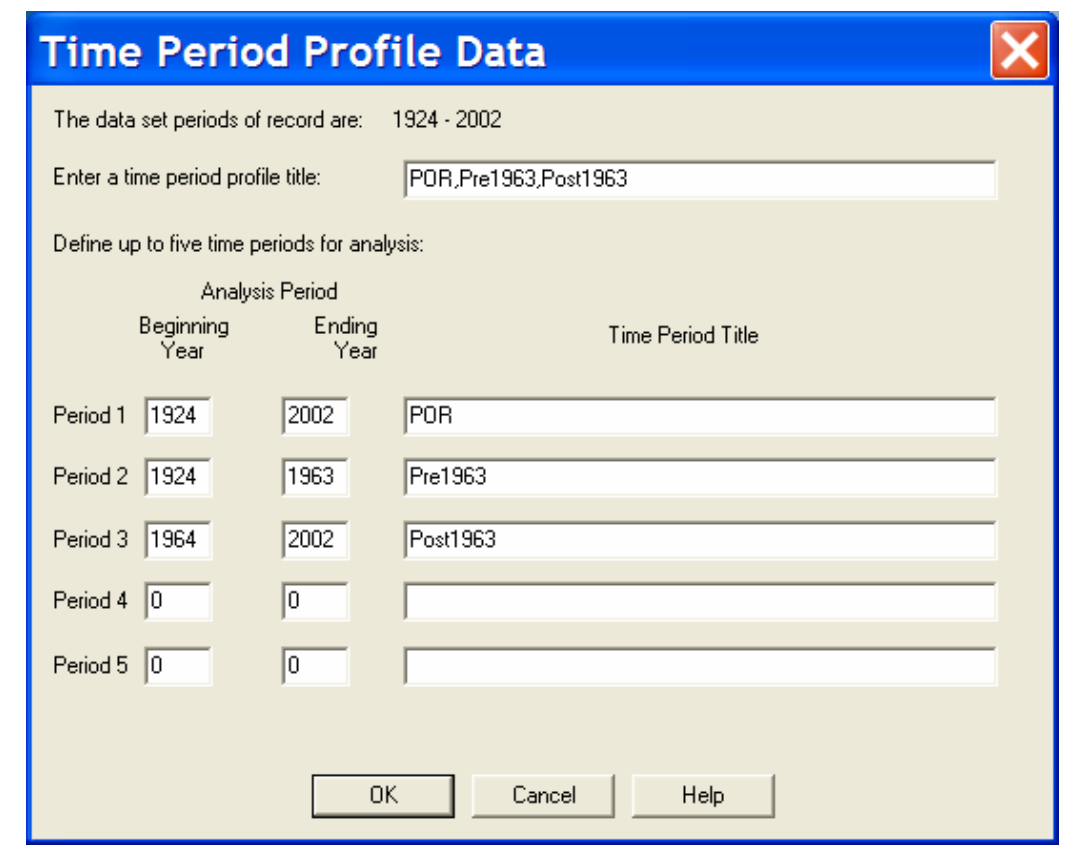

Figure 12. Window used to create a single or multiple time period profiles.

(impervious area) has accelerated since approximately 1964. Therefore, proceed to split the POR into three time periods: the POR, pre-1963, and post-1963. It is advisable to create a single time period profile for the POR since trend analyses cannot be conducted on multiple time period graphs. However, the graph for HIs will plot multiple time periods. Once you generate your time period profile, proceed to Compute Hydrologic Indices from the same drop-down menu and select the profile title you just created - POR, Pre1963, and Post1963. A window will appear (fig. 13) that requires three pieces of information: the drainage area for the gage site and the upper and lower percentile limits that will be applied to each index. The default for the percentile limits is $75 / 25$, 


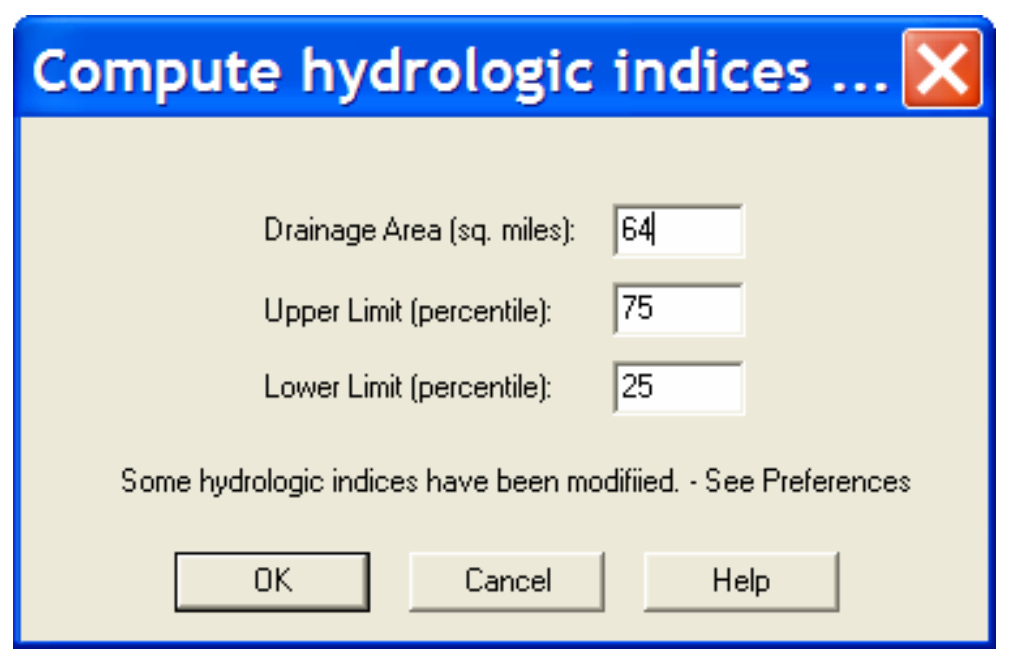

Figure 13. Compute hydrologic indices and percentiles window.

this, of course, would result in bounding 50 percent of the observations used to calculate the index. This is a good choice for comparing HIs for different time periods. However, deciding on the percentile limits has implications if the 10 primary indices will be used for impact analysis and establishing environmental flow standards (see "Establishing Environmental Flow Standards" below).

The message on this window - "Some hydrologic indices have been modified - See Preferences"is referring to the choice you made earlier under File menu - Preferences. The message indicates that you selected the option to calculate median values instead of mean values for 87 indices including MA3, MA12 - MA35, ML1 - ML12, ML17, ML19, ML22, MH1 - MH12, MH20, FL1, FL3, FH1, FH3-FH11, DL1-DL5, DL18, DH1-DH5, DH17-DH24, RA1, RA3, and RA8. At this point you can conduct trend and comparative analyses for the POR and the pre and post time periods you select. Use the Graph Time Period Data (toolbar button ) and Graph Hydrologic Indices (toolbar button figure 14; in this case there is an apparent decrease in the annual minimum flow after 1988.

Additional insight as to whether any hydrologic modification has occurred may be obtained by examining the various time steps (Resolution), monthly exceedence plots, and the Graph Hydrologic Indices option - see figures 15 and 16 (note that the scale has been reduced in figure 16 using the Set Y Axis button). Further analysis will determine if the hydrologic baseline should be the entire POR or a shorter period of time. All seven plots are useful for trend analysis with using the entire POR. Also use the monthly exceedence plots and compare the POR or multiple time periods to aid your decision as to the final baseline time period. 


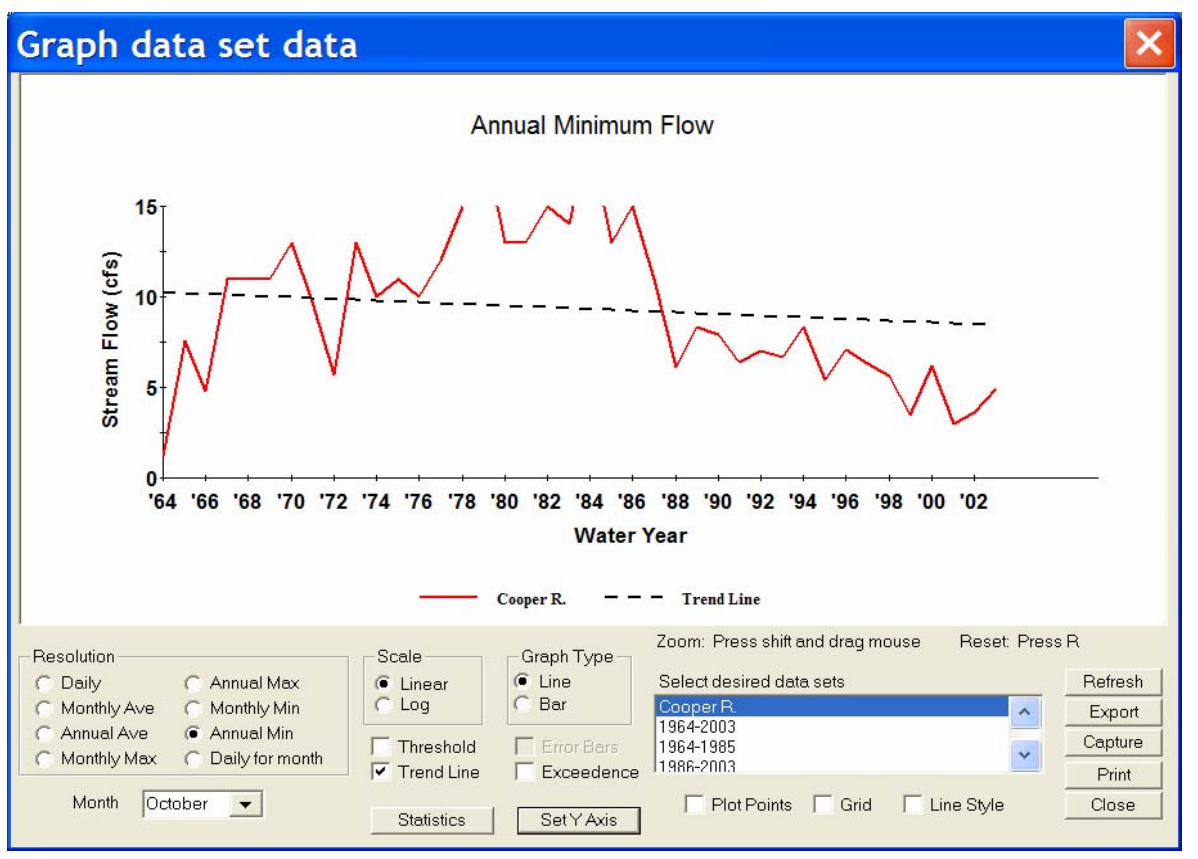

Figure 14. Trend analysis for the period of record using the graph time period profile option.

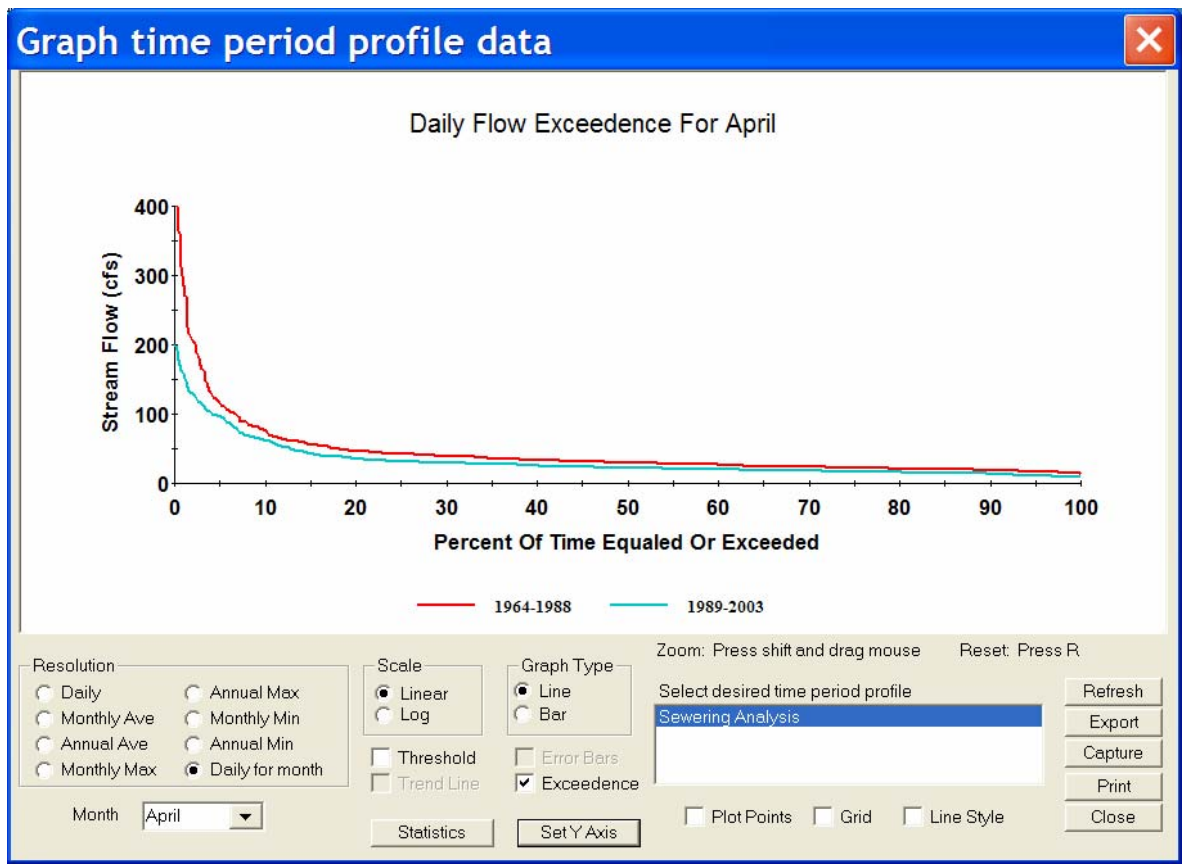

Figure 15. Monthly exceedence plot for the pre and post time periods profiles. 


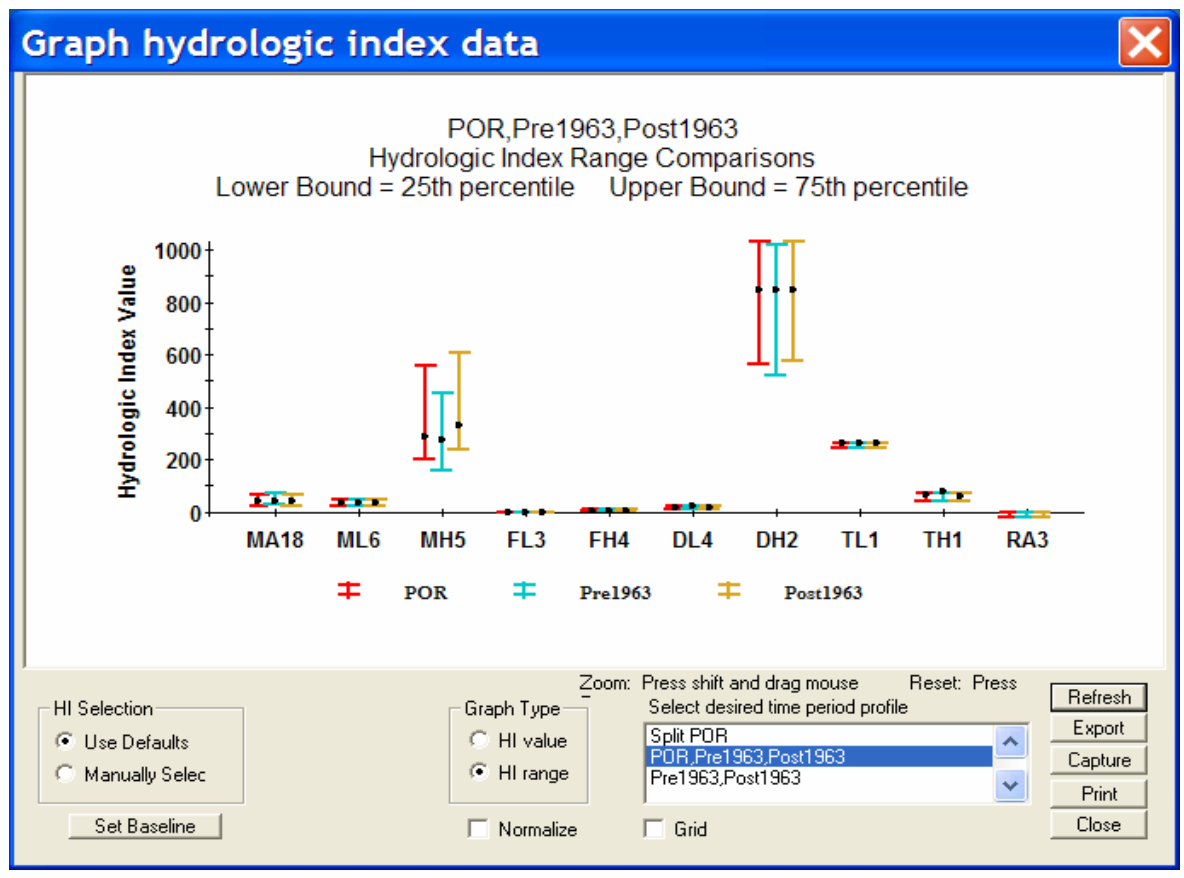

Figure 16. Graph of the primary hydrologic indices for three time periods.

The HI graphs allow you to compare HIs for time periods within a time period profile. Select the time period profile to be displayed from those contained in the list box. Click on the Refresh button to display the graph after selecting the time period profile. Each analysis period of the profile is plotted as a different color. Up to 12 HIs can be displayed at one time. There are two types of graphs that can be displayed. There is a bar graph of the HI values and a graph of $\mathrm{HI}$ ranges. HI ranges are derived from the percentile values entered for the upper and lower HI limits when the HI values were computed. The actual HI values are plotted as black points on the range graph. You can specify which HIs are displayed by selecting the default indices using the Preferences option of the File menu or by clicking on the Manually Select radio button and selecting from a list of the 171 indices that were calculated. Up to 12 indices may be selected. Checking the Normalize check box will result in the data being normalized to the baseline HI values. Click on the Set Baseline button to select one of the time intervals as the baseline. Click on Refresh to replot the graph. The time period selected as the baseline will be indicated as (-base) in the graph key. Checking the Grid check box will result in grid lines being displayed on the graph. For those indices with a narrow range, use the zoom feature to change the scale.

Select Display Hydrologic Index Tables to display a table of HIs for a time period profile. Select a time period profile from the list of time period profiles for which HIs have been computed. You may elect to use the default indices or manually select indices from the remaining list of the 161 indices that were calculated. A table of results for the time period profile selected will be opened in Microsoft WORDPAD. You may edit and print the table from WORDPAD. In addition to examining the 10 primary (or surrogates) stream-type specific indices, at least three additional plots should be constructed using MA12-23 (median of the monthly flows), ML1-12 (median minimum flows for each month), and MH1-12 (median maximum flow for each month). These plots are useful for identifying differences between time periods on a monthly time step and are helpful in further directing the analysis. For example, figure 17 clearly shows the difference between the 


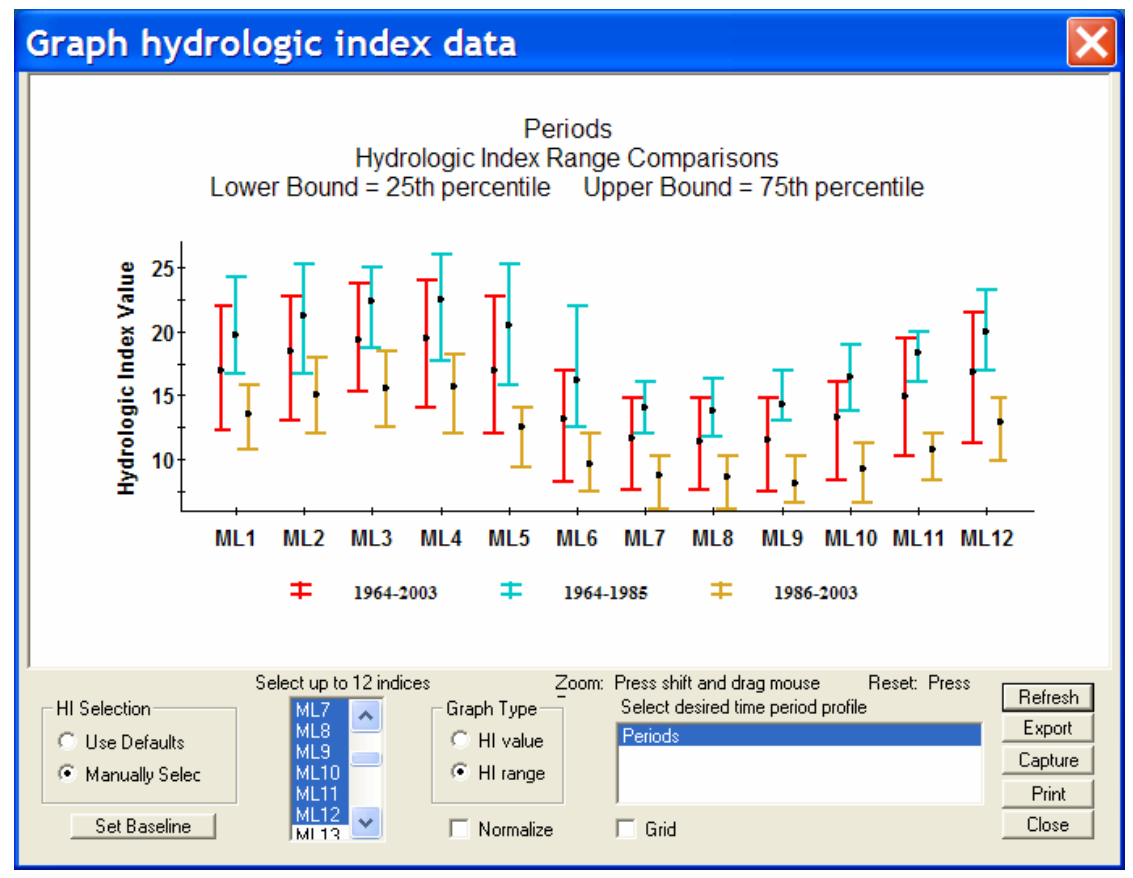

Figure 17. Example of the median of the minimum flows (ML1-12) for three time periods.

median minimum flow for three time periods. Due to an apparent flow modification that occurred after 1986, the baseline would be the earliest portion of the record, $1964-1985$. Click on the Generate Comparison Report option to display a table of HIs comparing two time periods within a time period profile. Select a time period profile from a list of time period profiles for which HIs have been computed. You may elect to use the default indices or manually select up to 12 indices at a time from a list of the 171 indices that were calculated. Select a time interval as a baseline. Select a time interval for comparison. Enter a title for the report. A report comparing results for the time intervals selected will be opened in Microsoft WORDPAD. The report shows the absolute and percent difference for each index for each time period. You may edit and print the table from WORDPAD.

\section{Establishing Environmental Flow Standards}

At this point a final decision should be made regarding which time period will represent the hydrologic baseline. Prior to creating a single time-period profile for the baseline, and calculating the values and percentile ranges for the indices that will be used as standards, the user should decide if only the 10 primary, stream class specific indices will be used, or if there is justification to substitute or add additional indices. Note, however, we recommend that at a minimum all 10 components of the flow regime addressed by 10 primary indices be used: three for magnitude low, median, high values; two for frequency - low, high values; two for duration - low, high values; two for timing - low, high values; and one for rate of change - median value.

The decision to substitute or add additional indices for use as a standard(s) is based on relevant stream research that has established a direct or indirect relationship between flow and, for example, channel geomorphology, riparian wetlands, habitat diversity or habitat for a community or species, or any relationship that has been shown to affect the diversity and (or) abundance of 
riverine species or communities. For example, Kennen and Ayers (2002) used aquatic community data - fish, invertebrates, and alga from 36 watersheds in New Jersey - to evaluate the response of these assemblages to environmental characteristics along a gradient of urban land use. Results from this study indicate that hydrologic instability (2-year peak flow associated with urban land use); that is, the "flashiness" of streamflow is a factor adversely affecting these aquatic assemblages. Consequently, it would be appropriate to add a magnitude high (MH) and a frequency high (FH) flow index to better reflect a 2-year peak-flow event (for example MH14 or MH24 and FH6 or FH9) if, depending on the stream class, the primary $\mathrm{MH}$ and $\mathrm{FH}$ indices do not address a 2-year flow event. Kennen and Ayers (2002) state that stormwater-management practices and preservation of existing forest, riparian wetlands, and riparian corridors will help maintain the relative abundance of sensitive taxa. This management goal would be complemented by managing water resource development to specifically prevent modification of the selected $\mathrm{MH}$ and $\mathrm{FH}$ indices that reflect "flashiness."

Deciding what indices constitute the full suite of indices that will be used for each stream type and the standards that will be applied to the indices is, of course, the responsibility of each management or regulatory agency. Richter and others $(1996,1997)$ proposed using a standard of \pm 1 standard deviation from the mean or the twenty-fifth to seventy-fifth percentile range of an index(s) as "initial flow management targets." Generally, this approach was being recommended in a situation downstream from an existing dam where significant water management was possible. If the mean or median compared to the baseline condition is, or will be with a proposed action, outside of the standard deviation or percentile range, it would be considered "unacceptable" or a "violation" of the standard, the premise being that modifying the hydrological variability of an index(s) will affect the biodiversity and ecological integrity of the aquatic communities. Thus, the management or regulatory agency may be as conservative as deemed appropriate for the resource being considered.

Differences among streams based on regulatory statutes in a State or region will also have a significant effect on the management measure (standard) used. For example, streams requiring the utmost protection from anthropogenic degradation (such as Category One designated streams in New Jersey that are of exceptional ecological significance, exceptional water-supply significance, exceptional recreational significance, or are an exceptional fisheries resource [see http://www.nj. gov/dep/cleanwater/cl.html] may require a more stringent flow target, such as the sixtieth to fortieth or even fiftieth to forty-fifth percentile range, which will provide adherence to antidegradation polices associated with such a designation.

Once the decision has been made regarding which indices will constitute the full set of standards, a new time-series profile would be constructed. This profile will consist of two time periods: (1) the permanent baseline and (2) the modified post-project time period (fig. 18). If the baseline is not the entire POR, then the project is combined with the modified pre-project time period to create a modified (plus) post-project time period. The implication is that all projects that are implemented are added to the modified pre-project condition and then combined with any new proposed project to create a new modified post-project condition. This allows the user to conduct a cumulative impact analysis. Furthermore, NJHAT can be used by a regulatory agency to be proactive to water development and land-use projects by identifying streams that are "over standard", that is, the current condition is that one or more of the agencies' environmental flow standards are not currently being met. This could be determined by identifying any stream with a baseline that is less than the full POR; in other words, a modified pre-project time period exists. A proactive approach 


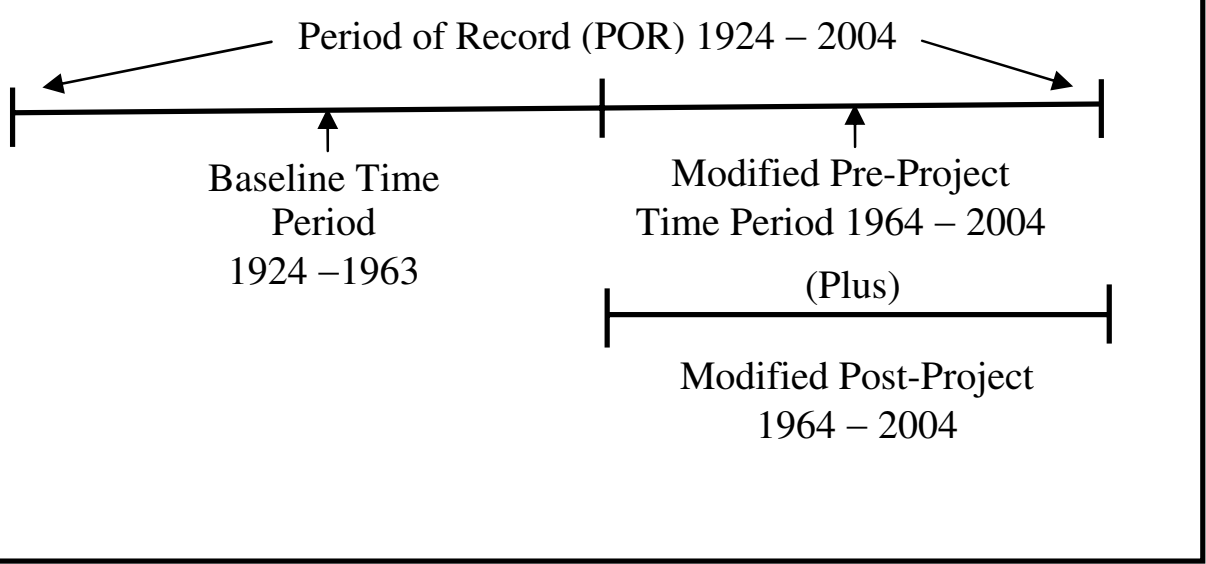

Figure 18. Example period of record, baseline, modified pre-project and modified post-project time periods for cumulative impact analyses.

could also be applied to current land-use conditions that are contributing to the agencies' environmental flow standards not being met.

\section{Alternatives Analyses}

NJHAT and NATHAT are designed with the capability to conduct alternatives analyses (project impact). Here you define and develop alternative hydrologic (that is, project-modified) flow regime(s) and compare the 10 (or more) baseline environmental flow standards (indices) to the project-modified indices. You must first create alternative flow data. This can be as elaborate as generating flow data from a sophisticated watershed simulation model or as simple as editing existing measured flow data. For example, you could create a text file of the daily flow record from NWIS (comma separated) and import it into a spreadsheet. Write the appropriate formulas to adjust the flows with a project that would divert $50 \mathrm{cfs}$ and leave a passing flow of $25 \mathrm{cfs}$. The project would be allowed to divert less than $50 \mathrm{cfs}$ when the flow was between 50 and $25 \mathrm{cfs}$. Once the spreadsheet file is modified to reflect the proposed project operational scheme, it would be saved as a text file with the same format as an NWIS file and imported back into NJHAT. In either case, the alternative data are compared to the baseline POR data or the modified post-project time period data (see fig. 18).

These data are brought into NJHAT via the Import Alternative Data As .CSV File option of the Data Management menu. No matter how you generate it, alternative data must be in the following format to be imported into NJHAT:

Import data format: Comma-separated data

Record $1 \quad$ Year1, Year2, Year3....................................................Year n

Record 2 day1 flow, day1 flow, day1 flow.......................................day1 flow 

Record 3
day2 flow, day2 flow, day2 flow.
day2 flow
Record 367 day 366 flow, day 366 flow, day 366 flow.
day 366 flow
Record 368 Number of peak flow values (n)
Record 369 peak flow1, peak flow2, peak flow 3
peak flow $n$
Record 370 average flow on peakflow day 1, average flow on peak flow day 2 ..,......average flow on peak flow day $\mathrm{n}$.

Do not forget to change flows on February 29 in leap years to 999999 . Once you have imported alternative data set(s), you must select the data set designated as your baseline. This is the data set with which you will compare alternatives. Click on the Select Baseline Data Set option or the Dipifif toolbar button. Select a data set from the list of existing data sets. After you have imported your alternative(s), compute the HI for each one by using the Compute Hydrologic Indices option. The procedure is the same as that used for the time period analysis.

Select Graph Alternative Data or click on the button to compare alternative flow data with the baseline data or the modified post-project data (fig. 19). These graphs are similar to the time period graphs except that the baseline data are always automatically plotted. Select the alternative(s) that you wish to compare and click on the Refresh button. Various controls are provided that control what data are displayed, control the appearance of the graph, and control how the data are displayed. These controls include:

Graph Type: Data sets can be displayed as lineor bar graphs. Click on the appropriate radio button to set the graph type.

Scale: $\quad$ Graphs can be linear or logarithmic.Click on the appropriate radio button to set the graph scale.

Resolution: There are eight data resolutions that can be plotted. These include daily, monthly average, annual average, monthly max, annual max, monthly min, annual min, and daily for month. Click on the appropriate radio button to select the resolution.

Month: $\quad$ Use this combo box to select the month to be used with the daily for month plots.

Grid: Checking the Grid check box will result in grid lines being displayed on the graph.

Plot Points: This check box controls whethe individual points are displayed on the graph.

Line Style: If you check the Line Style checkbox, the line style as well as the color of each successive curve will be different. 


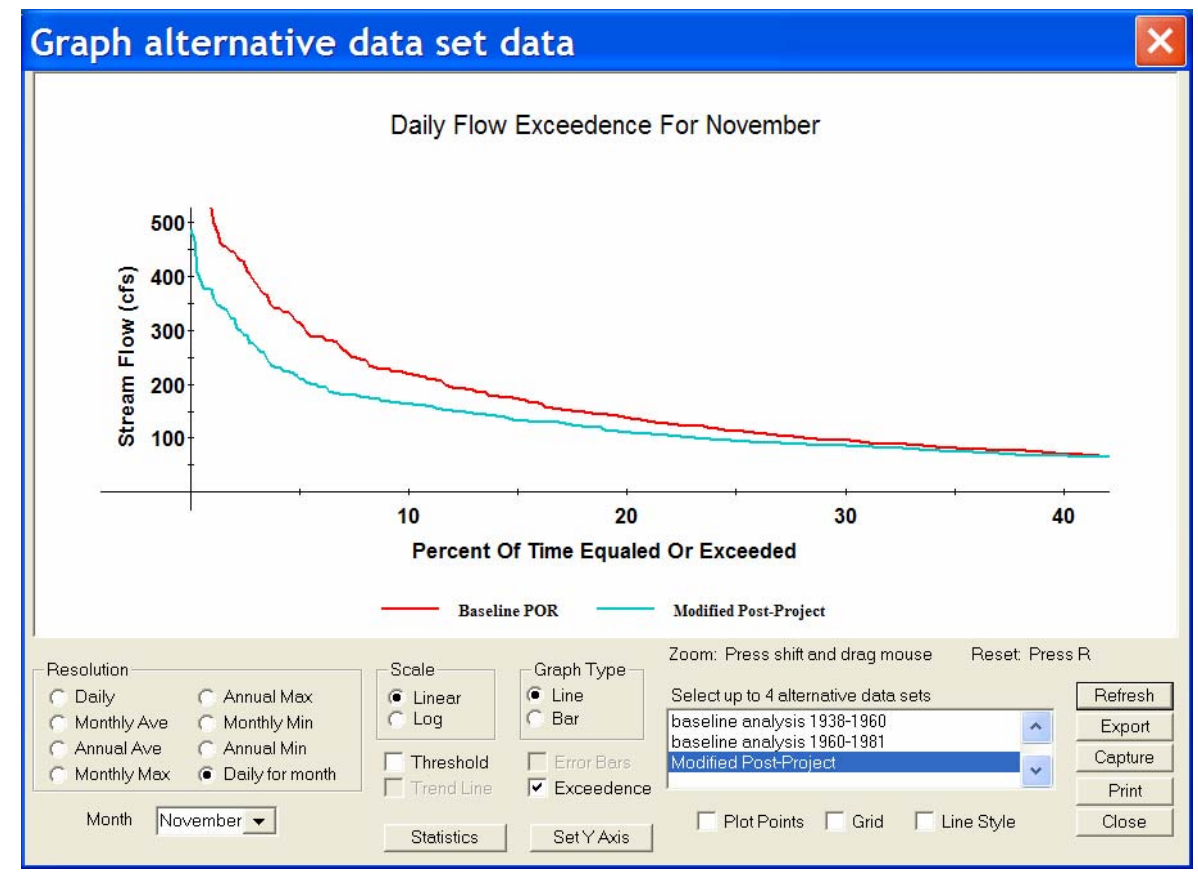

Figure 19. Graph alternative data set option for comparing a baseline to the modified post-project exceedence graph.

Threshold: A threshold can be displayed on the graph by checking the Threshold check box and entering a value in cubic feet per second.

Trend Line: If you want to generatea trend line (simple linear regression) for a single data set (the control is disabled when more than one data set is plotted), check the Trend Line box.

Error Bars: Error bars can be displayed whensingle data sets are displayed by checking the Error Bar box.

Exceedence: You can display exceedence valuesfor data sets by checking the Exceedence box.

Statistics: Click on the Statistics button to display the number of points, minimum curve value, maximum curve value, curve median, curve mean, standard deviation, and total for the data sets that are plotted.

Set Y axis: $\quad$ You can set the extents for the Y-axis scale by clicking on the Set Y-axis button. Enter the minimum and maximum y values or click on Use Defaults to restore the axis to its default values.

Data destination controls are common to all graphic screens and are located in the lower right corner of the graphic screen. These include: Refresh, Export, Capture, Print, and Close. The functions of these buttons are: 
Refresh: Redisplays the graphics based on the settings of the controls.

Export: $\quad$ Creates a comma-separated value file (.csv) containing the data to be graphed. This file can be read easily by MS Excel.

TIP: You can quickly view the values in Excel by pressing the Export button again after the original Export, highlighting the file just saved, right-clicking, and choosing Open off of the popup menu.

Capture: $\quad$ Save the graph as a Windows graphic file (.bmp) that you can import into a word processing program.

Print: $\quad$ Sends the data to be graphed to yourprinter after an additional dialog. Note that the printed graph will not include the control frame.

Close: $\quad$ Closes the window for this dialog.

Select the Graph Hydrologic Indices option - click on the values with those of the baseline. There are two types of graphs that can be displayed. These are a bar graph of the HI values and a high-low range graph, that is, the HI percentile range, with a median or a mean value. HI ranges are derived from the percentile values entered for the upper and lower HI limits when the HI values were computed. The actual HI values are plotted as black points on the range graph. Select the alternatives to be displayed (up to four) from those contained in the list box and click on the Refresh button to display the graph. Figure 20 shows the percentile range (in this example 60/40) for the 10 primary indices for a baseline-modified pre-project condition compared to two baseline-modified post-project alternatives. Each alternative is plotted as a different color. Ten (default) primary or surrogate HIs will be displayed. Note that both alternatives move the median value outside the percentile range for MH5 and DH2. Another hydrologic modification that may be of interest is the significant reduction in the range of variability index MH5 that occurred with Alternative A. Finally, note that due to scale differences the remaining indices cannot easily be interpreted; for example, MA18, ML6 or FL3.

Zoom in (press Shift and drag mouse) on the eight indices with values below 300 on the Y axis (fig. 21) or select the Normalize check box, which will result in the data being normalized to the baseline HI values (fig. 22).

Normalizing the values and ranges is the best option to plot all of the indices in one figure (fig 22.). However, take note of index TH1 - Julian date of the annual maximum. TH1 is an example of one of the 60 indices that results in a single mean value; a median cannot be calculated. Note also however, that NJHAT uses spatial data to calculate a percentile range. Consequently, a mean may occur outside the percentile range due to skewed data, while a median may occur outside the range due to the use of spatial data and the percentile range being calculated. NATHAT does not use spatial data, so a mean value may occur outside the percentile range due to skewed data. Checking the Grid check box will result in grid lines being displayed on the graphs. You can specify which HIs are displayed by selecting the default indices Preferences option of the File menu or by clicking on the Manually Select radio button and selecting from a list of the 171 indices that were calculated. Up to 12 indices may be selected. Figure 23, also rescaled, shows ML1 - ML12, the median (or mean) minimum flows for each month across all years. Note that Alternative A results 


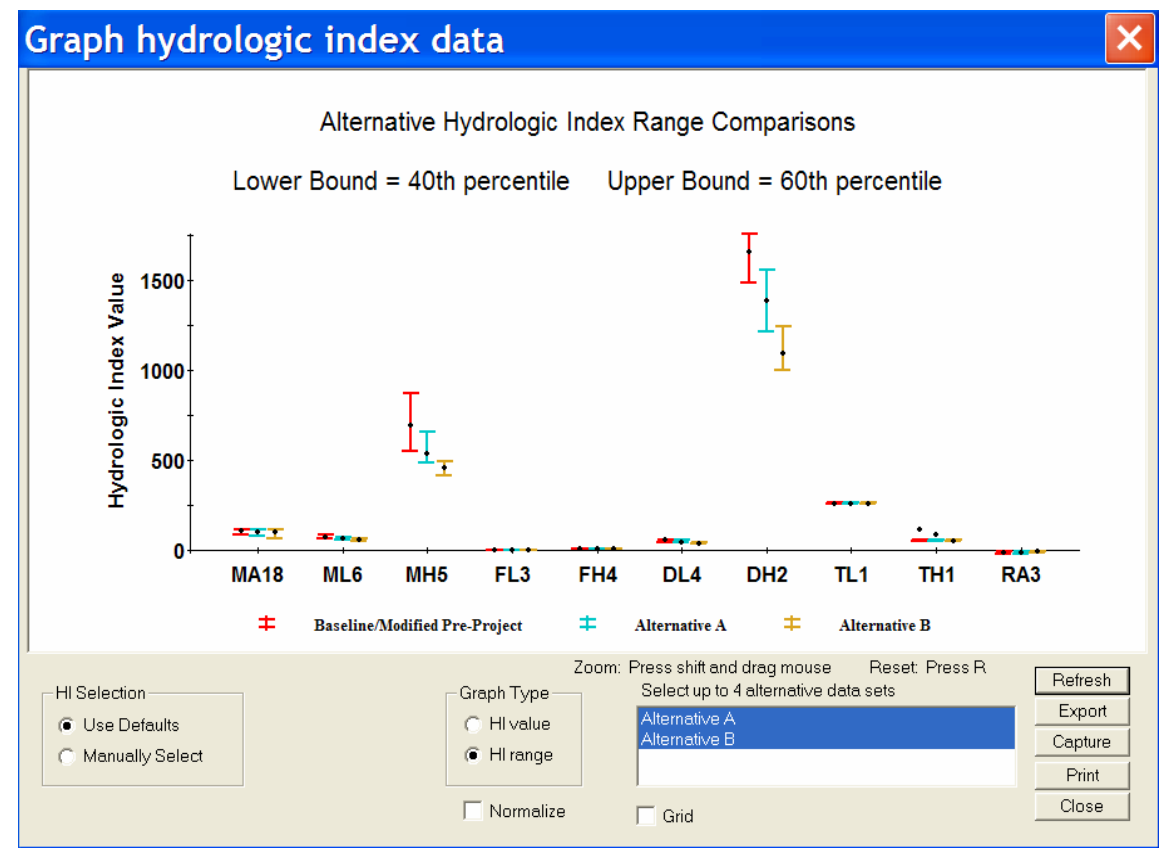

Figure 20. Alternative analyses index graph (high-range) comparing 10 baseline-modified preproject hydrologic indices to two baseline modified post-project alternatives.

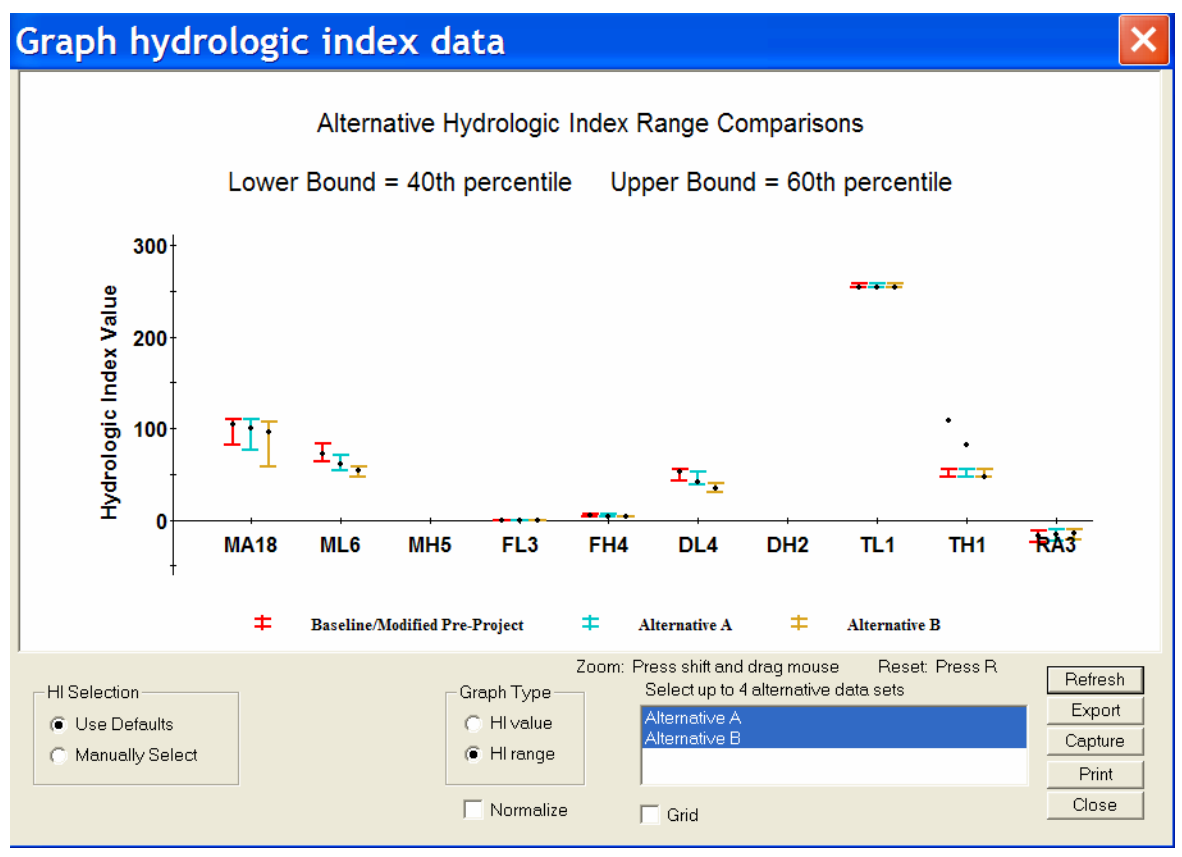

Figure 21. Alternative analyses index graph (high-range) rescaled comparing eight baselinemodified pre-project indices to two baseline-modified post-project alternatives.

in the median occurring outside the percentile range compared to the baseline for only 1 month (June), whereas Alternative B results in the median occurring outside the percentile range compared to the baseline for 6 months. 


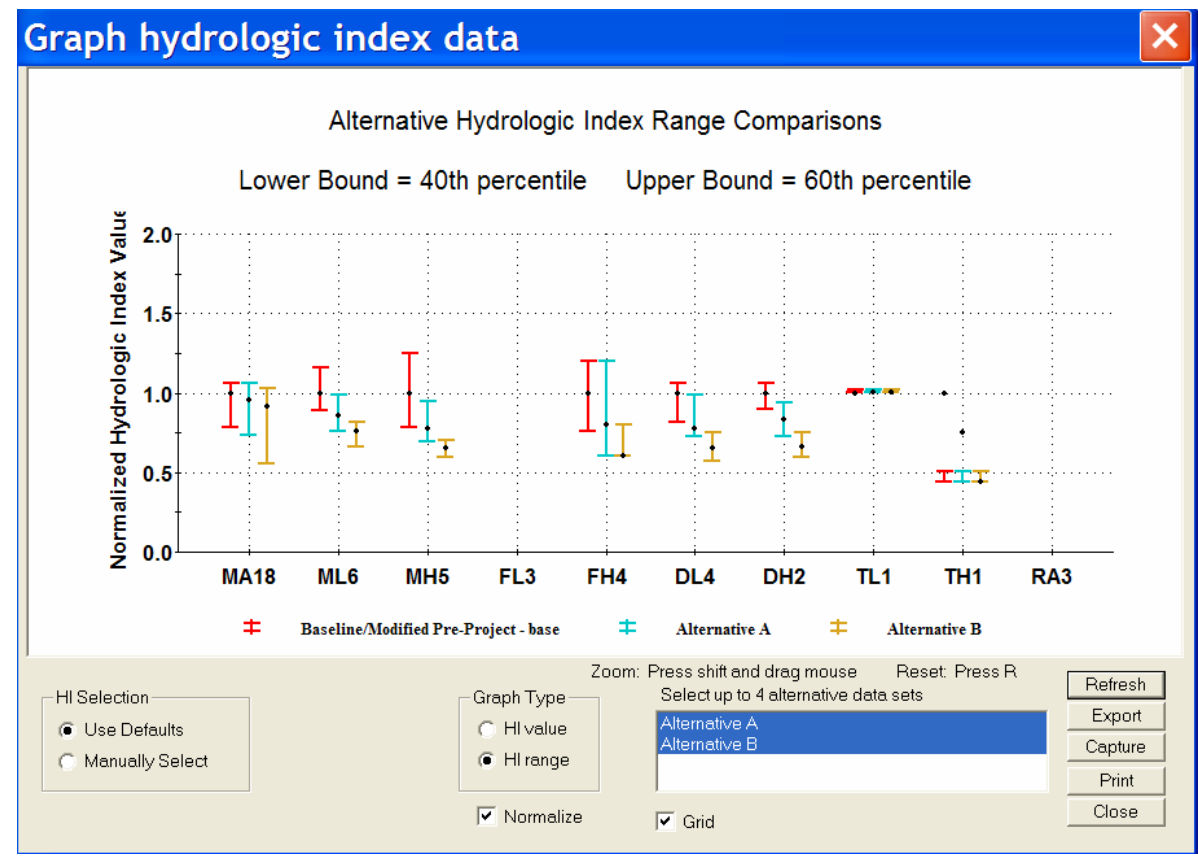

Figure 22. Alternative analyses index graph (high-range) rescaled to comparing the baselinemodified pre-project indices to two baseline-modified post-project alternatives.

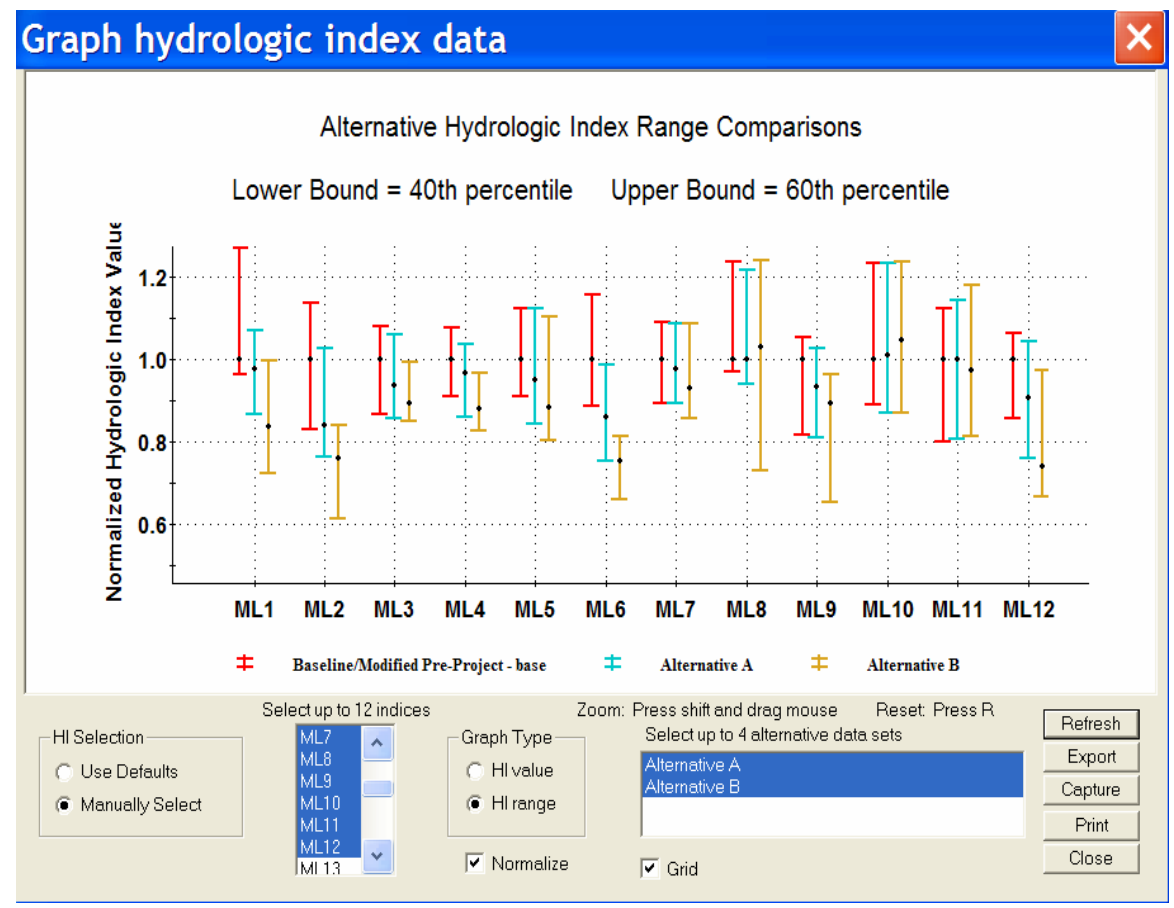

Figure 23. Alternative analyses index graph with 12 manually selected indices to comparing the baseline modified pre-project indices to two baseline modified post-project alternatives. 
A table and a report can be produced within the Alternative Analysis drop-down menu. To compare actual values, select Display Hydrologic Index Tables to display a table of HIs for the baseline and up to four alternatives (table 2). Select alternative data sets from a list of data sets for which HIs

Table 2. Partial example of a hydrologic index report from alternatives analysis.

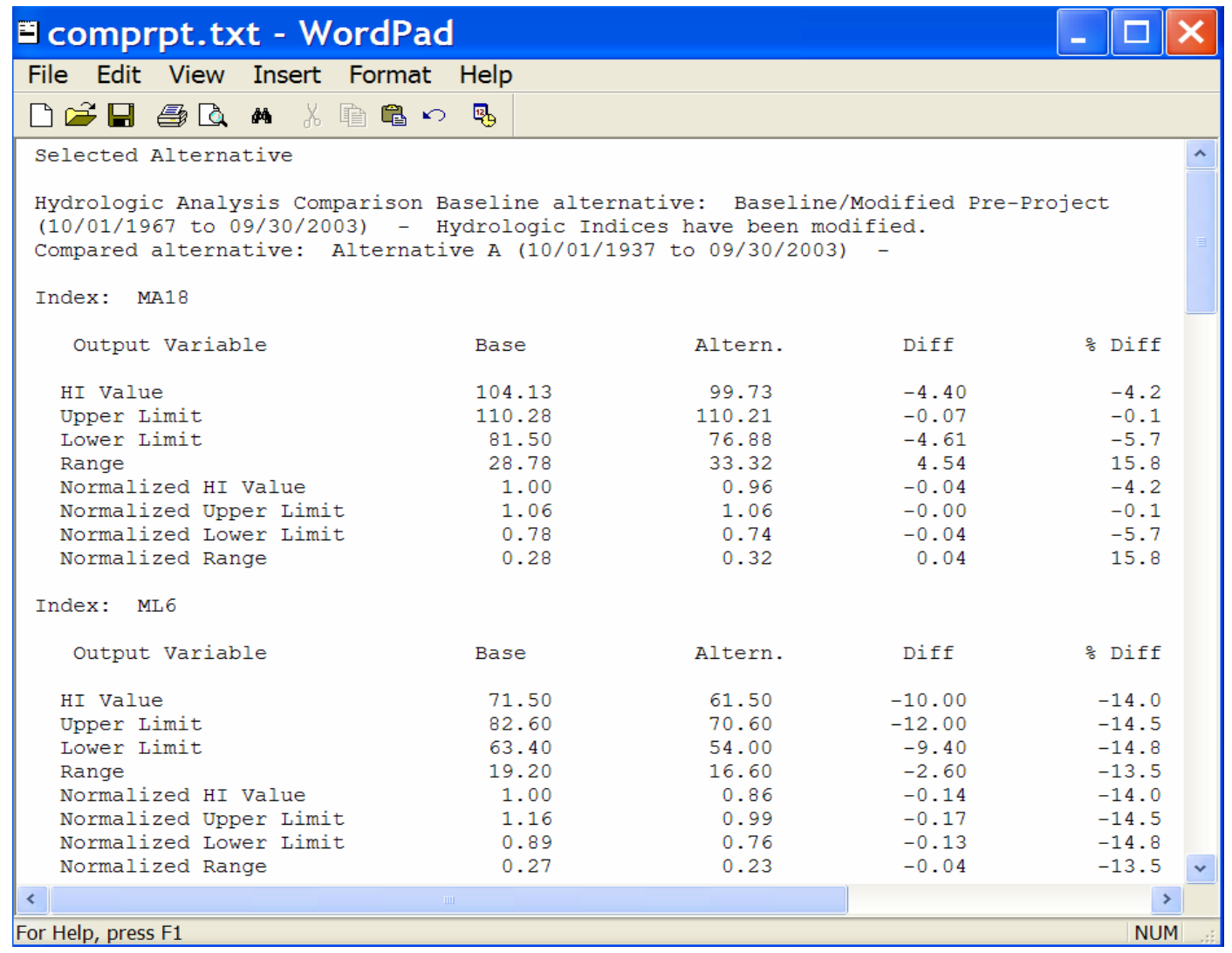

have been computed. You may elect to use the default indices specified as preferences or manually select up to 12 indices from a list of the 171 indices that were calculated. A table of results for the time period profile selected will be opened in Microsoft WORDPAD. You may edit and print the table from WORDPAD.

Click on the Generate Comparison Report option to display a table of HIs comparing the baseline with one alternative (table 3). Select an alternative data set from a list of data sets for which HIs have been computed. You may elect to use the default indices specified as preferences or manually select up to 12 indices at a time from a list of the 171 indices that were calculated. Enter a title for the report. A report comparing results for the baseline and the alternative selected will be opened in Microsoft WORDPAD. You may edit and print the table from WORDPAD. 
Table 3. Partial example of comparison report for alternatives analysis.

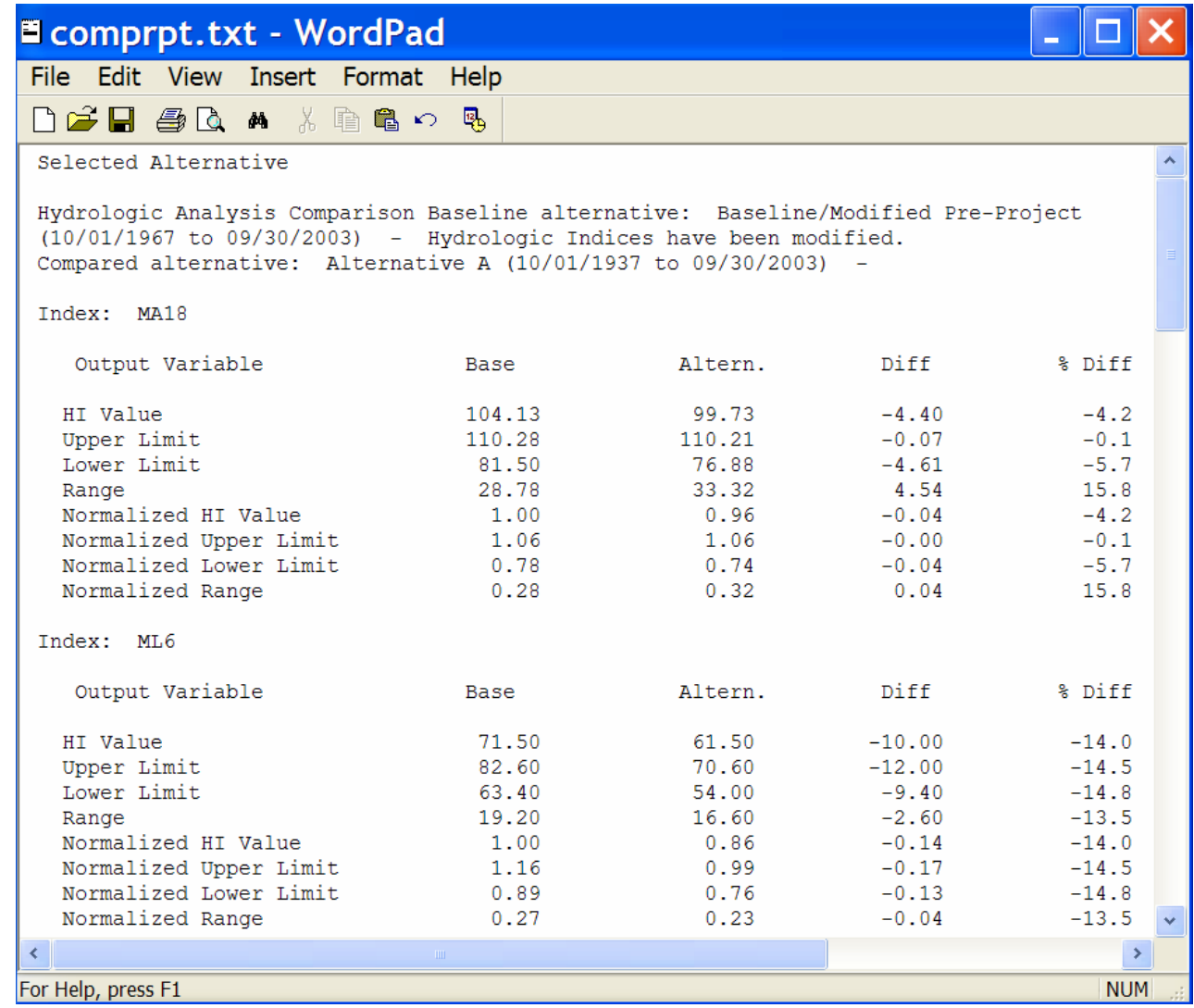




\section{ACKNOWLEDGMENTS}

The authors kindly thank the New Jersey Department of Environmental Protection (NJDEP) for supporting the Ecological Flow Goals project. Scientific guidance from members of the Technical Advisory Committee including Jeff Hoffman, Andy Didun, Patricia Hamilton, Marjorie Kaplan, Helen Rancan, Karen Schaffer, Jan Gheen, Donna Milligan, Harold Niebling, Mike Bleicher, Tom Belton, Jeanette Bowers-Altman, Bob Kecskes, and Flavian Stellerine with the NJDEP, Robert Schopp, Robert Reiser, Dave Steadfast, and Kara Watson with the U.S. Geological Survey, Nick Procopio with the Pinelands Commission, and Rich Horowitz with the Philadelphia Academy of Natural Sciences was greatly appreciated. Special thanks and recognition to Julian Olden and LeRoy Poff for providing the data sets and formulations used to verify index calculations and for the essential contribution made to the development of the Hydroecological Integrity Assessment Process software. Thanks also to Ward Hickman of the U.S. Geological Survey for his assistance with the index validation process. Finally, the authors thank Dave Hamilton and Murphy Laubhan of the U.S. Geological Survey for supporting the development of the National Hydrologic Assessment Tool. 


\section{References Cited}

Annear, T., Chisholm, I., Beecher, H., Locke, A., and 12 other authors, 2004, Instream flows for riverine resources, revised edition, Cheyenne, Wyo., 268 p.

Bunn, S.E., and Arthington, A.H., 2002, Basic principles and ecological consequences of altered flow regimes for aquatic biodiversity: Environmental management, v. 30, p. 492-507.

Calwell RK., 1974. Predictability, constancy, and contingency of periodic phenomena. Ecology 55: 1148-1153.

Gan K.C., McMahon, T.A., and Findlayson, B.L., 1991, Analysis of predicity in streamflow and rainfall data by Coldwell’s indices: Journal of Hydrology, v. 123, p. 105-118.

Interagency Advisory Committee on Water Data, 1981, Guidelines for determining flood flow frequency: U.S. Geological Survey, Office of Water Data Coordination, Bulletin \#17B of the Hydrology Subcommittee, revised September 1981.

Kennen, J.G., and Ayers, M.A., 2002, Relation of environmental characteristics to the composition of aquatic assemblages along a gradient of urban land use in New Jersey, 1996-98: U.S. Geological Survey Water-Resources Investigations Report 2002-4069, 77 p.

Nilsson, C., and Svedmark, M., 2002, Basic Principles and Ecological Consequences of Changing Water Regimes: Riparian Plant Communities. Environmental Management. v. 30, no. 4. p. 468480.

McCune, B., Grace J.B., and Urban, D.L., 2002, Analysis of ecological communities: Gleneden Beach, Oregon, MJM Software Design.

McCune, B., and Medford, M. J., 1999, PC-ORD - Multivariate analysis of ecological data Version 4.25: Gleneden Beach, Oregon, MJM Software Design.

Olden, J.D., and Poff, N.L., 2003, Redundancy and the choice of hydrologic indices for characterizing streamflow regimes: River Research and Applications, v. 19, p. 101-121.

Poff, N.L., 1996, A hydrogeography of unregulated streams in the United States and an examination of scale-dependence in some hydrological descriptors: Freshwater Biology, v. 36, p. 71-91.

Poff, N.L., Allan, J.D. , Bain, M.B. , Karr, J.R. , Prestegaard, K.L., Richter, B.D. , Sparks, R.E. , and Stromberg, J.C., 1997, The natural flow regime - A paradigm for conservation and restoration of river ecosystems: BioScience, v. 47, p. 769-784. 
Poff, N.L., and Ward, J.V., 1989, Implications of streamflow variability and predictability for lotic community structure - A regional analysis of streamflow patterns: Canadian Journal of Fisheries and Aquatic Sciences, v. 46, p. 1805-1818.

Powers, M.E., Sun, A., Parker, M., Dietrich, W.E., and Wootton, J.T., 1995, Hydraulic food-chain models - An approach to the study of food-web dynamics in large rivers: BioScience. v. 45, 159-167.

Resh, V.H., Brown, A.V., Covich, A.P., Gurtz, M.E., Li, H.W., Minshall, G.W., Reice, S.R., Sheldon, A.L., Wallace, J.B., and Wissmar, R.C., 1988, The role of disturbance in stream ecology: Journal of North American Benthological Society, v. 7, 433-455.

Richter, B.D., Baumgartner, J.V., Powell, J., and Braun, D.P., 1996, A method for assessing hydrologic alteration within ecosystems: Conservation Biology, v. 10, p. 1163-1174.

Richter, B.D., Baumgartner, J.V., Wigington, R., and Braun, D.P., 1997, How much water does a river need: Freshwater Biology, v. 37, p. 231-249.

SAS Institute Inc., 1989, SAS/STAT® user’s guide, 4th edition, v. 2, Cary, North Carolina.

SYSTAT, 2004, SYSTAT Incorporated: Version 11. 


\section{GLOSSARY}

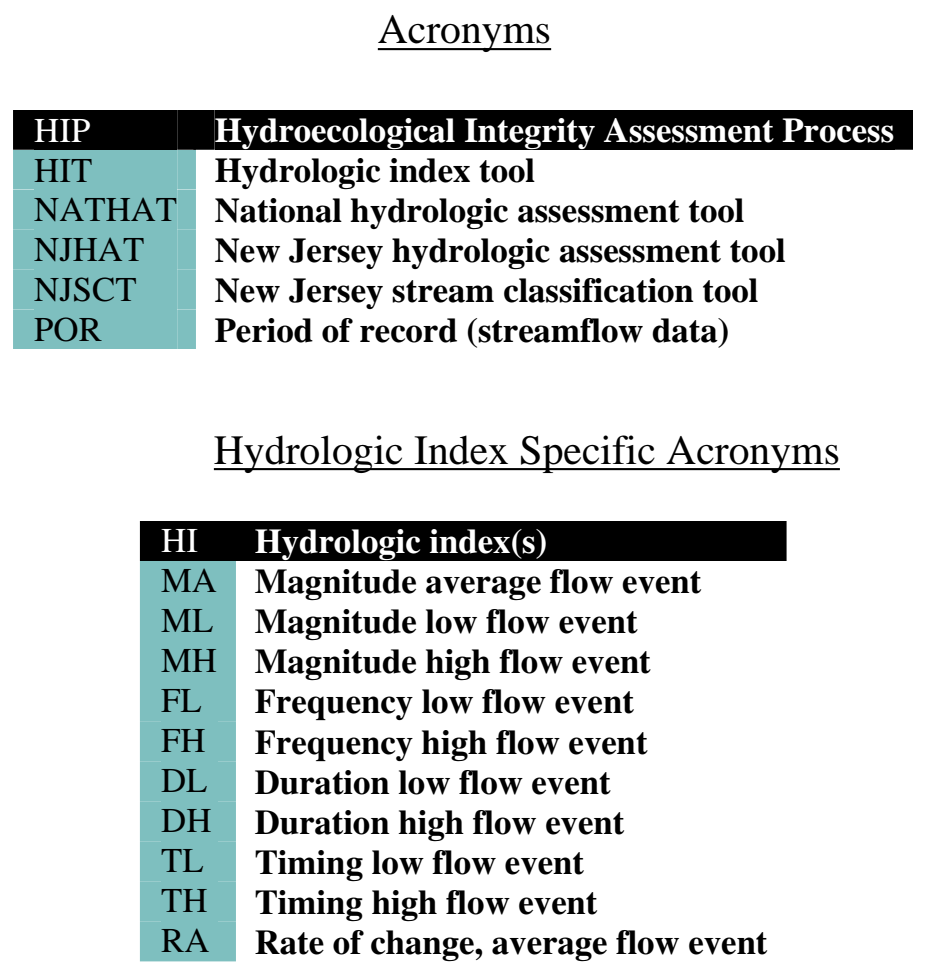


Appendix 1. Distinctive characteristics of the four stream types in New Jersey.

\section{Distinctive Characteristics of the Four Stream Types in New Jersey}
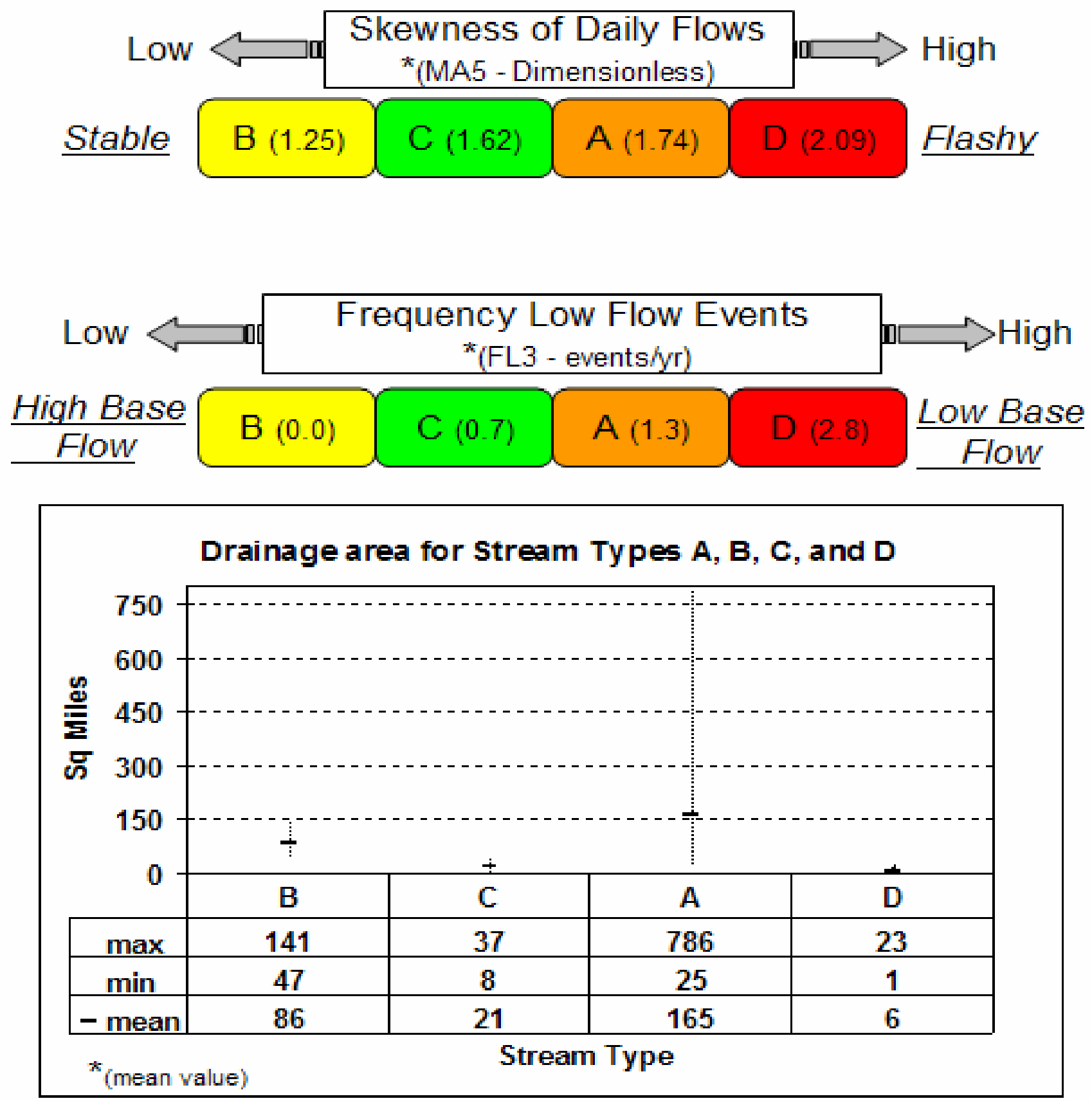


\section{Appendix 2. Gaging stations used to classify New Jersey streams, stream type, and pertinent}

information (sorted by station number).

\begin{tabular}{|c|c|c|c|c|c|}
\hline TYPE & STATION & STATION NAME & $\mathrm{DA}^{*}$ & RECORD & YEARS \\
\hline A & 01368000 & WALLKILL RIVER NEAR UNIONVILLE NY & 140 & 1938-1981 & 44 \\
\hline A & 01369000 & POCHUCK CREEK NEAR PINE ISLAND NY & 98 & 1939-1978 & 39 \\
\hline A & 01379000 & PASSAIC RIVER NEAR MILLINGTON NJ & 55.4 & 1979-2001 & 23 \\
\hline A & 01379500 & PASSAIC RIVER NEAR CHATHAM NJ & 100 & 1938-1960 & 23 \\
\hline $\mathrm{D}$ & 01379773 & GREEN POND BROOK AT PICATINNY ARSENAL NJ & 7.65 & 1983-2001 & 19 \\
\hline A & 01380500 & ROCKAWAY RIVER ABOVE RESERVOIR AT BOONTON NJ & 116 & 1938-1960 & 23 \\
\hline $\mathrm{C}$ & 01381500 & WHIPPANY RIVER AT MORRISTOWN NJ & 29.4 & $1922-1960$ & 39 \\
\hline $\mathrm{C}$ & 01383500 & WANAQUE RIVER AT AWOSTING NJ & 27.1 & 1919-2001 & 82 \\
\hline A & 01384000 & WANAQUE RIVER AT MONKS NJ & 40.4 & 1935-1985 & 50 \\
\hline $\mathrm{C}$ & 01384500 & RINGWOOD CREEK NEAR WANAQUE NJ & 19.1 & 1935--2001 & 59 \\
\hline $\mathrm{D}$ & 01385000 & CUPSAW BK NR WANAQUE NJ & 4.37 & 1936-1958 & 22 \\
\hline $\mathrm{C}$ & 01386000 & WEST BROOK NEAR WANAQUE NJ & 11.8 & 1935-1978 & 43 \\
\hline $\mathrm{D}$ & 01386500 & BLUE MINE BROOK NR WANAQUE NJ & 1.01 & 1935-1958 & 24 \\
\hline A & 01387000 & WANAQUE R AT WANAQUE NJ & 90.4 & 1920-1928 & 9 \\
\hline $\mathrm{C}$ & 01387450 & MAHWAH RIVER NEAR SUFFERN NY & 12.3 & 1959-1995 & 37 \\
\hline A & 01387500 & RAMAPO RIVER NEAR MAHWAH NJ & 120 & $1923-1960$ & 38 \\
\hline A & 01388000 & RAMAPO RIVER AT POMPTON LAKES NJ & 160 & $1922-1950$ & 29 \\
\hline A & 01389500 & PASSAIC RIVER AT LITTLE FALLS NJ & 762 & 1898-1927 & 30 \\
\hline
\end{tabular}




\begin{tabular}{|c|c|c|c|c|c|}
\hline $\mathrm{C}$ & 01390500 & SADDLE R AT RIDGEWOOD NJ & 21.6 & $1955-1975$ & 20 \\
\hline $\mathrm{C}$ & 01391000 & HOHOKUS BROOK AT HO-HO-KUS NJ & 16.4 & 1955-1974 & 19 \\
\hline A & 01391500 & SADDLE RIVER AT LODI NJ & 54.6 & 1923-1965 & 43 \\
\hline $\mathrm{D}$ & 01392000 & WEASEL BK AT CLIFTON NJ & 4.45 & $1938-1950$ & 13 \\
\hline $\mathrm{C}$ & 01392210 & THIRD RIVER AT PASSAIC NJ & 11.8 & 1977-1997 & 21 \\
\hline $\mathrm{C}$ & 01392500 & SECOND RIVER AT BELLEVILLE NJ & 11.6 & 1938-1964 & 28 \\
\hline A & 01396500 & SOUTH BRANCH RARITAN RIVER NEAR HIGH BRIDGE NJ & 65.3 & 1919-2002 & 84 \\
\hline $\mathrm{C}$ & 01396580 & SPRUCE RUN AT GLEN GARDNER NJ & 11.3 & 1979-2001 & 19 \\
\hline $\mathrm{C}$ & 01396660 & MULHOCKAWAY CREEK AT VAN SYCKEL NJ & 11.8 & 1977-2002 & 26 \\
\hline A & 01397000 & SB RARITAN R AT STANTON NJ & 147 & $1920-1963$ & 44 \\
\hline $\mathrm{D}$ & 01397500 & WALNUT BROOK NEAR FLEMINGTON NJ & 2.24 & 1937-1961 & 25 \\
\hline A & 01398000 & NESHANIC RIVER AT REAVILLE NJ & 25.7 & 1931-1960 & 30 \\
\hline $\mathrm{D}$ & 01398045 & BACK BROOK TRIBUTARY NEAR RINGOES NJ & 1.98 & 1978-1988 & 11 \\
\hline $\mathrm{D}$ & 01398107 & HOLLAND BROOK AT READINGTON NJ & 9 & 1979-1996 & 18 \\
\hline $\mathrm{C}$ & 01398500 & NB RARITAN RIVER NEAR FAR HILLS NJ & 26.2 & $1922-1975$ & 54 \\
\hline $\mathrm{D}$ & 01399190 & LAMINGTON (BLACK) RIVER AT SUCCASUNNA NJ & 7.37 & 1977-1987 & 11 \\
\hline $\mathrm{D}$ & 01399200 & LAMINGTON (BLACK) RIVER NEAR IRONIA NJ & 10.9 & 1976-1987 & 12 \\
\hline $\mathrm{C}$ & 01399500 & LAMINGTON (BLACK) RIVER NEAR POTTERSVILLE NJ & 32.8 & $1922-2001$ & 80 \\
\hline $\mathrm{D}$ & 01399510 & UPPER COLD BROOK NEAR POTTERSVILLE NJ & 2.18 & 1973-1996 & 23 \\
\hline $\mathrm{D}$ & 01399525 & AXLE BROOK NEAR POTTERSVILLE NJ & 1.22 & 1978-1988 & 11 \\
\hline $\mathrm{C}$ & 01399670 & SOUTH BRANCH ROCKAWAY CREEK AT WHITEHOUSE STATION NJ & 12.3 & $1977-2002$ & 25 \\
\hline A & 01400000 & NORTH BRANCH RARITAN RIVER NEAR RARITAN NJ & 190 & 1924-1962 & 39 \\
\hline
\end{tabular}




\begin{tabular}{|c|c|c|c|c|c|}
\hline $\mathrm{D}$ & 01400350 & MACS BROOK AT SOMERVILLE NJ & 0.77 & 1983-1995 & 13 \\
\hline A & 01400500 & RARITAN RIVER AT MANVILLE NJ & 490 & $1922-1963$ & 41 \\
\hline A & 01400730 & MILLSTONE RIVER AT PLAINSBORO NJ & 65.8 & 1964-1975 & 10 \\
\hline A & 01401000 & STONY BROOK AT PRINCETON NJ & 44.5 & $1954-2001$ & 48 \\
\hline A & 01401500 & MILLSTONE RIVER NEAR KINGSTON NJ & 171 & 1934-1949 & 16 \\
\hline $\mathrm{D}$ & 01401650 & PIKE RUN AT BELLE MEAD NJ & 5.36 & $1981-2002$ & 21 \\
\hline A & 01402000 & MILLSTONE RIVER AT BLACKWELLS MILLS NJ & 258 & $1922-1960$ & 39 \\
\hline A & 01403060 & RARITAN RIVER BELOW CALCO DAM AT BOUND BROOK NJ & 785 & $1945-1963$ & 18 \\
\hline $\mathrm{D}$ & 01403400 & GREEN BROOK AT SEELEY MILLS NJ & 6.23 & 1980-2001 & 21 \\
\hline $\mathrm{D}$ & 01403500 & GREEN BROOK AT PLAINFIELD NJ & 9.75 & $1939-1984$ & 45 \\
\hline $\mathrm{D}$ & 01403535 & EAST BRANCH STONY BROOK AT BEST LAKE AT WATCHUNG NJ & 1.57 & $1981-2000$ & 20 \\
\hline $\mathrm{D}$ & 01403540 & STONY BROOK AT WATCHUNG NJ & 5.51 & $1975-2001$ & 26 \\
\hline A & 01405030 & LAWRENCE BROOK AT WESTON MILLS NJ & 44.9 & 1989-2001 & 13 \\
\hline A & 01405300 & MATCHAPONIX BROOK AT SPOTSWOOD NJ & 43.9 & $1958-1967$ & 10 \\
\hline $\mathrm{D}$ & 01407000 & MATAWAN CREEK AT MATAWAN NJ & 6.11 & 1933-1955 & 22 \\
\hline A & 01408000 & MANASQUAN RIVER AT SQUANKUM NJ & 44 & $1932-1960$ & 29 \\
\hline $\mathrm{B}$ & 01408500 & TOMS RIVER NEAR TOMS RIVER NJ & 123 & $1929-1966$ & 37 \\
\hline B & 01409000 & CEDAR CREEK AT LANOKA HARBOR NJ & 53.3 & $1933-1958$ & 25 \\
\hline $\mathrm{D}$ & 01409095 & OYSTER CREEK NEAR BROOKVILLE NJ & 7.43 & $1966-1984$ & 18 \\
\hline $\mathrm{D}$ & 01409280 & WESTECUNK CREEK AT STAFFORD FORGE NJ & 15.8 & 1974-1988 & 14 \\
\hline $\mathrm{B}$ & 01409400 & MULLICA RIVER NEAR BATSTO NJ & 46.7 & $1958-2001$ & 43 \\
\hline B & 01409500 & BATSTO RIVER AT BATSTO NJ & 67.8 & $1940-2001$ & 62 \\
\hline
\end{tabular}




\begin{tabular}{|c|c|c|c|c|c|}
\hline $\mathrm{B}$ & 01409810 & WEST BRANCH WADING RIVER NEAR JENKINS NJ & 84.1 & $1975-1996$ & 21 \\
\hline $\mathrm{B}$ & 01410000 & OSWEGO RIVER AT HARRISVILLE NJ & 72.5 & $1931-2001$ & 70 \\
\hline $\mathrm{D}$ & 01410150 & EAST BRANCH BASS RIVER NEAR NEW GRETNA NJ & 8.11 & $1979-2001$ & 22 \\
\hline $\mathrm{B}$ & 01411000 & GREAT EGG HARBOR RIVER AT FOLSOM NJ & 57.1 & $1926-1960$ & 35 \\
\hline $\mathrm{C}$ & 01411300 & TUCKAHOW RIVER AT HEAD OF RIVER NJ & 30.8 & $1971-2001$ & 30 \\
\hline $\mathrm{D}$ & 01411456 & LITTLE EASE RUN NEAR CLAYTON NJ & 9.77 & 1989-2001 & 13 \\
\hline B & 01411500 & MAURICE RIVER AT NORMA NJ & 112 & $1933-2001$ & 68 \\
\hline $\mathrm{D}$ & 01412000 & MENANTICO CREEK NEAR MILLVILLE NJ & 23.2 & $1932-1957$ & 25 \\
\hline $\mathrm{C}$ & 01412800 & COHANSEY RIVER AT SEELEY NJ & 28 & $1978-1988$ & 10 \\
\hline A & 01437500 & NEVERSINK RIVER AT GODEFFROY NY & 307 & $1938-1954$ & 17 \\
\hline A & 01440000 & FLAT BROOK NEAR FLATBROOKVILLE NJ & 64 & $1924-2001$ & 77 \\
\hline A & 01443500 & PAULINS KILL AT BLAIRSTOWN NJ & 126 & $1922-1975$ & 54 \\
\hline $\mathrm{C}$ & 01445000 & PEQUEST RIVER AT HUNTSVILLE NJ & 31 & $1940-1962$ & 22 \\
\hline $\mathrm{B}$ & 01445500 & PEQUEST RIVER AT PEQUEST NJ & 106 & $1922-2001$ & 80 \\
\hline $\mathrm{C}$ & 01446000 & BEAVER BROOK NEAR BELVIDERE NJ & 36.7 & $1923-1961$ & 38 \\
\hline $\mathrm{C}$ & 01455200 & POHATCONG CREEK AT NEW VILLAGE NJ & 33.3 & $1960-1969$ & 9 \\
\hline $\mathrm{B}$ & 01456000 & MUSCONETCONG RIVER NEAR HACKETTSTOWN NJ & 68.9 & $1922-1973$ & 51 \\
\hline B & 01457000 & MUSCONETCONG RIVER NEARS BLOOMSBURY NJ & 141 & $1922-1960$ & 39 \\
\hline A & 01464000 & ASSUNPINK CREEK AT TRENTON NJ & 90.6 & $1924-1954$ & 30 \\
\hline A & 01464500 & CROSSWICKS CREEK AT EXTONVILLE NJ & 81.5 & $1941-2001$ & 60 \\
\hline $\mathrm{B}$ & 01465850 & S BRANCH RANCOCAS CREEK AT VINCENTOWN NJ & 64.5 & $1962-1975$ & 13 \\
\hline $\mathrm{D}$ & 01466000 & MB MOUNT MISERY BROOK IN LEBANON STATE FOREST NJ & 2.82 & 1953-1964 & 11 \\
\hline
\end{tabular}




\begin{tabular}{|c|c|l|c|c|c|}
\hline D & 01466500 & MCDONALDS BRANCH IN LEBANON STATE FOREST NJ & 2.35 & $1954-2001$ & 47 \\
\hline B & 01467000 & NORTH BRANCH RANCOCAS CREEK AT PEMBERTON NJ & 118 & $1922-2001$ & 79 \\
\hline C & 01467081 & SOUTH BRANCH PENNSAUKEN CREEK AT CHERRY HILL NJ & 8.98 & $1967-2001$ & 34 \\
\hline D & 01475000 & MANTUA CREEK AT PITMAN NJ & 6.05 & $1942-1976$ & 34 \\
\hline \multicolumn{2}{|l|}{ * DA - Drainage Area } & & & \\
\hline
\end{tabular}




\section{Appendix 3. Table III. (with permission from OIden and Poff, 2003) Hydrologic indices with the}

largest absolute loading for each of the two to four statistical significant principal components for each stream type in each of the nine components of the flow regime.

\begin{tabular}{|c|c|c|c|c|c|c|c|}
\hline \multirow[b]{3}{*}{ Flow component } & \multicolumn{6}{|c|}{ Stream classification } & \multirow[b]{3}{*}{ All streams } \\
\hline & \multicolumn{2}{|c|}{ Intermittent } & \multicolumn{4}{|c|}{ Perennial } & \\
\hline & $\begin{array}{l}\text { Harsh } \\
\text { intermittent }\end{array}$ & $\begin{array}{l}\text { Intermittent } \\
\text { flashy or } \\
\text { runoff }\end{array}$ & Snowmelt & Snow and rain & $\begin{array}{l}\text { Superstable or } \\
\text { stable } \\
\text { groundwater }\end{array}$ & $\begin{array}{l}\text { Perennial } \\
\text { flashy or } \\
\text { runoff }\end{array}$ & \\
\hline \multicolumn{8}{|l|}{ Magnitude of flow events } \\
\hline Average flow conditions & $\begin{array}{l}M_{A} 34, M_{A} 22, \\
M_{A} 16\end{array}$ & $\begin{array}{l}M_{A} 37, M_{A} 18 \\
M_{A} 21, M_{A} 9\end{array}$ & $\mathrm{M}_{\mathrm{A}} 29, \mathrm{M}_{\mathrm{A}} 40$ & $M_{A} 3, M_{A} 44$ & $\begin{array}{l}M_{A} 3, M_{A} 41, \\
M_{A} 8\end{array}$ & $\begin{array}{l}M_{A} 26, M_{A} 41 \\
M_{A} 10\end{array}$ & $\begin{array}{l}M_{A} 5, M_{A} 41 \\
M_{A} 3, M_{A} 11\end{array}$ \\
\hline Low flow conditions & $\begin{array}{l}M_{L} 13, M_{L} 15 \\
M_{L} 1\end{array}$ & $\begin{array}{l}M_{L} 16, M_{L} 6 \\
M_{L} 22, M_{L} 15\end{array}$ & $\mathrm{M}_{\mathrm{L}} 13, \mathrm{M}_{\mathrm{L}} 22$ & $\mathrm{M}_{\mathrm{L}} 13, \mathrm{M}_{\mathrm{L}} 14$ & $\begin{array}{l}\mathrm{M}_{\mathrm{L}} 18, \mathrm{M}_{\mathrm{L}} 14 \\
\mathrm{M}_{\mathrm{L}} 16\end{array}$ & $\begin{array}{l}M_{L} 17, M_{L} 14 \\
M_{L} 16\end{array}$ & $\begin{array}{l}\mathrm{M}_{\mathrm{L}} 17, \mathrm{M}_{\mathrm{L}} 4 \\
\mathrm{M}_{\mathrm{L}} 21, \mathrm{M}_{\mathrm{L}} 18\end{array}$ \\
\hline High flow conditions & $\begin{array}{l}M_{H}^{L} 23, M_{H} 14 \\
M_{H} 9\end{array}$ & $\begin{array}{l}M_{H}^{2} 23, M_{H}^{4} 4 \\
M_{H} 14, M_{H} 7\end{array}$ & $\mathrm{M}_{\mathrm{H}} 1, \mathrm{M}_{\mathrm{H}} 20$ & $\mathrm{M}_{\mathrm{H}} 17, \mathrm{M}_{\mathrm{H}} 20$ & $\begin{array}{l}M_{H} 17, M_{H} 19 \\
M_{H} 10\end{array}$ & $\begin{array}{l}\mathrm{M}_{\mathrm{H}}^{\mathrm{L}} 23, \mathrm{M}_{\mathrm{H}} 8 \\
\mathrm{M}_{\mathrm{H}} 14\end{array}$ & $\begin{array}{l}M_{H} 16, M_{H} 8, \\
M_{H} 10, M_{H} 14\end{array}$ \\
\hline \multicolumn{8}{|l|}{ Frequency of flow events } \\
\hline Low flow conditions & $\begin{array}{l}\mathrm{F}_{\mathrm{L}} 2, \mathrm{~F}_{\mathrm{L}} 3, \\
\mathrm{~F}_{\mathrm{L}} 1\end{array}$ & $\begin{array}{l}\mathrm{F}_{\mathrm{L}} 3, \mathrm{~F}_{\mathrm{L}} 2 \\
\mathrm{~F}_{\mathrm{L}} 1\end{array}$ & $\mathrm{~F}_{\mathrm{L}} 3, \mathrm{~F}_{\mathrm{L}} 2$ & $\mathrm{~F}_{\mathrm{L}} 3, \mathrm{~F}_{\mathrm{L}} 2$ & $\begin{array}{l}\mathrm{F}_{\mathrm{L}} 3, \mathrm{~F}_{\mathrm{L}} 1, \\
\mathrm{~F}_{\mathrm{L}} 2\end{array}$ & $\begin{array}{l}\mathrm{F}_{\mathrm{L}} 3, \mathrm{~F}_{\mathrm{L}} 2, \\
\mathrm{~F}_{\mathrm{L}} 3\end{array}$ & $\begin{array}{l}\mathrm{F}_{\mathrm{L}} 3, \mathrm{~F}_{\mathrm{L}} 2, \\
\mathrm{~F}_{\mathrm{L}} 3, \mathrm{~F}_{\mathrm{L}} 1\end{array}$ \\
\hline High flow conditions & $\begin{array}{l}\mathrm{F}_{\mathrm{H}} 2, \mathrm{~F}_{\mathrm{H}} 5, \\
\mathrm{~F}_{\mathrm{H}} 7\end{array}$ & $\begin{array}{l}\mathrm{F}_{\mathrm{H}} 3, \mathrm{~F}_{\mathrm{H}} 7, \\
\mathrm{~F}_{\mathrm{H}} 2, \mathrm{~F}_{\mathrm{H}} 10\end{array}$ & $\mathrm{~F}_{\mathrm{H}} 8, \mathrm{~F}_{\mathrm{H}} 11$ & $\mathrm{~F}_{\mathrm{H}} 3, \mathrm{~F}_{\mathrm{H}} 5$ & $\begin{array}{l}\mathrm{F}_{\mathrm{H}} 3, \mathrm{~F}_{\mathrm{H}} 6, \\
\mathrm{~F}_{\mathrm{H}} 11\end{array}$ & $\begin{array}{l}\mathrm{F}_{\mathrm{H}} 4, \mathrm{~F}_{\mathrm{H}} 6, \\
\mathrm{~F}_{\mathrm{H}} 7\end{array}$ & $\begin{array}{l}\mathrm{F}_{\mathrm{H}} 3, \mathrm{~F}_{\mathrm{H}} 6, \\
\mathrm{~F}_{\mathrm{H}} 7, \mathrm{~F}_{\mathrm{H}} 2\end{array}$ \\
\hline \multicolumn{8}{|l|}{ Duration of flow events } \\
\hline Low flow conditions & $\mathrm{D}_{\mathrm{L}} 13, \mathrm{D}_{\mathrm{L}} 1, \mathrm{D}_{\mathrm{L}} 2$ & $\begin{array}{l}D_{L} 18, D_{L} 16 \\
D_{L} 13, D_{L} 1\end{array}$ & $\mathrm{D}_{\mathrm{L}} 5, \mathrm{D}_{\mathrm{L}} 16$ & $\mathrm{D}_{\mathrm{L}} 6, \mathrm{D}_{\mathrm{L}} 13$ & $\begin{array}{l}\mathrm{D}_{\mathrm{L}} 9, \mathrm{D}_{\mathrm{L}} 11, \\
\mathrm{D}_{\mathrm{L}} 16\end{array}$ & $\begin{array}{l}D_{L} 10, D_{L} 17 \\
D_{L} 6\end{array}$ & $\begin{array}{l}D_{L} 18, D_{L} 17 \\
D_{L} 16, D_{L} 13\end{array}$ \\
\hline High flow conditions & $\begin{array}{l}\mathrm{D}_{\mathrm{H}} 10, \mathrm{D}_{\mathrm{H}} 5, \\
\mathrm{D}_{\mathrm{H}} 22\end{array}$ & $\begin{array}{l}D_{H} 13, D_{H} 15 \\
D_{H} 12, D_{H} 23\end{array}$ & $\mathrm{D}_{\mathrm{H}} 19, \mathrm{D}_{\mathrm{H}} 16$ & $\mathrm{D}_{\mathrm{H}} 12, \mathrm{D}_{\mathrm{H}} 24$ & $\begin{array}{l}D_{H} 11, D_{H} 20 \\
D_{H} 15\end{array}$ & $\begin{array}{l}D_{H} 13, D_{H} 16 \\
D_{H} 24\end{array}$ & $\begin{array}{l}D_{H} 13, D_{H} 16 \\
D_{H} 20, D_{H} 15\end{array}$ \\
\hline Timing of flow events & $\begin{array}{l}\mathrm{T}_{\mathrm{H}} 1, \mathrm{~T}_{\mathrm{L}} 2, \\
\mathrm{~T}_{\mathrm{H}} 2\end{array}$ & $\begin{array}{l}\mathrm{T}_{\mathrm{A}} 1, \mathrm{~T}_{\mathrm{A}} 2 \\
\mathrm{~T}_{\mathrm{L}} 1, \mathrm{~T}_{\mathrm{H}} 3\end{array}$ & $\mathrm{~T}_{\mathrm{A}} 1, \mathrm{~T}_{\mathrm{A}} 3$ & $\mathrm{~T}_{\mathrm{A}} 1, \mathrm{~T}_{\mathrm{L}} 1$ & $\begin{array}{l}\mathrm{T}_{\mathrm{A}} 1, \mathrm{~T}_{\mathrm{H}} 1 \\
\mathrm{~T}_{\mathrm{L}} 2\end{array}$ & $\begin{array}{l}\mathrm{T}_{\mathrm{A}} 1, \mathrm{~T}_{\mathrm{A}} 3, \\
\mathrm{~T}_{\mathrm{H}} 3\end{array}$ & $\begin{array}{l}\mathrm{T}_{\mathrm{A}} 1, \mathrm{~T}_{\mathrm{H}} 3, \\
\mathrm{~T}_{\mathrm{A}} 1, \mathrm{~T}_{\mathrm{L}} 2\end{array}$ \\
\hline Rate of change in flow events & $\begin{array}{l}\mathrm{R}_{\mathrm{A}} 4, \mathrm{R}_{\mathrm{A}} 1, \\
\mathrm{R}_{\mathrm{A}} 5\end{array}$ & $\begin{array}{l}R_{A} 9, R_{A} 6 \\
R_{A} 5, R_{A} 7\end{array}$ & $\mathrm{R}_{\mathrm{A}} 1, \mathrm{R}_{\mathrm{A}} 8$ & $\mathrm{R}_{\mathrm{A}} 9, \mathrm{R}_{\mathrm{A}} 8$ & $\begin{array}{l}R_{A} 9, R_{A} 8, \\
R_{A} 5\end{array}$ & $\begin{array}{l}\mathrm{R}_{\mathrm{A}} 9, \mathrm{R}_{\mathrm{A}} 7, \\
\mathrm{R}_{\mathrm{A}} 6\end{array}$ & $\begin{array}{l}R_{A} 9, R_{A} 8 \\
R_{A} 6, R_{A} 5\end{array}$ \\
\hline
\end{tabular}


Appendix 4. Hydrologic indices with the largest absolute loading on each of the four and five significant principal components for each group in each of the nine components of the flow regime for four New Jersey stream types.

\begin{tabular}{|c|c|c|c|c|c|}
\hline \multicolumn{6}{|c|}{ NEW JERSEY STREAM CLASSIFICATION } \\
\hline Flow Component & Group A* & Group B & Group C & Group D & All streams \\
\hline $\begin{array}{l}\text { Magnitude of flow events } \\
\text { Average flow conditions }\end{array}$ & $\begin{array}{l}\mathrm{M}_{\mathrm{A}} 18, \mathrm{M}_{\mathrm{A}} 39 \\
\mathrm{M}_{\mathrm{A}} 26, \mathrm{M}_{\mathrm{A}} 37\end{array}$ & $\begin{array}{l}M_{A} 9, M_{A} 15 \\
M_{A} 33, M_{A} 32\end{array}$ & $\begin{array}{l}M_{A} 24, M_{A} 11, \\
M_{A} 43, M_{A} 40 \\
M_{4} 45\end{array}$ & $\begin{array}{l}\mathrm{M}_{\mathrm{A}} 39, \mathrm{M}_{\mathrm{A}} 13, \\
\mathrm{M}_{\mathrm{A}} 44, \mathrm{M}_{\mathrm{A}} 40, \mathrm{M}_{\mathrm{A}} 9\end{array}$ & $\begin{array}{l}M_{A} 20, M_{A} 37 \\
M_{A} 34, M_{A} 40\end{array}$ \\
\hline Low-flow conditions & $\begin{array}{l}\mathrm{M}_{\mathrm{L}} 6, \mathrm{M}_{\mathrm{L}} 13, \mathrm{M}_{\mathrm{L}} 13 \\
\mathrm{M}_{\mathrm{L}} 16\end{array}$ & $\begin{array}{l}M_{L} 20, M_{L} 4, M_{L} 21 \\
M_{L} 16\end{array}$ & $\begin{array}{l}\mathrm{M}_{\mathrm{L}} 3, \mathrm{M}_{\mathrm{L}} 19, \mathrm{M}_{\mathrm{L}} 20 \\
\mathrm{M}_{\mathrm{L}} 3, \mathrm{M}_{\mathrm{L}} 13\end{array}$ & $\begin{array}{l}\mathrm{M}_{\mathrm{L}} 20, \mathrm{M}_{\mathrm{L}} 20 \\
\mathrm{M}_{\mathrm{L}} 13, \mathrm{M}_{\mathrm{L}} 15 \\
\mathrm{M}_{\mathrm{L}} 21\end{array}$ & $\begin{array}{l}\mathrm{M}_{\mathrm{L}} 8, \mathrm{M}_{\mathrm{L}} 19, \mathrm{M}_{\mathrm{L}} 13 \\
\mathrm{M}_{\mathrm{L}} 15\end{array}$ \\
\hline High-flow conditions & $\begin{array}{l}\mathrm{M}_{\mathrm{H}} 5, \mathrm{M}_{\mathrm{H}} 16 \\
\mathrm{M}_{\mathrm{H}} 20, \mathrm{M}_{\mathrm{H}} 18\end{array}$ & $\begin{array}{l}\mathrm{M}_{\mathrm{H}} 24, \mathrm{M}_{\mathrm{H}} 4 \\
\mathrm{M}_{\mathrm{H}} 18, \mathrm{M}_{\mathrm{H}} 26\end{array}$ & $\begin{array}{l}\mathrm{M}_{\mathrm{H}} 14, \mathrm{M}_{\mathrm{H}} 17 \\
\mathrm{M}_{\mathrm{H}} 12, \mathrm{M}_{\mathrm{H}} 13 \\
\mathrm{M}_{\mathrm{H}} 16\end{array}$ & $\begin{array}{l}M_{H} 16, M_{H} 2 \\
M_{H} 21, M_{H} 3, M_{H} 1\end{array}$ & $\begin{array}{l}\mathrm{M}_{\mathrm{H}} 20, \mathrm{M}_{\mathrm{H}} 3 \\
\mathrm{M}_{\mathrm{H}} 20, \mathrm{M}_{\mathrm{H}} 23\end{array}$ \\
\hline $\begin{array}{c}\text { Frequency of flow events } \\
\text { Low-flow conditions }\end{array}$ & $\mathrm{F}_{\mathrm{L}} 3, \mathrm{~F}_{\mathrm{L}} 3, \mathrm{~F}_{\mathrm{L}} 1, \mathrm{~F}_{\mathrm{L}} 1$ & $\mathrm{~F}_{\mathrm{L}} 3, \mathrm{~F}_{\mathrm{L}} 2, \mathrm{~F}_{\mathrm{L}} 1, \mathrm{~F}_{\mathrm{L}} 1$ & $\begin{array}{l}\mathrm{F}_{\mathrm{L}} 1, \mathrm{~F}_{\mathrm{L}} 3, \mathrm{~F}_{\mathrm{L}} 3, \mathrm{~F}_{\mathrm{L}} 2 \\
\mathrm{~F}_{\mathrm{L}} 3\end{array}$ & $\begin{array}{l}\mathrm{F}_{\mathrm{L}} 3, \mathrm{~F}_{\mathrm{L}} 1, \mathrm{~F}_{\mathrm{L}} 1, \mathrm{~F}_{\mathrm{L}} 2 \\
\mathrm{~F}_{\mathrm{L}} 3\end{array}$ & $\mathrm{~F}_{\mathrm{L}} 3, \mathrm{~F}_{\mathrm{L}} 3, \mathrm{~F}_{\mathrm{L}} 1, \mathrm{~F}_{\mathrm{L}} 2$ \\
\hline High-flow conditions & $\mathrm{F}_{\mathrm{H}} 4, \mathrm{~F}_{\mathrm{H}} 3, \mathrm{~F}_{\mathrm{H}} 1, \mathrm{~F}_{\mathrm{H}} 9$ & $\begin{array}{l}\mathrm{F}_{\mathrm{H}} 4, \mathrm{~F}_{\mathrm{H}} 10, \mathrm{~F}_{\mathrm{H}} 1 \\
\mathrm{~F}_{\mathrm{H}} 10\end{array}$ & $\begin{array}{l}\mathrm{F}_{\mathrm{H}} 7, \mathrm{~F}_{\mathrm{H}} 3, \mathrm{~F}_{\mathrm{H}} 3, \mathrm{~F}_{\mathrm{H}} 4, \\
\mathrm{~F}_{\mathrm{H}} 11\end{array}$ & $\begin{array}{l}\mathrm{F}_{\mathrm{H}} 3, \mathrm{~F}_{\mathrm{H}} 9, \mathrm{~F}_{\mathrm{H}} 5 \\
\mathrm{~F}_{\mathrm{H}} 10, \mathrm{~F}_{\mathrm{H}} 11\end{array}$ & $\mathrm{~F}_{\mathrm{H}} 7, \mathrm{~F}_{\mathrm{H}} 3, \mathrm{~F}_{\mathrm{H}} 9 . \mathrm{F}_{\mathrm{H}} 2$ \\
\hline $\begin{array}{l}\text { Duration of flow events } \\
\text { Low-flow conditions }\end{array}$ & $\begin{array}{l}\mathrm{D}_{\mathrm{L}} 4, \mathrm{D}_{\mathrm{L}} 12, \mathrm{D}_{\mathrm{L}} 16 \\
\mathrm{D}_{\mathrm{L}} 6\end{array}$ & $\begin{array}{l}\mathrm{D}_{\mathrm{L}} 15, \mathrm{D}_{\mathrm{L}} 1, \mathrm{D}_{\mathrm{L}} 16 \\
\mathrm{D}_{\mathrm{L}} 12\end{array}$ & $\begin{array}{l}D_{L} 16, D_{L} 14, D_{L} 5 \\
D_{L} 9, D_{L} 17\end{array}$ & $\begin{array}{l}D_{L} 4, D_{L} 16, D_{L} 16 \\
D_{L} 11, D_{L} 7\end{array}$ & $\begin{array}{l}D_{L} 3, D_{L} 12, D_{L} 16 \\
D_{L} 6\end{array}$ \\
\hline High-flow conditions & $\begin{array}{l}\mathrm{D}_{\mathrm{H}} 2, \mathrm{D}_{\mathrm{H}} 13, \mathrm{D}_{\mathrm{H}} 20, \\
\mathrm{D}_{\mathrm{H}} 8\end{array}$ & $\begin{array}{l}\mathrm{D}_{\mathrm{H}} 12, \mathrm{D}_{\mathrm{H}} 2, \mathrm{D}_{\mathrm{H}} 20, \\
\mathrm{D}_{\mathrm{H}} 24\end{array}$ & $\begin{array}{l}D_{H} 11, D_{H} 14, D_{H} 1, \\
D_{H} 9, D_{H} 23\end{array}$ & $\begin{array}{l}\mathrm{D}_{\mathrm{H}} 14, \mathrm{D}_{\mathrm{H}} 2, \mathrm{D}_{\mathrm{H}} 17 \\
\mathrm{D}_{\mathrm{H}} 12, \mathrm{D}_{\mathrm{H}} 23\end{array}$ & $\begin{array}{l}\mathrm{D}_{\mathrm{H}} 11, \mathrm{D}_{\mathrm{H}} 2, \mathrm{D}_{\mathrm{H}} 15 \\
\mathrm{D}_{\mathrm{H}} 8\end{array}$ \\
\hline Timing of flow events & $\mathrm{T}_{\mathrm{A}} 1, \mathrm{~T}_{\mathrm{A}} 1, \mathrm{~T}_{\mathrm{L}} 1, \mathrm{~T}_{\mathrm{A}} 3$ & $\mathrm{~T}_{\mathrm{A}} 1, \mathrm{~T}_{\mathrm{H}} 2, \mathrm{~T}_{\mathrm{L}} 2, \mathrm{~T}_{\mathrm{H}} 3$ & $\begin{array}{l}\mathrm{T}_{\mathrm{H}} 3, \mathrm{~T}_{\mathrm{A}} 1, \mathrm{~T}_{\mathrm{L}} 2, \\
\mathrm{~T}_{\mathrm{L}} 1, \mathrm{~T}_{\mathrm{A}} 3\end{array}$ & $\begin{array}{l}\mathrm{T}_{\mathrm{A}} 1, \mathrm{~T}_{\mathrm{H}} 3, \mathrm{~T}_{\mathrm{H}} 2 \\
\mathrm{~T}_{\mathrm{A}} 1, \mathrm{~T}_{\mathrm{A}} 2\end{array}$ & $\begin{array}{l}\text { TA1, TH2, TL3, } \\
\text { TA1 }\end{array}$ \\
\hline Rate of change in flow events & $\begin{array}{l}\mathrm{R}_{\mathrm{A}} 3, \mathrm{R}_{\mathrm{A}} 7, \mathrm{R}_{\mathrm{A}} 8 \\
\mathrm{R}_{\mathrm{A}} 5\end{array}$ & $\begin{array}{l}\mathrm{R}_{\mathrm{A}} 7, \mathrm{R}_{\mathrm{A}} 1, \mathrm{R}_{\mathrm{A}} 6 \\
\mathrm{R}_{\mathrm{A}} 2\end{array}$ & $\begin{array}{l}\mathrm{R}_{\mathrm{A}} 6, \mathrm{R}_{\mathrm{A}} 3, \mathrm{R}_{\mathrm{A}} 1 \\
\mathrm{R}_{\mathrm{A}} 2, \mathrm{R}_{\mathrm{A}} 4\end{array}$ & $\begin{array}{l}\mathrm{R}_{\mathrm{A}} 7, \mathrm{R}_{\mathrm{A}} 3, \mathrm{R}_{\mathrm{A}} 8 \\
\mathrm{R}_{A} 1, \mathrm{R}_{\mathrm{A}} 6\end{array}$ & $\begin{array}{l}\mathrm{R}_{\mathrm{A}} 6, \mathrm{R}_{\mathrm{A}} 3, \mathrm{R}_{\mathrm{A}} 8 \\
\mathrm{R}_{\mathrm{A}} 2\end{array}$ \\
\hline
\end{tabular}

* Some indices can appear more than once in the table because they may be the most highly loaded variable on PCA axis one, two, three, and so forth, for a given index. 


\section{Appendix 5. Definitions for the 171 hydrologic indices.}

Explanation - The following information for the 171 hydrologic indices is from Olden and Poff (2003) (see citation at end of this Help page). The USGS revised a limited number of the formula and (or) definitions when deemed appropriate. A USGS Scientific Investigations Report in preparation will document these changes. The Olden and Poff (2003) article contains 12 additional references from which the indices were derived. Two of these articles are referenced here because they provide examples and additional explanation for complex indices.

The alphanumeric code preceding each definition refers to the category of the flow regime (magnitude, frequency, duration, timing, and rate of change) and type of flow event (A, average, L, low, and $\mathrm{H}$, high) the hydrologic index was developed to describe. Indices are numbered successively within each category. For example, MA1 is the first index describing magnitude of the average flow condition.

MA\# - Magnitude, average flow event

ML\# - Magnitude, low flow event

MH\# - Magnitude, high flow event

FL\# - Frequency, low flow event

FH\# - Frequency, high flow event

DL\# - Duration, low flow event

DH\# - Duration, high flow event

TA\# - Timing, average flow event

TL\# - Timing, low flow event

TH\# - Timing, high flow event

RA\# - Rate of change, average event

Following each definition, in parentheses, are (1) the units of the index, and (2) the type of data, temporal or spatial data, from which the upper and lower percentiles limits (for example, 75/25) are derived. Temporal data are from a multiyear daily flow record from a single stream gage. For example, index MA1- mean for the entire flow record - uses 365 mean daily flow values for each year in the flow record to calculate the mean for the entire flow record. Consequently, there are 365 values for each year to calculate upper and lower percentile limits. However, formulas for 60 of the indices do not produce a range of values from which percentile limits can be calculated. MA5 (skewness), for example, the mean for the entire flow record divided by the median for the entire record results in a single value, and thus, upper and lower percentile limits cannot be calculated. NJHAT uses spatial data, values for each stream gage for all the streams within a stream type, to compute limits. Upper and lower percentile limits are calculated from the 31 MA5 values from the 31 stream gages that were identified from the classification analysis as Stream type A.

Exceedence and percentile are used in the calculation for a number of indices. Note the difference a 90 percent exceedence means that 90 percent of the values are equal to or greater than the 90 
percent exceedence value, while a 90 th percentile means that 10 percent of the values are equal to or greater than the 90 th percentile value.

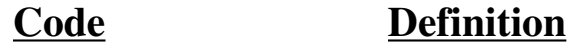

MA1 Mean of the daily mean flow values for the entire flow record (cubic feet per second - temporal).

MA2 Median of the daily mean flow values for the entire flow record (cubic feet per second - temporal).

MA3 Mean (or median - Use Preference option) of the coefficients of variation (standard deviation/mean) for each year. Compute the coefficient of variation for each year of daily flows. Compute the mean of the annual coefficients of variation (percent - temporal).

MA4 Standard deviation of the percentiles of the logs of the entire flow record divided by the mean of percentiles of the logs. Compute the $\log 10$ of the daily flows for the entire record. Compute the 5th, 10th, 15th, 20th, 25th, 30th, 35th, 40th, 45th, 50th, 55th, 60th, 65th, 70th, 75th, 80th, 85th, 90th, and 95th percentiles for the logs of the entire flow record. Percentiles are computed by interpolating between the ordered (ascending) logs of the flow values. Compute the standard deviation and mean for the percentile values. Divide the standard deviation by the mean (percent - spatial).

MA5 The skewness of the entire flow record is computed as the mean for the entire flow record (MA1) divided by the median (MA2) for the entire flow record (dimensionless - spatial).

MA6 Range in daily flows is the ratio of the 10 percent to 90 percent exceedence values for the entire flow record. Compute the 5 percent to 95 percent exceedence values for the entire flow record. Exceedence is computed by interpolating between the ordered (descending) flow values. Divide the 10 percent exceedence value by the 90 percent value (dimensionless - spatial).

MA7 Range in daily flows is computed like MA6 except using the 20 percent and 80 percent exceedence values. Divide the 20 percent exceedence value by the 80 percent value (dimensionless - spatial).

MA8 Range in daily flows is computed like MA6 except using the 25 percent and 75 percent exceedence values. Divide the 25 percent exceedence value by the 75 percent value (dimensionless - spatial).

MA9 Spread in daily flows is the ratio of the difference between the 90th and 10th percentile of the logs of the flow data to the log of the median of the entire flow record. Compute the $\log 10$ of the daily flows for the entire record. Compute the 5 th, 10th, 15th, 20th, 25th, 30th, 35th, 40th, 45th, 50th, 55th, 60th, 65th, 70th, 75th, 80th, 85 th, 90th, and 95th percentiles for the logs of the entire flow record. Percentiles are 
computed by interpolating between the ordered (ascending) logs of the flow values. Compute MA9 as (90th - 10th) /log10(MA2) (dimensionless - spatial).

MA10 Spread in daily flows is computedlike MA9 except using the 20th and 80th percentiles (dimensionless - spatial).

MA11 Spread in daily flows is computedlike MA9 except using the 25th and 75th percentiles (dimensionless - spatial).

MA12 - $\quad$ Means (or medians - Use Preference option) of monthly flow values.

MA23 Compute the means for each month over the entire flow record. For example, MA12 is the mean of all January flow values over the entire record (cubic feet per second - temporal).

MA24 - Variability (coefficient of variation) of monthly flow values. Compute the MA35 standard deviation for each month in eachyear over the entire flow record. Divide the standard deviation by the mean for each month. Average (or median - Use Preference option) these values for each month across all years (percent - temporal).

MA36 Variability across monthly flows. Compute the minimum, maximum, and mean flows for each month in the entire flow record. MA36 is the maximum monthly flow minus the minimum monthly flow divided by the median monthly flow (dimensionless - spatial).

MA37 Variability across monthly flows. Computethe first (25th percentile) and the third (75th percentile) quartiles (every month in the flow record). MA37 is the third quartile minus the first quartile divided by the median of the monthly means (dimensionless - spatial).

MA38 Variability across monthly flows. Compue the 10th and 90th percentiles for the monthly means (every month in the flow record). MA38 is the 90th percentile minus the 10 th percentile divided by the median of the monthly means (dimensionless spatial).

MA39 Variability across monthly flows. Computethe standard deviation for the monthly means. MA39 is the standard deviation times 100 divided by the mean of the monthly means (percent - spatial).

MA40 Skewness in the monthly flows. MA40 isthe mean of the monthly flow means minus the median of the monthly means divided by the median of the monthly means (dimensionless - spatial).

MA41 Annual runoff. Compute the annud mean daily flows. MA41 is the mean of the annual means divided by the drainage area (cubic feet per second/square mile - temporal).

MA42 Variability across annual flows. MA42 isthe maximum annual flow minus the minimum annual flow divided by the median annual flow (dimensionless - spatial). 
MA43 Variability across annual flows. Compute the first (25th percentile) and third (75th percentile) quartiles and the 10th and 90th percentiles for the annual means (every year in the flow record). MA43 is the third quartile minus the first quartile divided by the median of the annual means (dimensionless -spatial).

MA44 Variability across annual flows. Compute the first (25th percentile) and third (75th percentile) quartiles and the 10th and 90th percentiles for the annual means (every year in the flow record). MA44 is the 90th percentile minus the 10th percentile divided by the median of the annual means (dimensionless - spatial).

MA45 Skewness in the annual flows. MA45is the mean of the annual flow means minus the median of the annual means divided by the median of the annual means (dimensionless - spatial).

ML1 ML12

Mean (or median - Use Preferenceoption) minimum flows for each month across all years. Compue the minimums for each month over the entire flow record. For example, ML1 is the mean of the minimums of all January flow values over the entire record (cubic feet per second - temporal).

ML13 Variability (coefficient of variation)across minimum monthly flow values. Compute the mean and standard deviation for the minimum monthly flows over the entire flow record. ML13 is the standard deviation times 100 divided by the mean minimum monthly flow for all years (percent - spatial).

ML14 Compute the minimum annual flow for eachyear. ML14 is the mean of the ratios of minimum annual flows to the median flow for each year (dimensionless - temporal).

ML15 Low flow index. ML15 is the mean ofthe ratios of minimum annual flows to the mean flow for each year (dimensionless - temporal).

ML16 Median of annual minimum flows. ML16 is the median of the ratios of minimum annual flows to the median flow for each year (dimensionless - temporal).

ML17 Base flow. Compute the mean annual flows. Compute the minimum of a 7-day moving average flow for each year and divide them by the mean annual flow for that year. ML17 is the mean (or median - Use Preference option) of those ratios (dimensionless - temporal).

ML18 Variability in base flow. Compute the standard deviation for the ratios of 7-day moving average flows to mean annual flows for each year. ML18 is the standard deviation times 100 divided by the mean of the ratios (percent - spatial).

ML19 Base flow. Compute the ratios of the minimum annual flow to mean annual flow for each year. ML19 is the mean (or median - Use Preference option) of these ratios times 100 (dimensionless - temporal). 
ML20 Base flow. Divide the daily flow record into 5-day blocks. Find the minimum flow for each block. Assign the minimum flow as a base flow for that block if 90 percent of that minimum flow is less than the minimum flows for the blocks on either side. Otherwise, set it to zero. Fill in the zero values using linear interpolation. Compute the total flow for the entire record and the total base flow for the entire record. ML20 is the ratio of total flow to total base flow (dimensionless - spatial).

ML21 Variability across annual minimum flows. Compute the mean and standard deviation for the annual minimum flows. ML21 is the standard deviation times 100 divided by the mean (percent - spatial).

ML22 Specific mean annual minimum flow.ML22 is the mean (or median - Use Preference option) of the annual minimum flows divided by the drainage area (cubic feet per second/square mile - temporal).

MH1 - $\quad$ Mean (or median - Use Preference option) maximum flows for each month MH12 across all years. Compute the maximums for each month over the entire flow record. For example, MH1 is the mean of the maximums of all January flow values over the entire record (cubic feet per second - temporal).

MH13 Variability (coefficient of variation) across maximum monthly flow values. Compute the mean and standard deviation for the maximum monthly flows over the entire flow record. MH13 is the standard deviation times 100 divided by the mean maximum monthly flow for all years (percent - spatial).

MH14 Median of annual maximum flows.Compute the annual maximum flows from monthly maximum flows. Compute the ratio of annual maximum flow to median annual flow for each year. MH14 is the median of these ratios (dimensionless - temporal).

MH15 High flow discharge index. Compute the 1percent exceedence value for the entire data record. MH15 is the 1 percent exceedence value divided by the median flow for the entire record (dimensionless - spatial).

MH16 High flow discharge index. Compute the10 percent exceedence value for the entire data record. MH16 is the 10 percent exceedence value divided by the median flow for the entire record (dimensionless - spatial).

MH17 High flow discharge index. Compute the25 percent exceedence value for the entire data record. MH17 is the 25 percent exceedence value divided by the median flow for the entire record (dimensionless - spatial).

MH18 Variability across annual maximum flous. Compute the $\operatorname{logs}(\log 10)$ of the maximum annual flows. Find the standard deviation and mean for these values. MH18 is the standard deviation times 100 divided by the mean (percent - spatial).

MH19 Skewness in annual maximum flows. Use the equation: 


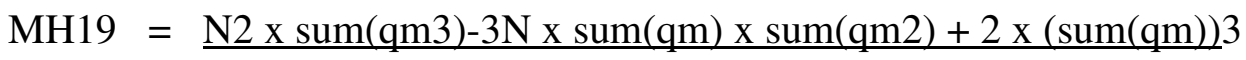

$\mathrm{N} \times(\mathrm{N}-1) \times(\mathrm{N}-2) \times \operatorname{stddev} 3$

where: $\mathrm{N}=$ Number of years

$\mathrm{qm}=\log 10$ (annual maximum flows)

stddev $=$ Standard deviation of the annual maximum flows

(dimensionless - spatial).

MH20 Specific mean annual maximum flow. MH20 is themean (or median - Use Preference option) of the annual maximum flows divided by the drainage area (cubic feet per second/square mile - temporal).

MH21 High flow volume index. Compute the average volume for flow events above a threshold equal to the median flow for the entire record. MH21 is the average volume divided by the median flow for the entire record (days - temporal).

MH22 High flow volume. Compute the average volume for flow events above a threshold equal to three times the median flow for the entire record. MH22 is the average volume divided by the median flow for the entire record (days - temporal).

MH23 High flow volume. Compute the average volime for flow events above a threshold equal to seven times the median flow for the entire record. MH23 is the average volume divided by the median flow for the entire record (days - temporal).

MH24 High peak flow. Compute the average peak flow value for flow events above a threshold equal to the median flow for the entire record. MH24 is the average peak flow divided by the median flow for the entire record (dimensionless - temporal).

MH25 High peak flow. Compute the average peak-flow value for flow events above a threshold equal to three times the median flow for the entire record. MH25 is the average peak flow divided by the median flow for the entire record (dimensionless temporal).

MH26 High peak flow. Compute the average peak flow value for flow events above a threshold equal to seven times the median flow for the entire record. MH26 is the average peak flow divided by the median flow for the entire record (dimensionless temporal).

MH27 High peak flow. Compute the average peak flow value for flow events above a threshold equal to 75th percentile value for the entire flow record. MH27 is the average peak flow divided by the median flow for the entire record (dimensionless temporal).

FL1 Low flood pulse count. Compute the average number of flow events with flows below a threshold equal to the 25 th percentile value for the entire flow record. FL1 is the average (or median - Use Preference option) number of events (number of events/year - temporal). 
FL2 Variability in low pulse count. Compute the standard deviation in the annual pulse counts for FL1. FL2 is 100 times the standard deviation divided by the mean pulse count (percent - spatial).

FL3 Frequency of low pulse spells. Compute the average number of flow events with flows below a threshold equal to 5 percent of the mean flow value for the entire flow record. FL3 is the average (or median - Use Preference option) number of events (number of events/year - temporal).

FH1 High flood pulse count. Compute the avenge number of flow events with flows above a threshold equal to the 75th percentile value for the entire flow record. FH1 is the average (or median - Use Preference option) number of events (number of events/year - temporal).

FH2 Variability in high pulse count. Computethe standard deviation in the annual pulse counts for FH1. FH2 is 100 times the standard deviation divided by the mean pulse count (number of events/year - spatial).

FH3 High flood pulse count. Compute the averagenumber of days per year that the flow is above a threshold equal to three times the median flow for the entire record. FH3 is the mean (or median - Use Preference option) of the annual number of days for all years (number of days/year - temporal).

FH4 High flood pulse count. Compute the averagenumber of days per year that the flow is above a threshold equal to seven times the median flow for the entire record. FH4 is the mean (or median - Use Preference option) of the annual number of days for all years (number of days/year - temporal).

FH5 Flood frequency. Compute the average number of flow events with flows above a threshold equal to the median flow value for the entire flow record. FH5 is the average (or median - Use Preference option) number of events (number of events/year - temporal).

FH6 Flood frequency. Compute the average number of flow events with flows above a threshold equal to three times the median flow value for the entire flow record. FH6 is the average (or median - Use Preference option) number of events (number of events/year - temporal).

FH7 Flood frequency. Compute the average number of flow events with flows above a threshold equal to seven times the median flow value for the entire flow record. FH6 is the average (or median - Use Preference option) number of events (number of events/year - temporal).

FH8 Flood frequency. Compute the average number of flow events with flows above a threshold equal to 25 percent exceedence value for the entire flow record. FH8 is the average (or median - Use Preference option) number of events (number of events/year - temporal). 
FH9

FH10

Note - $\quad$ 1.67-year flood threshold (Poff, 1996) - For indices FH11, DH22, DH23, DH24, TA3, and TH3 compute the $\log 10$ of the peak annual flows. Compute the $\log 10$ of the daily flows for the peak annual flow days. Calculate the coefficients for a linear regression equation for logs of peak annual flow versus logs of average daily flow for peak days. Using the log peak flow for the 1.67 year recurrence interval (60th percentile) as input to the regression equation, predict the $\log 10$ of the average daily flow. The threshold is 10 to the $\log 10$ (average daily flow) power (cubic feet/second).

FH11 Flood frequency. Compute the average number of flow events with flows above a threshold equal to flow corresponding to a 1.67-year recurrence interval. FH11 is the average (or median - Use Preference option) number of events (number of events/year - temporal).

DL1 Annual minimum daily flow. Computethe minimum 1-day average flow for each year. DL1 is the mean (or median - Use Preference option) of these values (cubic feet per second - temporal).

DL2 Annual minimum of 3-day moving averag flow. Compute the minimum of a 3-day moving average flow for each year. DL2 is the mean (or median - Use Preference option) of these values (cubic feet per second - temporal).

DL3 Annual minimum of 7-day moving averag flow. Compute the minimum of a 7-day moving average flow for each year. DL3 is the mean (or median - Use Preference option) of these values (cubic feet per second - temporal).

DL4 Annual minimum of 30-day moving arerage flow. Compute the minimum of a 30day moving average flow for each year. DL4 is the mean (or median - Use Preference option) of these values (cubic feet per second - temporal).

DL5 Annual minimum of 90-day moving average flow. Compute the minimum of a 90day moving average flow for each year. DL5 is the mean (or median - Use Preference option) of these values (cubic feet per second - temporal).

DL6 Variability of annual minimum daily average flow. Compute the standard deviation for the minimum daily average flow. DL6 is 100 times the standard deviation divided by the mean (percent - spatial). 
DL7 Variability of annual minimum of 3-day moving average flow. Compute the standard deviation for the minimum 3-day moving averages. DL7 is 100 times the standard deviation divided by the mean (percent - spatial).

DL8 Variability of annual minimum of 7-day moving average flow. Compute the standard deviation for the minimum 7-day moving averages. DL8 is 100 times the standard deviation divided by the mean (percent - spatial).

DL9 Variability of annual minimum of 30tay moving average flow. Compute the standard deviation for the minimum 30-day moving averages. DL9 is 100 times the standard deviation divided by the mean (percent - spatial).

DL10 Variability of annual minimum of 90-day moving average flow. Compute the standard deviation for the minimum 90-day moving averages. DL10 is 100 times the standard deviation divided by the mean (percent - spatial).

DL11 Annual minimum daily fbw divided by the median for the entire record. Compute the minimum daily flow for each year. DL11 is the mean of these values divided by the median for the entire record (dimensionless - temporal).

DL12 Annual minimum of 7-day moving avenge flow divided by the median for the entire record. Compute the minimum of a 7-day moving average flow for each year. DL12 is the mean of these values divided by the median for the entire record (dimensionless - temporal).

DL13 Annual minimum of 30-day moving average flow divided by the median for the entire record. Compute the minimum of a 30-day moving average flow for each year. DL13 is the mean of these values divided by the median for the entire record (dimensionless - temporal).

DL14 Low exceedence flows. Compute the 75 percent exceedence value for the entire flow record. DL14 is the exceedence value divided by the median for the entire record (dimensionless - spatial).

DL15 Low exceedence flows. Compute the 90 percent exceedence value for the entire flow record. DL14 is the exceedence value divided by the median for the entire record (dimensionless - spatial).

DL16 Low flow pulse duration. Compute the average pulse duration for each year for flow events below a threshold equal to the 25th percentile value for the entire flow record. DL16 is the median of the yearly average durations (number of days temporal).

DL17 Variability in low pulse duration. Compue the standard deviation for the yearly average low pulse durations. DL17 is 100 times the standard deviation divided by the mean of the yearly average low pulse durations (percent - spatial). 
DL18 Number of zero-flow days. Count thenumber of zero-flow days for the entire flow record. DL18 is the mean (or median - Use Preference option) annual number of zero flow days (number of days/year - temporal).

DL19 Variability in the number of zero-flow days. Compute the standard deviation for the annual number of zero-flow days. DL19 is 100 times the standard deviation divided by the mean annual number of zero-flow days (percent - spatial).

DL20 Number of zero-flow months. Whilecomputing the mean monthly flow values, count the number of months in which there was no flow over the entire flow record (percent - spatial).

DH1 Annual maximum daily flow. Computethe maximum of a 1-day moving average flow for each year. DH1 is the mean (or median - Use Preference option) of these values (cubic feet per second - temporal).

DH2 Annual maximum of 3-day moving avenge flows. Compute the maximum of a 3day moving average flow for each year. DH2 is the mean (or median - Use Preference option) of these values (cubic feet per second - temporal).

DH3 Annual maximum of 7-day moving avenge flows. Compute the maximum of a 7day moving average flow for each year. DH3 is the mean (or median - Use Preference option) of these values (cubic feet per second - temporal).

DH4 Annual maximum of 30-day moving arerage flows. Compute the maximum of 30day moving average flows. Compute the maximum of a 30-day moving average flow for each year. DH4 is the mean (or median - Use Preference option) of these values (cubic feet per second - temporal).

DH5 Annual maximum of 90-day moving avenge flows. Compute the maximum of a 90day moving average flow for each year. DH5 is the mean (or median - Use Preference option) of these values (cubic feet per second - temporal).

DH6 Variability of annual maximum daily flows Compute the standard deviation for the maximum 1-day moving averages. DH6 is 100 times the standard deviation divided by the mean (percent - spatial).

DH7 Variability of annual maximum of 3 day moving average flows. Compute the standard deviation for the maximum 3-day moving averages. DH7 is 100 times the standard deviation divided by the mean (percent - spatial).

DH8 Variability of annual maximum of 7 day moving average flows. Compute the standard deviation for the maximum 7-day moving averages. DH8 is 100 times the standard deviation divided by the mean (percent - spatial).

DH9 Variability of annual maximum of 30-day moving average flows. Compute the standard deviation for the maximum 30-day moving averages. DH9 is 100 times the standard deviation divided by the mean (percent - spatial). 
DH10 Variability of annual maximum of 90-dy moving average flows. Compute the standard deviation for the maximum 90-day moving averages. DH10 is 100 times the standard deviation divided by the mean (percent - spatial).

DH11 Annual maximum of 1-day moving average flows divided by the median for the entire record. Compute the maximum of a 1-day moving average flow for each year. DL11 is the mean of these values divided by the median for the entire record (dimensionless - temporal).

DH12 Annual maximum of 7-day moving averag flows divided by the median for the entire record. Compute the maximum daily average flow for each year. DL12 is the mean of these values divided by the median for the entire record (dimensionless temporal).

DH13 Annual maximum of 30-day moving average flows divided by the median for the entire record. Compute the maximum of a 30-day moving average flow for each year. DL13 is the mean of these values divided by the median for the entire record (dimensionless - temporal).

DH14 Flood duration. Compute the mean of the mean monthly flow values. Find the 95th percentile for the mean monthly flows. DH14 is the $95^{\text {th }}$ percentile value divided by the mean of the monthly means (dimensionless - spatial).

DH15 High flow pulse duration. Compute the avenge duration for flow events with flows above a threshold equal to the 75th percentile value for each year in the flow record. DH15 is the median of the yearly average durations (days/year - temporal).

DH16 Variability in high flow pulse duration. Compute the standard deviation for the yearly average high pulse durations. DH16 is 100 times the standard deviation divided by the mean of the yearly average high pulse durations (percent - spatial).

DH17 High flow duration. Compute the average duntion of flow events with flows above a threshold equal to the median flow value for the entire flow record. DH17 is the average (or median - Use Preference option) duration of the events (days temporal).

DH18 High flow duration. Compute the average duntion of flow events with flows above a threshold equal to three times the median flow value for the entire flow record. DH18 is the average (or median - Use Preference option) duration of the events (days - temporal).

DH19 High flow duration. Compute the average duntion of flow events with flows above a threshold equal to seven times the median flow value for the entire flow record. DH19 is the average (or median - Use Preference option) duration of the events (days - temporal).

DH20 High flow duration. Compute the 75th percentile value for the entire flow record. Compute the average duration of flow events with flows above a threshold equal to 
the 75th percentile value for the median annual flows. DH20 is the average (or median - Use Preference option) duration of the events (days - temporal).

DH21 High flow duration. Compute the 25th percentile value for the entire flow record. Compute the average duration of flow events with flows above a threshold equal to the 25th percentile value for the entire set of flows. DH21 is the average (or median - Use Preference option) duration of the events (days - temporal).

DH22 Flood interval. Compute the flood threshold as the flow equivalent for a flood recurrence of 1.67 years. Determine the median number of days between flood events for each year. DH22 is the mean (or median - Use Preference option) of the yearly median number of days between flood events (days - temporal).

DH23 Flood duration. Compute the flood threshold as the flow equivalent for a flood recurrence of 1.67 years. Determine the number of days each year that the flow remains above the flood threshold. DH23 is the mean (or median - Use Preference option) of the number of flood days for years in which floods occur (days temporal).

DH24 Flood-free days. Compute the flood threshold as the flow equivalent for a flood recurrence of 1.67 years. Compute the maximum number of days that the flow is below the threshold for each year. DH24 is the mean (or median - Use Preference option) of the maximum yearly no-flood days (days - temporal).

TA1 Constancy. Constancy is computed via the formulation of Colwell (see example in Colwell, 1974). A matrix of values is compiled where the rows are 11 flow categories and the columns are 365 (no February 29th) days of the year. The cell values are the number of times that a flow falls into a category on each day. The categories are:

$\log$ (flow) $<.1 \times \log$ (mean flow $)$

$.1 \times \log$ (mean flow $)<=\log$ (flow $)<.25 \times \log$ (mean flow)

$.25 \times \log$ (mean flow $)<=\log ($ flow $)<.5 \times \log$ (mean flow $)$

$.5 \times \log$ (mean flow $)<=\log ($ flow $)<.75 \times \log$ (mean flow $)$

$.75 \times \log ($ mean flow $)<=\log$ (flow $)<1.0 \times \log$ (mean flow $)$

$1.0 \times \log$ (mean flow $)<=\log$ (flow) $<1.25 \times \log$ (mean flow)

$1.25 \times \log$ (mean flow) $<=\log$ (flow) $<1.5 \times \log$ (mean flow)

$1.5 \times \log$ (mean flow $)<=\log$ (flow) $<1.75 \times \log$ (mean flow) $1.75 \times \log$ (mean flow) $<=\log$ (flow) $<2.0 \times \log$ (mean flow)

$2.0 \times \log ($ mean flow $)<=\log$ (flow $)<2.25 \times \log$ (mean flow $)$ $\log$ (flow) $>=2.25 \times \log$ (mean flow)

The row totals, column totals, and grand total are computed. Using the equations for Shannon information theory parameters, constancy is computed as:

\section{1- (uncertainty with respect to state)}

$\log$ (number of state) 


$$
\text { (dimensionless - spatial). }
$$

TA2 Predictability. Predictability is computed from the same matrix as constancy (see example in Colwell, 1974). It is computed as:

1- (uncertainty with respect to interaction of time and state - uncertainty with respect to time $\log$ (number of state)

(dimensionless - spatial).

TA3 Seasonal predictability of flooding. Divide years up into 2-month periods (that is, Oct-Nov, Dec-Jan, and so forth). Count the number of flood days (flow events with flows $>1.67$-year flood) in each period over the entire flow record. TA3 is the maximum number of flood days in any one period divided by the total number of flood days (dimensionless - temporal).

TL1 Julian date of annual minimum. Determine the Julian date that the minimum flow occurs for each water year. Transform the dates to relative values on a circular scale (radians or degrees). Compute the $\mathrm{x}$ and $\mathrm{y}$ components for each year and average them across all years. Compute the mean angle as the arc tangent of $y$-mean divided by x-mean. Transform the resultant angle back to Julian date (Julian day - spatial).

TL2 Variability in Julian date of annual minima. Compute the coefficient of variation for the mean $\mathrm{x}$ and $\mathrm{y}$ components and convert to a date (Julian day - spatial).

Note - $\quad$ 5-year flood threshold (Poff, 1996) - For TL3 and TH3, compute the $\log 10$ of the peak annual flows. Compute the $\log 10$ of the daily flows for the peak annual flow days. Calculate the coefficients for a linear regression equation for logs of peak annual flow versus logs of average daily flow for peak days. Using the log peak flow for the 5-year recurrence interval (20th percentile) as input to the regression equation, predict the $\log 10$ of the average daily flow. The threshold is 10 to the $\log 10$ (average daily flow) power (cubic feet per second).

TL3 Seasonal predictability of low flow. Divide years up into 2-month periods (that is, Oct-Nov, Dec-Jan, and so forth). Count the number of low flow events (flow events with flows $<=5$ year flood threshold) in each period over the entire flow record. TL3 is the maximum number of low flow events in any one period divided by the total number of low flow events (dimensionless - spatial).

TL4 Seasonal predictability of non-low flow. Compute the number of days that flow is above the 5-year flood threshold as the ratio of number of days to 365 or 366 (leap year) for each year. TL4 is the maximum of the yearly ratios (dimensionless spatial).

TH1 Julian date of annual maximum. Determine the Julian date that the maximum flow occurs for each year. Transform the dates to relative values on a circular scale (radians or degrees). Compute the $\mathrm{x}$ and $\mathrm{y}$ components for each year and average 
them across all years. Compute the mean angle as the arc tangent of y-mean divided by x-mean. Transform the resultant angle back to Julian date (Julian day - spatial).

TH2 Variability in Julian dateof annual maxima. Compute the coefficient of variation for the mean $\mathrm{x}$ and $\mathrm{y}$ components and convert to a date (Julian days - spatial).

TH3 Seasonal predictability of nonflooding. Computed as the maximum proportion of a 365-day year that the flow is less than the 1.67-year flood threshold and also occurs in all years. Accumulate nonflood days that span all years. TH3 is maximum length of those flood-free periods divided by 365 (dimensionless - spatial).

RA1 Rise rate. Compute the change in flow fordays in which the change is positive for the entire flow record. RA1 is the mean (or median - Use Preference option) of these values (cubic feet per second/day - temporal).

RA2 Variability in rise rate. Compute the standard deviation for the positive flow changes. RA2 is 100 times the standard deviation divided by the mean (percent spatial).

RA3 Fall rate. Compute the change in flow for days in which the change is negative for the entire flow record. RA3 is the mean (or median - Use Preference option) of these values (cubic feet per second/day - temporal).

RA4 Variability in fall rate. Compute thestandard deviation for the negative flow changes. RA4 is 100 times the standard deviation divided by the mean (percent spatial).

RA5 Number of day rises. Compute the numberof days in which the flow is greater than the previous day. RA5 is the number of positive gain days divided by the total number of days in the flow record (dimensionless - spatial).

RA6 Change of flow. Compute the $\log 10$ of the flows for the entire flow record. Compute the change in log of flow for days in which the change is positive for the entire flow record. RA6 is the median of these values (cubic feet per second - temporal).

RA7 Change of flow. Compute the $\log 10$ of the flows for the entire flow record. Compute the change in log of flow for days in which the change is negative for the entire flow record. RA7 is the median of these log values (cubic feet per second/day temporal).

RA8 Number of reversals. Compute the numberof days in each year when the change in flow from one day to the next changes direction. RA8 is the average (or median Use Preference option) of the yearly values (days - temporal).

RA9 Variability in reversals. Computethe standard deviation for the yearly reversal values. RA9 is 100 times the standard deviation divided by the mean (percent - spatial). 


\section{$\underline{\text { References for Appendix } 5}$}

Calwell RK., 1974. Predictability, constancy, and contingency of periodic phenomena. Ecology 55: $1148-1153$.

Olden, J.D., and Poff, N.L., 2003, Redundancy and the choice of hydrologic indices for characterizing streamflow regimes: River Research and Applications, v. 19, p. 101-121.

Poff, N.L., 1996, A hydrogeography of unregulated streams in the United States and an examination of scale-dependence in some hydrological descriptors: Freshwater Biology, v. 36, p. $71-91$. 


\section{Appendix 6. Verification Results for the 171 Hydrologic Indices}

Implementation of mathematical or statistical relationships as computer code should be verified as to its proper representation of the relationships being computerized. Verification was done for the HIP software (Hydrologic Indices Tool - HIT, New Jersey Hydrologic Assessment Tool - NJHAT, and the National Hydrologic Assessment Tool - NATHAT by (1) comparing the computer code with the definitions being implemented and (2) by comparing the results of applying the same input data set(s) to alternative implementations of the definitions. In this case, inputting the data to alternative, commercially available software (CAS) - MATLAB, SAS, and EXCEL.

The USGS (Fort Collins Science Center) conducted tests to verify that the computer code is representative of the formulas being computerized by:

1. Reviewing the computer code and the definitions.

2. Comparing results using the HIP implementation for some indices to results of implementing the index formulation in Microsoft Excel.

3. Comparing the results using the HIP implementation for the remaining indices to results previously generated by Julian D. Olden at Colorado State University (Department of Biology) using MATLAB and SAS.

The criterion for verification was arbitrarily set to 5 percent difference in index values for the two implementations. For those indices where the difference was greater than 5 percent, the computer code was again compared to the index definitions. The indices were compared using the formulation:

$$
\text { Absolute Percent difference }=\frac{\mid \text { Index Value }_{\text {HIP }}-\text { Index Value }_{\text {CAS }} \mid}{\text { Average }\left(\text { Index }_{\text {HIP }}, \text { Index }_{\text {CAS }}\right)} * 100
$$

where CAS is commercially available software.

Table A6-1 presents the results for the 171 indices. Figure A6-1 show that there is less than a 5 percent difference between 168 of the indices. For the three remaining indices, subjective adjustment of the index formulation most likely accounted for larger differences.

The USGS (New Jersey Water Science Center) compared results using the NJHAT implementation for 64 indices with the results of implementing the definitions for those indices using the commercial available software SAS. The index values were calculated using data sets from 19 stream gage sites obtained from the USGS National Water Information System (NWIS) using the formulation:

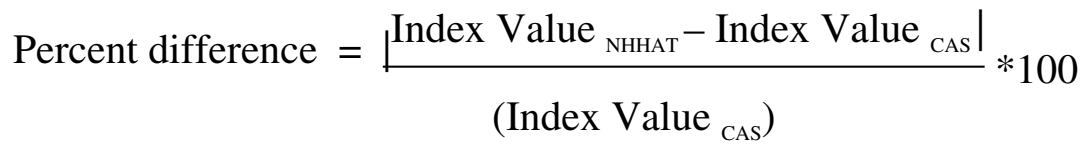


Table A6-1. Verification results for 171 indices calculated in Hydrologic Indices Tool.

\begin{tabular}{|c|c|c|c|c|c|}
\hline INDEX & $\begin{array}{l}\text { VERIFICATION METHOD } \\
\text { See Footnote }(1),(2) \text {, and (3) }\end{array}$ & $\begin{array}{c}\text { HIT } \\
\text { INDEX } \\
\text { VALUE }\end{array}$ & $\begin{array}{l}\text { VERIFICATION } \\
\text { INDEX VALUE }\end{array}$ & $\begin{array}{c}\text { PERCENT } \\
\text { DIFFERENCE } \\
(\%)(4)\end{array}$ & COMMENTS \\
\hline MA1 & USGS - Microsoft Excel (CAS) & 126.29 & 126.29 & 0.00 & \\
\hline MA2 & USGS - Microsoft Excel (CAS) & 126.29 & 126.29 & 0.00 & \\
\hline MA3 & CSU - CAS & 101.70 & 102.20 & 0.12 & \\
\hline MA4 & USGS - Microsoft Excel (CAS) & 15.49 & 15.08 & 0.68 & \\
\hline MA5 & USGS - Microsoft Excel (CAS) & 1.49 & 1.49 & 0.00 & \\
\hline MA6 & CSU - CAS & 7.27 & 7.24 & 0.08 & \\
\hline MA7 & CSU - CAS & 3.87 & 3.87 & 0.00 & \\
\hline MA8 & CSU - CAS & 2.98 & 2.98 & 0.00 & \\
\hline MA9 & CSU - CAS & 0.45 & 0.45 & 0.00 & \\
\hline MA10 & CSU - CAS & 0.30 & 0.30 & 0.00 & \\
\hline MA11 & CSU - CAS & 0.25 & 0.25 & 0.00 & \\
\hline MA12 & USGS - Microsoft Excel (CAS) & 146.52 & 146.52 & 0.00 & \\
\hline MA13 & USGS - Microsoft Excel (CAS) & 167.71 & 167.71 & 0.00 & \\
\hline MA14 & USGS - Microsoft Excel (CAS) & 201.94 & 201.94 & 0.00 & \\
\hline MA15 & USGS - Microsoft Excel (CAS) & 209.95 & 209.95 & 0.00 & \\
\hline MA16 & USGS - Microsoft Excel (CAS) & 147.21 & 147.21 & 0.00 & \\
\hline MA17 & USGS - Microsoft Excel (CAS) & 101.53 & 101.53 & 0.00 & \\
\hline MA18 & USGS - Microsoft Excel (CAS) & 78.39 & 78.39 & 0.00 & \\
\hline MA19 & USGS - Microsoft Excel (CAS) & 73.37 & 73.37 & 0.00 & \\
\hline MA20 & USGS - Microsoft Excel (CAS) & 68.81 & 68.81 & 0.00 & \\
\hline MA21 & USGS - Microsoft Excel (CAS) & 73.25 & 73.25 & 0.00 & \\
\hline MA22 & USGS - Microsoft Excel (CAS) & 106.67 & 106.67 & 0.00 & \\
\hline MA23 & USGS - Microsoft Excel (CAS) & 143.16 & 143.16 & 0.00 & \\
\hline MA24 & USGS - Microsoft Excel (CAS) & 57.23 & 57.23 & 0.00 & \\
\hline MA25 & USGS - Microsoft Excel (CAS) & 71.08 & 71.08 & 0.00 & \\
\hline MA26 & USGS - Microsoft Excel (CAS) & 54.05 & 54.05 & 0.00 & \\
\hline MA27 & USGS - Microsoft Excel (CAS) & 46.48 & 46.48 & 0.00 & \\
\hline MA28 & USGS - Microsoft Excel (CAS) & 51.30 & 51.30 & 0.00 & \\
\hline
\end{tabular}




\begin{tabular}{|c|c|c|c|c|c|}
\hline MA29 & USGS - Microsoft Excel (CAS) & 43.91 & 43.91 & 0.00 & \\
\hline MA30 & USGS - Microsoft Excel (CAS) & 54.06 & 54.06 & 0.00 & \\
\hline MA31 & USGS - Microsoft Excel (CAS) & 60.55 & 60.55 & 0.00 & \\
\hline MA32 & USGS - Microsoft Excel (CAS) & 53.34 & 53.34 & 0.00 & \\
\hline MA33 & USGS - Microsoft Excel (CAS) & 58.13 & 58.13 & 0.00 & \\
\hline MA34 & USGS - Microsoft Excel (CAS) & 64.71 & 64.71 & 0.00 & \\
\hline MA35 & USGS - Microsoft Excel (CAS) & 59.84 & 59.84 & 0.00 & \\
\hline MA36 & CSU - CAS & 4.94 & 4.94 & 0.00 & \\
\hline MA37 & CSU - CAS & 1.07 & 1.07 & 0.09 & \\
\hline MA38 & CSU - CAS & 2.12 & 2.11 & 0.08 & \\
\hline MA39 & CSU - CAS & 66.45 & 66.45 & 0.00 & \\
\hline MA40 & CSU - CAS & 0.23 & 0.23 & 0.00 & \\
\hline MA41 & CSU - CAS & 0.75 & 0.75 & 0.00 & \\
\hline MA42 & CSU - CAS & 1.30 & 1.30 & 0.00 & \\
\hline MA43 & CSU - CAS & 0.60 & 0.57 & 1.03 & HIT percentile calculations are more accurate \\
\hline MA44 & CSU - CAS & 0.91 & 0.75 & 4.66 & HIT percentile calculations are more accurate \\
\hline MA45 & CSU - CAS & 0.04 & 0.04 & 0.00 & \\
\hline ML1 & USGS - Microsoft Excel (CAS) & 71.56 & 71.56 & 0.00 & \\
\hline ML2 & USGS - Microsoft Excel (CAS) & 77.69 & 77.69 & 0.00 & \\
\hline ML3 & USGS - Microsoft Excel (CAS) & 102.06 & 102.06 & 0.00 & \\
\hline ML4 & USGS - Microsoft Excel (CAS) & 110.14 & 110.14 & 0.00 & \\
\hline ML5 & USGS - Microsoft Excel (CAS) & 80.39 & 80.39 & 0.00 & \\
\hline ML6 & USGS - Microsoft Excel (CAS) & 56.28 & 56.28 & 0.00 & \\
\hline ML7 & USGS - Microsoft Excel (CAS) & 42.17 & 42.17 & 0.00 & \\
\hline ML8 & USGS - Microsoft Excel (CAS) & 37.89 & 37.89 & 0.00 & \\
\hline ML9 & USGS - Microsoft Excel (CAS) & 37.75 & 37.75 & 0.00 & \\
\hline ML10 & USGS - Microsoft Excel (CAS) & 40.42 & 40.42 & 0.00 & \\
\hline ML11 & USGS - Microsoft Excel (CAS) & 52.17 & 52.17 & 0.00 & \\
\hline ML12 & USGS - Microsoft Excel (CAS) & 68.78 & 68.78 & 0.00 & \\
\hline ML13 & USGS - Microsoft Excel (CAS) & 55.92 & 55.92 & 0.00 & \\
\hline ML14 & CSU - CAS & 0.34 & 0.35 & 0.36 & \\
\hline ML15 & CSU - CAS & 0.24 & 0.23 & 0.94 & \\
\hline ML16 & CSU - CAS & 0.32 & 0.34 & 1.43 & \\
\hline ML17 & CSU - CAS & 0.27 & 0.26 & 0.47 & \\
\hline
\end{tabular}




\begin{tabular}{|c|c|c|c|c|c|}
\hline ML18 & CSU - CAS & 26.44 & 24.54 & 1.86 & Variation in standard deviation formulas \\
\hline ML19 & CSU - CAS & 24.32 & 24.32 & 0.00 & \\
\hline ML20 & CSU - CAS & 0.61 & 0.61 & 0.12 & \\
\hline ML21 & CSU - CAS & 31.39 & 31.39 & 0.00 & \\
\hline ML22 & CSU - CAS & 0.17 & 0.18 & 0.14 & \\
\hline MH1 & USGS - Microsoft Excel (CAS) & 536.39 & 536.39 & 0.00 & \\
\hline MH2 & USGS - Microsoft Excel (CAS) & 629.00 & 629.00 & 0.00 & \\
\hline MH3 & USGS - Microsoft Excel (CAS) & 621.14 & 621.14 & 0.00 & \\
\hline MH4 & USGS - Microsoft Excel (CAS) & 612.25 & 612.25 & 0.00 & \\
\hline MH5 & USGS - Microsoft Excel (CAS) & 466.83 & 466.83 & 0.00 & \\
\hline MH6 & USGS - Microsoft Excel (CAS) & 300.67 & 300.67 & 0.00 & \\
\hline MH7 & USGS - Microsoft Excel (CAS) & 328.47 & 328.47 & 0.00 & \\
\hline MH8 & USGS - Microsoft Excel (CAS) & 319.78 & 319.78 & 0.00 & \\
\hline MH9 & USGS - Microsoft Excel (CAS) & 267.69 & 267.29 & 0.04 & \\
\hline MH10 & USGS - Microsoft Excel (CAS) & 276.50 & 276.50 & 0.00 & \\
\hline MH11 & USGS - Microsoft Excel (CAS) & 409.86 & 409.86 & 0.00 & \\
\hline MH12 & USGS - Microsoft Excel (CAS) & 519.69 & 519.69 & 0.00 & \\
\hline MH13 & USGS - Microsoft Excel (CAS) & 97.90 & 97.90 & 0.00 & \\
\hline MH14 & CSU - CAS & 12.89 & 12.89 & 0.00 & \\
\hline MH15 & CSU - CAS & 8.11 & 8.02 & 0.28 & \\
\hline MH16 & CSU - CAS & 2.91 & 2.88 & 0.19 & \\
\hline MH17 & CSU - CAS & 1.79 & 1.77 & 0.30 & \\
\hline MH18 & CSU - CAS & 6.70 & 6.70 & 0.00 & \\
\hline MH19 & CSU - CAS & -0.01 & -0.01 & 0.00 & \\
\hline MH20 & CSU - CAS & 7.79 & 7.79 & 0.00 & \\
\hline MH21 & CSU - CAS & 17.50 & 17.30 & 0.28 & \\
\hline MH22 & CSU - CAS & 5.73 & 5.71 & 0.07 & \\
\hline MH23 & CSU - CAS & 5.57 & 5.56 & 0.06 & \\
\hline MH24 & CSU - CAS & 3.65 & 3.63 & 0.16 & \\
\hline MH25 & CSU - CAS & 6.36 & 6.37 & 0.03 & \\
\hline MH26 & CSU - CAS & 11.57 & 11.57 & 0.00 & \\
\hline MH27 & CSU - CAS & 4.91 & 4.87 & 0.22 & \\
\hline FL1 & CSU - CAS & 9.25 & 9.00 & 0.69 & \\
\hline FL2 & CSU - CAS & 46.18 & 46.18 & 0.00 & \\
\hline FL3 & CSU - CAS & 0.00 & 0.00 & 0.00 & \\
\hline
\end{tabular}




\begin{tabular}{|c|c|c|c|c|c|}
\hline FH1 & CSU - CAS & 16.33 & 16.33 & 0.00 & \\
\hline $\mathrm{FH} 2$ & CSU - CAS & 33.53 & 33.53 & 0.00 & \\
\hline FH3 & CSU - CAS & 33.92 & 33.14 & 0.58 & \\
\hline FH4 & CSU - CAS & 5.28 & 5.14 & 0.67 & \\
\hline FH5 & CSU - CAS & 14.28 & 14.14 & 0.24 & \\
\hline FH6 & CSU - CAS & 13.36 & 13.03 & 0.63 & \\
\hline FH7 & CSU - CAS & 3.75 & 3.64 & 0.75 & \\
\hline FH8 & CSU - CAS & 16.33 & 16.22 & 0.17 & \\
\hline FH9 & CSU - CAS & 9.53 & 8.63 & 2.48 & HIT percentile calculations are more accurate \\
\hline FH10 & CSU - CAS & 3.33 & 2.28 & 9.40 & Computer code checked - OK \\
\hline FH11 & CSU - CAS & 0.86 & 0.76 & 3.15 & Threshold has subjective elements \\
\hline DL1 & CSU - CAS & 29.53 & 29.53 & 0.00 & \\
\hline DL2 & CSU - CAS & 30.35 & 30.25 & 0.08 & \\
\hline DL3 & CSU - CAS & 31.95 & 31.77 & 0.14 & \\
\hline DL4 & CSU - CAS & 40.04 & 38.48 & 0.99 & \\
\hline DL5 & CSU - CAS & 61.24 & 55.04 & 2.67 & Computer code checked - OK \\
\hline DL6 & $\mathrm{CSU}$ - CAS & 49.17 & 49.17 & 0.00 & \\
\hline DL7 & CSU - CAS & 30.58 & 30.44 & 0.12 & \\
\hline DL8 & CSU - CAS & 31.94 & 31.75 & 0.15 & \\
\hline DL9 & CSU - CAS & 37.78 & 36.21 & 1.06 & \\
\hline DL10 & CSU - CAS & 49.07 & 43.85 & 2.81 & Computer code checked - OK \\
\hline DL11 & CSU - CAS & 0.35 & 0.35 & 0.00 & \\
\hline DL12 & CSU - CAS & 0.38 & 0.38 & 0.00 & \\
\hline DL13 & CSU - CAS & 0.47 & 0.47 & 0.00 & \\
\hline DL14 & CSU - CAS & 0.60 & 0.60 & 0.00 & \\
\hline DL15 & CSU - CAS & 0.40 & 0.40 & 0.00 & \\
\hline DL16 & CSU - CAS & 8.40 & 8.83 & 1.26 & \\
\hline DL17 & CSU - CAS & 65.30 & 65.30 & 0.00 & \\
\hline DL18 & CSU - CAS & 0.00 & 0.00 & 0.00 & \\
\hline DL19 & CSU - CAS & 0.00 & 0.00 & 0.00 & \\
\hline DL20 & CSU - CAS & 0.00 & 0.00 & 0.00 & \\
\hline DH1 & CSU - CAS & 1318.92 & 1318.92 & 0.00 & \\
\hline $\mathrm{DH} 2$ & CSU - CAS & 838.54 & 838.54 & 0.00 & \\
\hline DH3 & CSU - CAS & 553.62 & 553.62 & 0.00 & \\
\hline
\end{tabular}




\begin{tabular}{|c|c|c|c|c|c|}
\hline DH4 & CSU - CAS & 303.16 & 303.16 & 0.00 & \\
\hline DH5 & CSU - CAS & 216.84 & 218.58 & 0.20 & \\
\hline DH6 & CSU - CAS & 49.17 & 49.17 & 0.00 & \\
\hline DH7 & CSU - CAS & 41.07 & 41.07 & 0.00 & \\
\hline DH8 & CSU - CAS & 38.71 & 38.71 & 0.00 & \\
\hline DH9 & CSU - CAS & 31.78 & 31.78 & 0.00 & \\
\hline DH10 & CSU - CAS & 31.97 & 31.11 & 0.68 & \\
\hline DH11 & CSU - CAS & 15.52 & 15.52 & 0.00 & \\
\hline DH12 & CSU - CAS & 6.51 & 6.51 & 0.00 & \\
\hline DH13 & CSU - CAS & 3.57 & 3.57 & 0.00 & \\
\hline DH14 & CSU - CAS & 0.24 & 0.24 & 0.42 & \\
\hline DH15 & USGS Manual Calculation & 4.63 & 4.63 & 0.00 & \\
\hline DH16 & USGS Manual Calculation & 56.72 & 56.72 & 0.00 & \\
\hline DH17 & USGS Manual Calculation & 15.82 & 15.82 & 0.00 & \\
\hline DH18 & CSU - CAS & 2.53 & 2.54 & 0.11 & \\
\hline DH19 & CSU - CAS & 1.43 & 1.41 & 0.26 & \\
\hline DH20 & $\mathrm{CSU}$ - CAS & 5.56 & 5.59 & 0.12 & \\
\hline DH21 & USGS Manual Calculation & 45.40 & 45.40 & 0.00 & \\
\hline DH22 & CSU - CAS & 93.98 & 83.00 & 3.10 & Threshold has subjective elements \\
\hline DH23 & CSU - CAS & 1.70 & 1.53 & 2.63 & Threshold has subjective elements \\
\hline DH24 & USGS Manual Calculation & 116.89 & 116.89 & 0.00 & \\
\hline TA1 & Colwell (1974) table 1 & 0.10 & 0.10 & 0.00 & \\
\hline TA2 & Colwell (1974) table 1 & 0.29 & 0.29 & 0.00 & \\
\hline TA3 & CSU - CAS & 0.21 & 0.30 & 8.65 & Threshold has subjective elements \\
\hline TL1 & CSU - CAS & 261.50 & 260.90 & 0.06 & \\
\hline TL2 & CSU - CAS & 28.44 & 28.30 & 0.12 & \\
\hline TL3 & CSU - CAS & 0.46 & 0.68 & 9.95 & Threshold has subjective elements \\
\hline TL4 & USGS Manual Calculation & 0.04 & 0.04 & 0.00 & \\
\hline TH1 & USGS Manual Calculation & 62.82 & 62.82 & 0.00 & \\
\hline TH2 & USGS Manual Calculation & 61.45 & 61.45 & 0.00 & \\
\hline TH3 & CSU - CAS & 0.08 & 0.07 & 3.59 & Threshold has subjective elements \\
\hline RA1 & CSU - CAS & 70.15 & 70.15 & 0.00 & \\
\hline RA2 & USGS Manual Calculation & 233.73 & 233.73 & 0.00 & \\
\hline RA3 & CSU - CAS & -31.35 & -30.66 & 0.56 & \\
\hline
\end{tabular}




\begin{tabular}{|c|c|c|c|c|c|}
\hline RA4 & USGS Manual Calculation & -290.07 & -290.07 & 0.00 & \\
\hline RA5 & CSU - CAS & 0.28 & 0.31 & 2.37 & \\
\hline RA6 & CSU - CAS & 0.15 & 0.15 & 0.00 & \\
\hline RA7 & CSU - CAS & -0.08 & -0.08 & 0.00 & \\
\hline RA8 & CSU - CAS & 118.08 & 117.94 & 0.03 & \\
\hline RA9 & CSU - CAS & 8.16 & 8.09 & 0.21 & \\
\hline \multicolumn{6}{|c|}{$\begin{array}{l}\text { Notes - (1) U.S. Geological Survey, FORT Science Center computed HIT results to results using Microsoft Excel. } \\
\text { (2) Julian D. Olden at Colorado State University provided previously calculated results using commercial available software (CAS) - Excel, MATLAB, SAS. } \\
\text { (3) Colwell, R.K., 1974, Predictability, constancy, and contingency of periodic phenomena: Ecology, v. 55, p. 1148-1153. } \\
\text { (4) Absolute Percent Difference = HIP Index Value - CAS Index Value/Average (HIP Value, CAS Value) * 100 }\end{array}$} \\
\hline
\end{tabular}


Figure A6-1. Verification results - percent difference between HIT index values and commercial available software values.

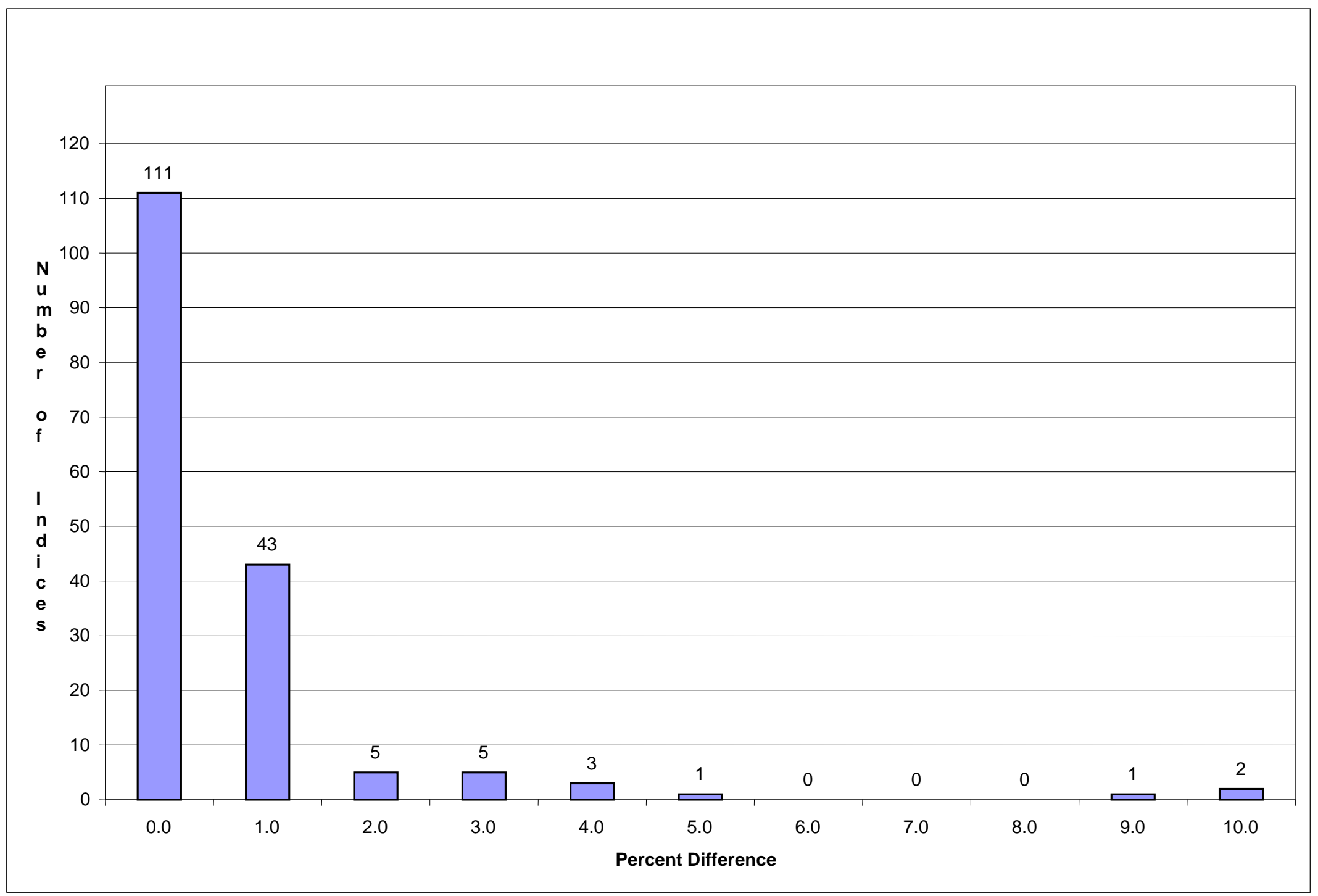


Table A6-2 lists the indices used and a summary of the findings. In the initial comparison, the results for four indices were considered

Table A6-2. Verification results for the computer code used in National Hydrologic Assessment Tool to calculate 64 indices -19 gaging stations.

\begin{tabular}{|l|l|}
\hline \hline Index & \multicolumn{1}{|c|}{ Results } \\
\hline \hline MA1 & All values within 2 percent of NJHAT values \\
\hline MA2 & All values within 3 percent of NJHAT values \\
\hline MA12-MA23 & All values within 2 percent of NJHAT values \\
\hline MA24-MA35 & All values within 3 percent of NJHAT values \\
\hline MA36 & All values within 3 percent of the NJHAT values \\
\hline MA41 & All values within 2 percent of NJHAT values \\
\hline ML1-ML12 & $\begin{array}{l}\text { 223 values within 2 percent of NJHAT values. For August, } \\
\text { September, and October, the months with lowest flows, 5 values } \\
\text { within 6.2 percent of NJHAT }\end{array}$ \\
\hline ML22 & All values within 2 percent of NJHAT values \\
\hline MH1-MH12 & All values within 3 percent of NJHAT values \\
\hline MH14 & All values within 3 percent of NJHAT values \\
\hline MH15 & All values within 3 percent of NJHAT values \\
\hline MH25 & All values within 3 percent of NJHAT values \\
\hline FL1 & $\begin{array}{l}\text { 17 of the values within 2 percent of NJHAT values and 2 values } \\
5-6 \text { percent different than NJHAT values }\end{array}$ \\
\hline FH3 & All values within 2 percent of NJHAT values \\
\hline FH6 & All values within 2 percent of NJHAT values \\
\hline DL3 & All of values within 2 percent of NJHAT values \\
\hline DL14 & All of values within 2 percent of NJHAT values \\
\hline DL16 & $\begin{array}{l}\text { 16 values within 3 percent of the NJHAT values, 2 value } \\
\text { within 5 percent and 1 value 12.8 percent difference }\end{array}$ \\
\hline DH3 & All of values within 2 percent of NJHAT values. \\
\hline DH8 & $\begin{array}{l}17 \text { values within 2 percent, 2 values are within 4 percent of } \\
\text { NJHin 3 percent of NJHAT values }\end{array}$ \\
\hline RA1 & percent of NJHAT values \\
\hline RA3 & Allues \\
\hline
\end{tabular}

problematic. For two indices, FH3 and FH6, the ratios varied from 106 percent to 164 percent for three gage sites. All other gage sites were within 2 percent. Since NJHAT used water year (October through September) data and the SAS analysis used calendar year (January through December) data, the SAS calculations for FH3 and FH6 were recalculated using the water year and the ratios for all stream-gage sites were then within 2 percent. The ratios for ML22 varied from 103 percent to 133 percent with most in the 106 percent to 115 percent range. The ratio of DL16 varied from 105 percent to 126 percent with most being between 110 percent and 126 percent. The definitions for both ML22 and DL16 were checked and the input data reviewed. ML22 was recalculated using the water year and all results were within 2 percent. For DL16, the definition was changed from the mean to using the median. The ratios were recalculated using the median with 16 of the ratios being within 3 percent; one had a 12.8 percent difference. 
One of the differences in the data used in NJHAT and the SAS calculations of the indices was how missing daily streamflow values were handled in the input data. In NJHAT and NJHAT, all water year data are used and missing daily values are not used in the calculations. In the SAS

calculations, the data for an entire year were not used if there was more than one missing value. This could explain the small differences between the indices determined using NJHAT and those calculated using SAS.

Since none of the problems in the analysis were associated with the NJHAT software and the issues found using independent calculations of the indices were related to the input data structure, it was concluded that the NJHAT software was performing satisfactorily. 
